\title{
LASER VELOCIMETER MEASUREMENTS OF MULTIPHASE FLOW OF SOLIDS
}

Final Report for the Period September 1986-April 1989

\section{By}

J. R. Kadambi

R. C. Chen

S. Bhunia

Work Performed Under Contract No. FG22-86PC90961

For

U.S. Department of Energy

Pittsburgh Energy Technology Center

Pittsburgh, Pennsylvania

By

Case Western Reserve University

Cleveland, Ohio 


\section{DISCLAIMER}

This report was prepared as an account of work sponsored by an agency of the United States Government. Neither the United States Government nor any agency thereof, nor any of their employees, makes any warranty, express or implied, or assumes any legal liability or responsibility for the accuracy, completeness, or usefulness of any information, apparatus, product, or process disclosed, or represents that its use would not infringe privately owned rights, Reference herein to any specific commercial product, process, or service by trade name, trademark, manufacturer, or otherwise does not necessarily constitute or imply its endorsement, recommendation, or favoring by the United States Government or any agency thereof. The views and opinions of authors expressed herein do not necessarily state or reflect those of the United States Government or any agency thereof.

This report has been reproduced directly from the best available copy.

Available to DOE and DOE contractors from the Office of Scientific and Technical Information, P.O. Box 62, Oak Ridge, TN 37831; prices available from (615)576-8401, FTS 626-8401.

Available to the public from the National Technical Information Service, U.S. Department of Commerce, 5285 Port Royal Rd., Springfield, VA 22161.

Price: Printed Copy A06

Microfiche A01 


\section{DISCLAIMER}

This report was prepared as an account of work sponsored by an agency of the United States Government. Neither the United States Government nor any agency Thereof, nor any of their employees, makes any warranty, express or implied, or assumes any legal liability or responsibility for the accuracy, completeness, or usefulness of any information, apparatus, product, or process disclosed, or represents that its use would not infringe privately owned rights. Reference herein to any specific commercial product, process, or service by trade name, trademark, manufacturer, or otherwise does not necessarily constitute or imply its endorsement, recommendation, or favoring by the United States Government or any agency thereof. The views and opinions of authors expressed herein do not necessarily state or reflect those of the United States Government or any agency thereof. 


\section{DISCLAIMER}

Portions of this document may be illegible in electronic image products. Images are produced from the best available original document. 


\title{
LASER VELOCIMETER MEASUREMENTS OF MULTIPHASE FLOW OF SOLIDS
}

\author{
Final Report
}

\section{Prepared for}

Pittsburgh Energy Technology Center U.S. Department of Energy Pittsburgh, Pennsylvania

Report prepared by

J.R. Kadambi, R.C. Chen and S. Bhunia

\section{Contract Participants}

J.R. Kadambi(P.I.), A. Dybbs(Co. P.I.), R.V. Edwards(Co. P.I.)

Graduate Students - R.C. Chen, S. Bhunia Engineer - J. Kral

\author{
Departments of Mechanical \& Aerospace Engineering \\ and \\ Chemical Engineering \\ Case Western Reserve University \\ Cleveland, Ohio
}

DOE Project Manager: J.M. Ekmann

Contract Number: DE FG 2286 PC90961

(September, 1986 - April, 1989) 
ABSTRACT

A unique refractive index matched facility for studying solid-liquid multiphase flow has been developed. The refractive index matching of the solid and the liquid allows the use of non-intrusive Laser Doppler Velocimetry (LDV) to measure the solid and the liquid velocities. These measurements will be useful in developing a better understanding of solid -liquid flows, especially solid-liquid and solid-solid interactions.

Silica gel and $50 \%$ sodium iodide solution in water (refractive index $\approx 1.443$ ) are used as the refractive index matched solid and liquid respectively. The one inch internal diameter test section configuration can be horizontal as well as inclined. A two color back scatter mode LDV is used for making velocity measurements. Single phase calibration tests conducted with $50 \%$ sodium iodide solution showed that the flow in the test section is fully developed for laminar and turbulent flows. The flow rate obtained from integration of the velocity profiles matched within $\pm 0.5 \%$ of the flowmeter data.

Tests were conducted in solid-liquid slurries with volumetric solid concentration levels of $5 \%$ and $15 \%$ in the Reynolds number (Re) range of 400 to 9200 . Silica gel particles of mean diameter 40 microns were used. Measurements included mapping of the solid and liquid velocities and obtaining the pressure drop data. The four flow regimes for the $5 \%$ and $15 \%$ slurries were identified as stationary bed flow up to Re of 2000 , saltation flow in the Re range of 2000 to nearly 4000 , heterogeneous flow in the Re range of 4000 to nearly 5200 and homogeneous flow for Re greater than 5200 .

Signal processing technique utilizing histogram of velocity measurements made at a point and signal amplitude discrimination was successfully used for differentiating between solid and liquid velocities. Differences between the solid and liquid velocities were observed for the saltation flow and heterogeneous flow regimes. Preliminary experiments with denser slurries indicate that tests can be conducted with solid concentrations as high as $50 \%$ by volume. The details of the refractive index matched facility and results of the tests conducted on $5 \%$ and $15 \%$ slurries are discussed in the report. 
ABSTRACT 1

TABLE OF CONTENTS 2

LIST OF TABLES

LIST OF FIGURES

1. INTRODUCTION 9

2. LITERATURE REVIEW 12

3. EXPERIMENTAL APPARATUS 17

3.1 Refractive index matched solid and liquid 17

3.2 Preliminary tests to find pressure loss 22

3.3 The refractive index matched multiphase flow loop 32

3.4 LDV instrumentation - set up 40

3.5 Signal processing 44

4. TEST PROCEDURE

5. RESULTS AND DISCUSSION 51

5.1 Single phase flow 51

5.2 Solid - liquid slurry flow $\quad 55$

$5.2 .15 \%$ sodium iodide solution-silica gel slurr $\quad 60$

$5.2 .215 \%$ sodium iodide - silica gel slurry $\quad 70$

5.2.3 Solid liquid velocity discrimination $\$ 5$

5.3 Pressure loss measurements 91

6. CONCLUSION 95

7. RECOMMENDATIONS 97

8. REFERENCES 99

9. APPENDICES 102

A: Determination of density of wet silica gel 102

B: Determination of parameters of slurry 103

C: Shift of probe volume due to refraction 104

D: Uncertainty analysis $\quad 110$ 


\section{LIST OF TABLES}

Table

Page

1. Desired range of test parameters for the multiphase flow experiment

2. Various combination of solids and liquids for

19 refractive index matching

3. Comparison of friction factors for the $9 / 32$ "ID and $3 / 8$ " ID pipes

$\begin{array}{lll}\text { 4. Test parameters } & 98\end{array}$

5. Parameters of optical system \& probe volume 44

A1. The location errors of laser beams due to refraction 107 


\section{LIST OF FIGURES}

Figure Page

1.1 Development of slurry flow 11

3.1 Variation in the refractive index of sodium iodide $\quad 21$ solution as a function of temperature and concentration levels

3.2 Friction factor vs. Reynolds number (9/32" ID pipe)

3.3 Friction factor vs. Reynolds number (9/32" ID pipe)

3.4 Friction factor vs. Reynolds number (3/8" ID pipe)

3.5 Friction factor vs. Reynolds number (3/S" ID pipe)

3.6 Head loss vs. velocity (9/32" ID pipe) 27

3.7 Head loss vs. velocity ( $9 / 32^{\prime \prime}$ ID pipe) 28

3.8 Apparent viscosity vs. velocity (10\% slurry, 33 $3 / 8^{\prime \prime}$ ID pipe)

3.9 Apparent viscosity vs. velocity (40\% slurry, $\quad 34$ $3 / 8^{\prime \prime}$ ID pipe)

3.10 Apparent viscosity vs. concentration of 35 the slurry (3/S" ID pipe)

3.11 Schematic diagram of multiphase flow system 36

3.12 Calibration data of Mariam inclined tube manometer I 38

3.13 Calibration data of Mariam inclined tube manometer II 39

3.14 A view of the matched index of refraction flow system 41

3.15 Laser velocimeter and allied instruments for 41 the matched index of refraction flow system

3.16 Laser beams and the probe volume 42

3.17 Interference fringes at the probe volume, section $A-A \quad 42$

3.18 A Doppler burst $\quad 46$ 
4.1 Schematic diagram of LDA measurement location 49

5.1 Axial velocity profile along the horizontal diameter 52 for water flow at a Reynolds number $\mathbf{2 5 3 0}$

5.2 Axial velocity profile along the horizontal diameter 53 for water flow at a Reynolds number $\$ 200$

5.3 Axial velocity profile along the horizontal diameter for water flow at a Reynolds number 9870

5.4 Axial velocity profile along the horizontal diameter for 50 percent sodium iodide solution flow at a Reynolds number 1061

5.5 Axial velocity profile along the horizontal diameter for 50 percent sodium iodide solution flow at a Reynolds number 1826

5.6 Axial velocity profile along the horizontal diameter for 50 percent sodium iodide solution flow at a Reynolds number 4981

5.7 Axial velocity profile along the horizontal diameter for 50 percent sodium iodide solution flow at a Reynolds number 6645

5.8 Axial velocity profiles along the horizontal and vertical diameters for 5 percent silica gel-sodium iodide solution slurry at a Reynolds number 1745

5.9 Axial velocity profiles along the horizontal and vertical diameters for 5 percent silica gel-sodium iodide solution slurry at a Reynolds number 4014

5.10 Axial velocity profiles along the horizontal and vertical diameters for 5 percent silica gel-sodium iodide solution slurry at a Reynolds number 4766

5.11 Axial velocity profiles along the horizontal and vertical diameters for 5 percent silica gel-sodium iodide solution slurry at a Reynolds number 5544

5.12 Axial velocity profiles along the horizontal and vertical diameters for 5 percent silica gel-sodium iodide solution slurry at a Reynolds number 8001

5.13 Axial velocity profiles along several horizontal and vertical lines for 5 percent silica gel-sodium iodide solution slurry at a Reynolds number 5544

5.14 Axial velocity profiles along the horizontal and vertical diameters for 5 percent silica gel-sodium iodide solution slurry at various Reynolds number. 
5.15 Axial velocity profiles along the vertical diameters for 5 percent silica gel-sodium iodide solution slurry at various Reynolds number.

5.16 Axial velocity profile along the horizontal diameter for 5 percent silica gel-sodium iodide solution slurry flow at a Reynolds number 1745

5.17 Axial velocity profile along the vertical diameter for 5 percent silica gel-sodium iodide solution slurry flow at a Reynolds number 4766

5.18 Axial velocity profile along the horizontal diameter for 5 percent silica gel-sodium iodide solution slurry flow at a Reynolds number 4766

5.19 Axial velocity profile along the horizontal diameter for 5 percent silica gel-sodium iodide solution slurry flow at a Reynolds number 8001

5.20 Axial velocity profile along the vertical diamete for 5 percent silica gel-sodium iodide solution slurry flow at a Reynolds number $\mathrm{S001}$

5.21 Axial velocity profiles along the horizontal and vertical diameters for 15 percent silica gel-sodium iodide solution slurry at various Reynolds Numbers

5.22 Axial velocity profiles along the vertical diameters for 15 percent silica gel-sodium iodide solution slurry at various Reynolds numbers

5.23 Axial velocity profiles along several vertical lines for 15 percent silica gel-sodium iodide solution slurry at a Reynolds number 3960

5.24 Axial velocity profiles along several vertical lines for 15 percent silica gel-sodium iodide solution slurry at a Reynolds number 5665

5.25 Axial velocity profiles along the horizontal diameter for liquid and solid phase for 15 percent silica gel-sodium iodide solution slurry at a Reynolds number 4497

5.26 Axial velocity profiles along the vertical diameter for liquid and solid phase for 15 percent silica gel-sodium iodide solution slurry at a Reynolds number 4497 
5.27 Axial velocity profile along the horizontal diameter

for 15 percent silica gel-sodium iodide solution slurry

at a Reynolds number 8028

5.28 Axial velocity profile along the horizontal diameter

for 15 percent silica gel-sodium iodide solution slurry at a Reynolds number 9169

5.29 Change in axial velocity of the solid along the vertical diameter with respect to time for 15 percent silica

gel-sodium iodide solution slurry at a Reynolds number 2322

5.30 Change in axial velocity of the solid along the

vertical diameter with respect to time for 15 percent silica

gel-sodium iodide solution slurry at a Reynolds number 2685 .

5.31 Histogram of velocity versus number of particles for

88

measurement location at pipe center for 15 percent silica

gel-sodium iodidesolution slurry at a Reynolds number 4497 ,

the number of measurement $=1000$

5.32 Histogram of velocity versus number of particles for

88

measurement location at $0.05^{\prime \prime}$ below center for 15 percent

silica gel-sodium iodide solution slurry at a Reynolds number 4497 , the number of measurement $=1000$

5.33 Histogram of velocity versus number of particles for measurement location at $0.10^{\prime \prime}$ below center for 15 percent

silica gel-sodium iodide solution slurry at a Reynolds number 4497 , the number of measurement $=1000$

5.34 Histogram of velocity versus number of particles for measurement location at $0.15^{\prime \prime}$ below center for 15 percent silica gel-sodium iodide solution slurry at a Reynolds number 4497 , the number of measurement $=1000$

5.35 Histogram of velocity versus number of particles for measurement location at pipe center for 5 percent silica gel-sodium iodide solution slurry at a Reynolds number 3813 , the number of measurement $=1000$

5.36 Histogram of velocity versus number of particles for measurement location at $0.15^{\prime \prime}$ below center for 5 percent silica gel-sodium jodide solution slurry at a Reynolds number 3813 , the number of measurement $=1000$

5.37 Histogram of velocity versus number of particles for measurement location at 0.20 " below center for 5 percent silica gel-sodium iodide solution slurry at a Reynolds number 3813 , the number of measurement $=1000$ 
5.38 Histogram of velocity versus number of particles for measurement location at 0.30 " below center for 5 percent silica gel-sodium iodide solution slurry at a Reynolds number 3813 , the number of measurement $=1000$

5.39 Quantitative Flow Visualization of flow field along

92 the pipe cross-section for $5 \%$ slurry at Reynolds number of 1745 (The solids are settled down at the bottom for the Re)

5.40 Quantitative Flow Visualization of flow field along the pipe cross-section for $5 \%$ slurry at Reynolds number of 1745 (Homogeneous flow regime)

5.41 Friction factors versus Reynolds numbers for 5 percent and 15 percent silica gel-sodium jodide solution slurry

A1 Refraction of the laser beams through test section 


\section{INTRODUCTION}

Multiphase flows of solids in liquid are widely encountered in fossil energy processes including transportation of crushed coal in slurry form, coal conversion process streams, movement of ash etc. Thes flows can have particle concentrations ranging from nearly zero to as high as 50 percent by volume. The lack of understanding of such solid-liquid slurry flows has resulted in design deficiencies leading to either operational problems like clogging or plugging in many fossil energy processes and industrial applications or in inefficient use of resources such as oversized pumps and other devices. Biological flows are among other important examples. There is a need for more efficient methods of transportation of slurries like coal-water, col-oil etc. for power stations, metallized liquid fuel for rocketry, ores from the mines etc. This study was motivated by the need for a better understanding of the mechanism of coal-water slurry transportation.

In the past studies have concentrated on high velocity flow regime based on the rationale that slurry transportation pipelines are generally operated at high velocity to prevent particle deposition in the pipes. These studies include both the theoretical and experimental ones. But at the time when single phase turbulent flow is not well understood these studies had to deal with two very complex phenomena - turbulence and the effect of the presence of particles in a fluid in motion. So, not surprisingly, many of these studies have found close similarities between these flows and turbulent flow. Quite possibly, this may be due to the dominance of turbulence over the effect of the presence of solid particles in the fluid especially for low solid concentrations. To fully understand the nature of solid-liquid multiphase flows it may be very useful to study them at low speeds thereby eliminating the effect of turbulence. Since the low speed flows are better understood it might be easier to understand he effects of solid particles in such flows. Such 
studies may reveal the nature of fluid-particle and particle-particle interactions and provide us with the information to develop successful physical models of all solid-liquid multiphase flows.

Different flow regimes for solid-liquid multiphase flow are identified in Figure 1.1. Solid particles settle at the bottom of the pipeline if the slurry is kept stationary for sufficiently long time. Now if the flow is started, in the initial stage fluid at the top moves along with a small amount of solid particles at the interface. this is called the flow with a stationarv bed. If the velocity is increased, a substantial amount of solid particles start rolling over a thin layer of solids which remain at the bottom of the pipe. This changes the flow pattern as shown in the figure. This flow regime is called saltation flow. With further increase in velocity a stage is reached where all the solid particles are in motion but the solid concentration varies from the top of the pipe to the bottom, the highest concentration being at the bottom. This is heterogeneous flow. When velocity is increased further, the liquid and the solid move as an uniform mixture. This is homogeneous flow.

The objectives of this project were as follows:

(a). To design, construct and develop a Laser Doppler Velocimeter based experimental set-up to make measurements in slurry flows using refractive index matching technique.

(b). Conduct benchmark experiments and obtain solid and liquid velocities using non-intrusive Laser Doppler Velocimeter (LDV) for a range of solid concentrations. 


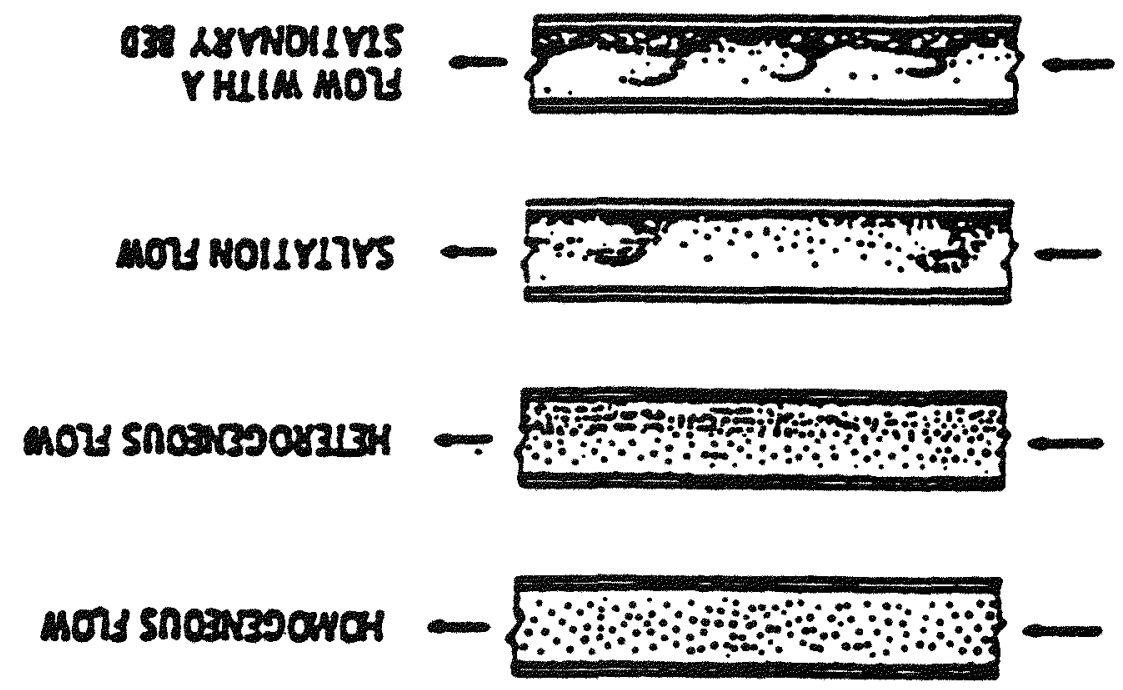




\section{LITERATURE REVIEW}

One of the early studies in solid-liquid multiphase flow was conducted by Blatch (1906) for finding a correlation for pressure drop. He used sand-water mixture in a one inch diameter pipe. He obtained the following correlation:

$$
\mathrm{h}=\mathrm{h}_{\mathrm{w}}+\mathrm{A} \cdot \mathrm{C}
$$

where $\quad h=$ head loss in unit height of liquid phase column per unit length of pipe

$$
h_{w}=\text { same as above when only liquid is flowing }
$$

$\mathrm{C}=$ average solid concentration of slurry

$A=$ constant coefficient

A similar experiment with sand-water slurries was done by Howard (1939) in a 4" diameter pipe. He found that the coefficient, $A$ used in the above expression depends on particle size.

Wilson (1942) made an attempt to find the theoretical background for pressure drops in the slurry flows. He considered the work required to maintain the solids in suspension and also the energy dissipation for the flowing liquid. He found the following correlation,

$$
\mathrm{h}=\mathrm{h}_{\mathrm{w}}+\mathrm{A}^{\prime} \frac{\mathrm{V}_{\mathrm{s}}}{\mathrm{V}^{\prime}} \mathrm{C}^{\prime}
$$

where, $\quad V_{S}=$ settling velocity of the particles inside a pipe

$\mathrm{V}=$ mean velocity of the slurry

$\mathrm{A}^{\prime}=$ constant coefficient

$C^{\prime}=$ spatial concentration of solids in a pipe

Vanoni (1946) used an impact tube to find out change in velocity profile due to addition of solid particles. He observed that the local mean velocity profile has a smaller magnitude for suspensions than for the pure fluid profile. He also found that Karman 
constant for logarithmic velocity variation from the wall, decreases with increase in solid concentrations.

Newitt, Richardson, Abbott \& Turtle (1955), based on Wilson's approach experimented with solid particles of different sizes up to $4.76 \mathrm{~mm}$ and specific gravity between 1.18 and 4.6 in an $1^{\prime \prime}$ diameter pipe. They came up with slightly different correlation,

For homogeneous flow: $V \geq V_{h}=\left(1800 \mathrm{gDV}_{\infty}\right)^{1 / 3}$

$$
\frac{\mathrm{h}-\mathrm{h}_{\mathrm{w}}}{\mathrm{h}_{\mathrm{w}} \mathrm{C}}=0.6(\mathrm{~s}-1)
$$

For homogeneous flow: $V_{b} \leq V \leq V_{h}$

$$
\frac{h-h_{w}}{h_{w} C}=1100 \frac{g D}{V^{2}}(s-1)
$$

For moving-bed flow: $\mathrm{V} \leq \mathrm{V}_{\mathrm{b}}=17 \mathrm{~V}_{\infty}$

$$
\frac{\mathrm{h}-\mathrm{h}_{\mathrm{w}}}{\mathrm{h}_{\mathrm{w}} \mathrm{C}}=66 \frac{\mathrm{gD}}{\mathrm{V}^{2}}(\mathrm{~s}-1)
$$

where $\quad V_{\infty}=$ terminal velocity of a sphere settling in an unbounded fluid.

$V_{h}=$ critical velocity of homogeneous flow regime

$\mathrm{V}_{\mathrm{b}}=$ critical velocity of moving-bed flow regime

Durand, Condolios et. al. (1951- 53) used sand-water slurries with particle sizes from 0.2 to $25 \mathrm{~mm}$, pipe diameters from 3.8 to $58 \mathrm{~cm}$ and solid concentrations up to $60 \%$ by volume. They cam up with the following correlation,

$$
\begin{aligned}
\frac{h-h_{w}}{h_{w} C}=K & {\left[\frac{V^{2}}{g D(s-1)} \sqrt{C_{d}}\right]^{m} } \\
g & =\text { acceleration due to gravity } \\
D & =\text { pipe ID } \\
s & =\text { ratio of densities of solid to liquid }
\end{aligned}
$$




$$
\begin{aligned}
& C_{d}=\text { drag coefficient for settling of particles } \\
& K, m=\text { constant coefficients }
\end{aligned}
$$

Roco and Shook $(1981,1983)$ studied slurry flows and also investigated the effect of particle size. They also proposed models to predict concentration and velocity distributions.

Several other researchers have made significant contributions to the measurement and prediction of pressure losses in slurry flows. An excellent review may be found in the paper by Turian \& Yuan (1977). Using the results of various researchers as well as their own data, they developed some correlations. Hanks (1962) attempted to predict laminar to turbulent transition velocity. In his investigation both Bingham plastic and power law models were used.

Bingham plastic:

$$
\tau=\tau_{0}+\mu \frac{\partial u}{\partial y}
$$

Power law:

$$
\tau=\mu\left[\frac{\partial u}{\partial y}\right]^{\mathrm{n}}
$$

where

$$
\begin{aligned}
& \tau: \text { shear stress } \\
& \tau_{0} \text { : constant coefficient of shear stress } \\
& \mu \text { : viscosity } \\
& \mathrm{n}: \text { constant coefficent }
\end{aligned}
$$

Meanwhile Bagnold (1954) postulated the existence of collisional stresses due to net momentum transfer during collision of particles. Based on this Shen (1963) developed a model for slurry flows. He derived an expression similar to that for turbulent flow of a single phase fluid where the velocity varies logarithmically with the distance from the wall. 
Einav and Lee (19i3) attempted to study the motion of solid particles in a laminar boundary layer. Measurements were made using Laser Doppler Velocimeter at 4 and $6 \%$ concentrations with neutrally buoyant solid particles. The study included separate measurements of fluid and solid particles. This was done by amplitude and frequency discriminations. However the effects of biasing, filter induced errors and other sources of errors were not considered though signals were processed through 'narrow-band' filters. This may be crucial especially when trying $t$ separate fluid and particle velocities.

Durst and Zare (1975) pointed out the feasibility of applying LDV in multiphase flows and studied the effects of laser beam interaction with opaque and transparent particles. Experiments were restricted to a swinging solid sphere to study the case of solid opaque particles.

Ohba (1974), Lehmann (1975), Delhaye (1975) performed experiments in water-air bubble and air-water droplet flows.

Following these Zisselmr and Molerus (1978) used LDA for measuring slurry properties. Methyl benzoate and glass beads ( $12-120$ microns, mean $=53$ microns) were used to form the slurry. Concentration of the slurry was raised up to $5.6 \%$ by volume. The key point of the study was in the use of the refractive index matching technique.

Edwards, Dybbs et. al. (1984) reported various combinations of solid and liquid suitable for refractive index matching. They used combinations of commercially available oils with glass and plexiglass. Measurements were made in flow through rod bundles modeling porous media and flow over small glass beads, modeling effects of surface roughness within boundary layer.

Whitelaw and Yianneskis (1984) and Nouri, Whitelaw and Yianneskis (1986) reported studies on slurries using LDV. They also used refractive index matching technique. Diakon (plexiglass) particles as solids and a water and di-n-butyl-phthalate 
combination as liquid were used in the former study. In the later study a mixture of tetraline and turpentine and plexiglass particles were used. The depth of field which could be penetrated using LDV was around $180 \mathrm{~mm}$ for a solid concentration of only $2 \%$.

Abbas \& Crowe (1985) studied solid-liquid slurries using a refractive index matched combination of silica-gel and chloroform. Solid concentration range of 0 - to nearly 30 percent was tried and data were taken for homogeneous slurry flow at high Reynolds numbers $(3000$ to 30,000$)$. No differences in solid and liquid velocities were reported. Velocity profiles were measured only along a horizontal diameter of the pipe. Therefore any variations in the solid-liquid velocities along the vertical diameter could not be ascertained. However, for the homogeneous slurry flow at high Reynolds numbers they concluded that the velocity varies logarithmically with the distance from the wall.

The literature survey reported in this section suggests that there is not enough experimental data available to model multiphase flows. This calls for precise and insightful experiments to be done in this area to reveal the mechanics of slurry flows. Non-intrusive Laser Doppler Velocimetry, coupled with refractive index matching technique offers a suitable vehicle for studying particle-particle, particle-fluid and particle -wall interactions. 


\section{EXPERIMENTAL APPARATUS}

It has always been very difficult to perform accurate experiments to obtain constituent velocity components in slurries. This is mainly due to unavailability of appropriate instruments to handle the slurry flows. In this project, apart from the bulk properties, we are looking for the detailed local properties in the slurry flows over a wide range of velocities including fairly low velocities. This makes the design of experimental set-up and choice of instruments very critical.

Laser Doppler Velocimeter (LDV) was chosen as the non-intrusive velocity measuring instrument. An intrusive instrument would change the flow pattern. The choice of LDV imposed some restrictions. From the experience of previous researchers it became evident that opaque solid particles restrict the use of LDV to low concentration below $2 \%$ - slurries only. To overcome this difficulty a refractive-index-matching technique was employed. In this technique the refractive indices of solid and liquid are matched. Since the project was motivated by the interest in the transportation of coal-water slurry, properties of the refractive index matched slurry were aimed to match the properties of coal-water slurry (Table 1).

\subsection{Refractive Index Matched Solid and Liquid}

The first phase of the work involved selection of a suitable refractive index matched, solid-liquid combination. Available information is presented in Table 2. As a first attempt, a combination of sodium iodide (NaI) solution in water as the liquid and glass as the solid was tried. Tests were conducted to study the variation of refractive index of sodium iodide solution as a function of sodium iodide concentration and temperature. The results are plotted in Figure 3.1. A Bausch and Lomb-Abbe-3L Refractometer was used in these tests. By varying the concentration of sodium jodide from 0 to $60 \%$ by weight and 


\section{TABLE I}

Desired Range of Test Parameters for the Multiphase Flow Experiment

A. Parametric Ranges of Interest

1. Reynolds Number: base on average velocity, pipe diameters, and pure fluid viscosity (\$ 1200) for haminar flow.

2. Average Concentration: .

$0-40 \%$ by volume

3. Pipe Diameter:

small $\left(<2^{n}\right)$

4. Density Ratio:

Psolid/Prieid $\approx 1.3$

5. State of Flow:

a) Laminar

b) Homogeneons

B. Particle and Geometric Specifications

1. Particle Diameter:

(for flocty ground cosd < $200 \mu$ )

2. Pipe Length:

(short $<100 \mathrm{ft}$ )

3. Particle Diameter:
a) uniform
b) disperse

4. Flow in the Test Section:

Horimontal

C. Required Measurements

1. Fluid Velocity

2. Particle Velocity

3. Pressure Drop

4. Particle Concentration 


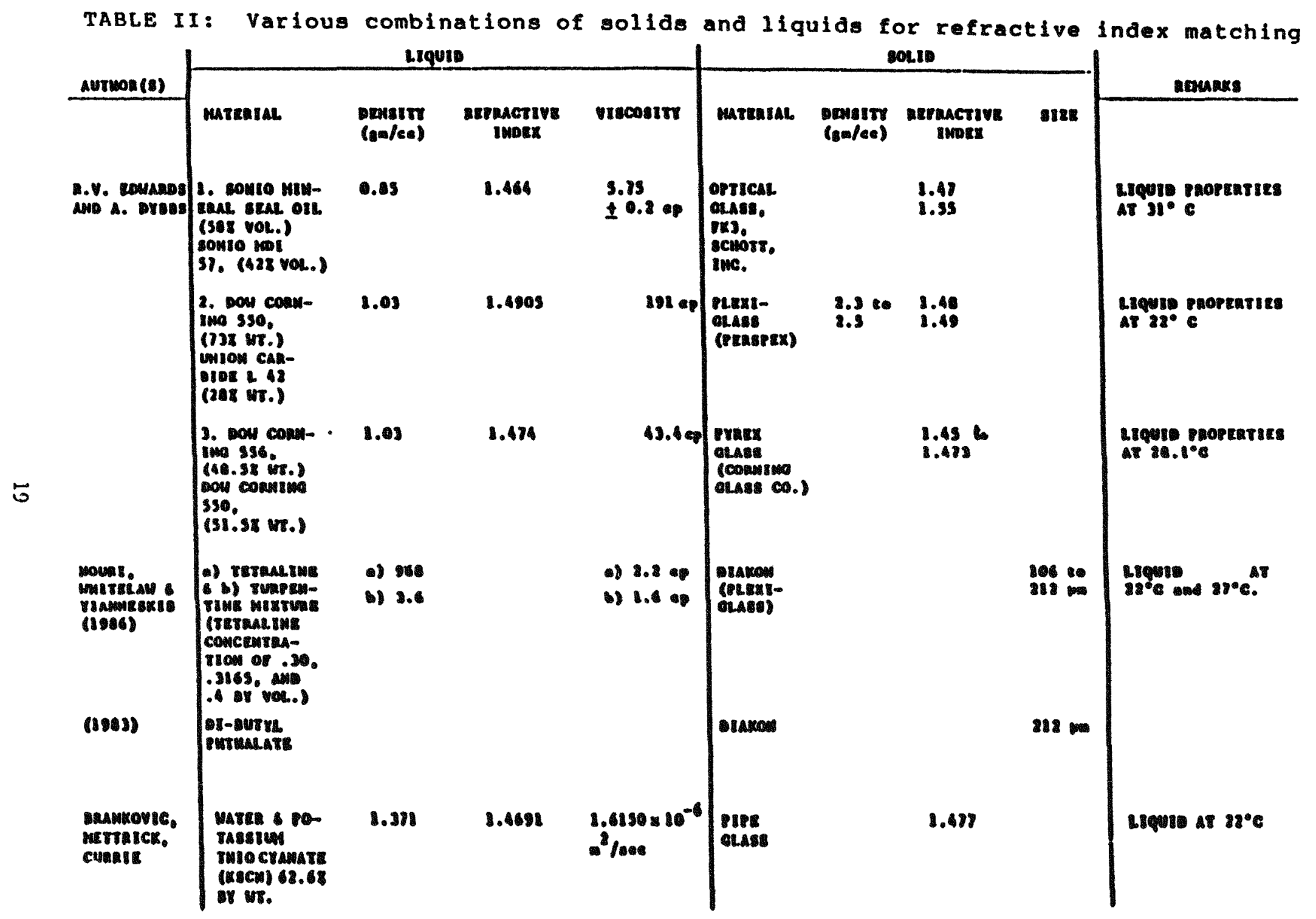


TABLE II (continued)

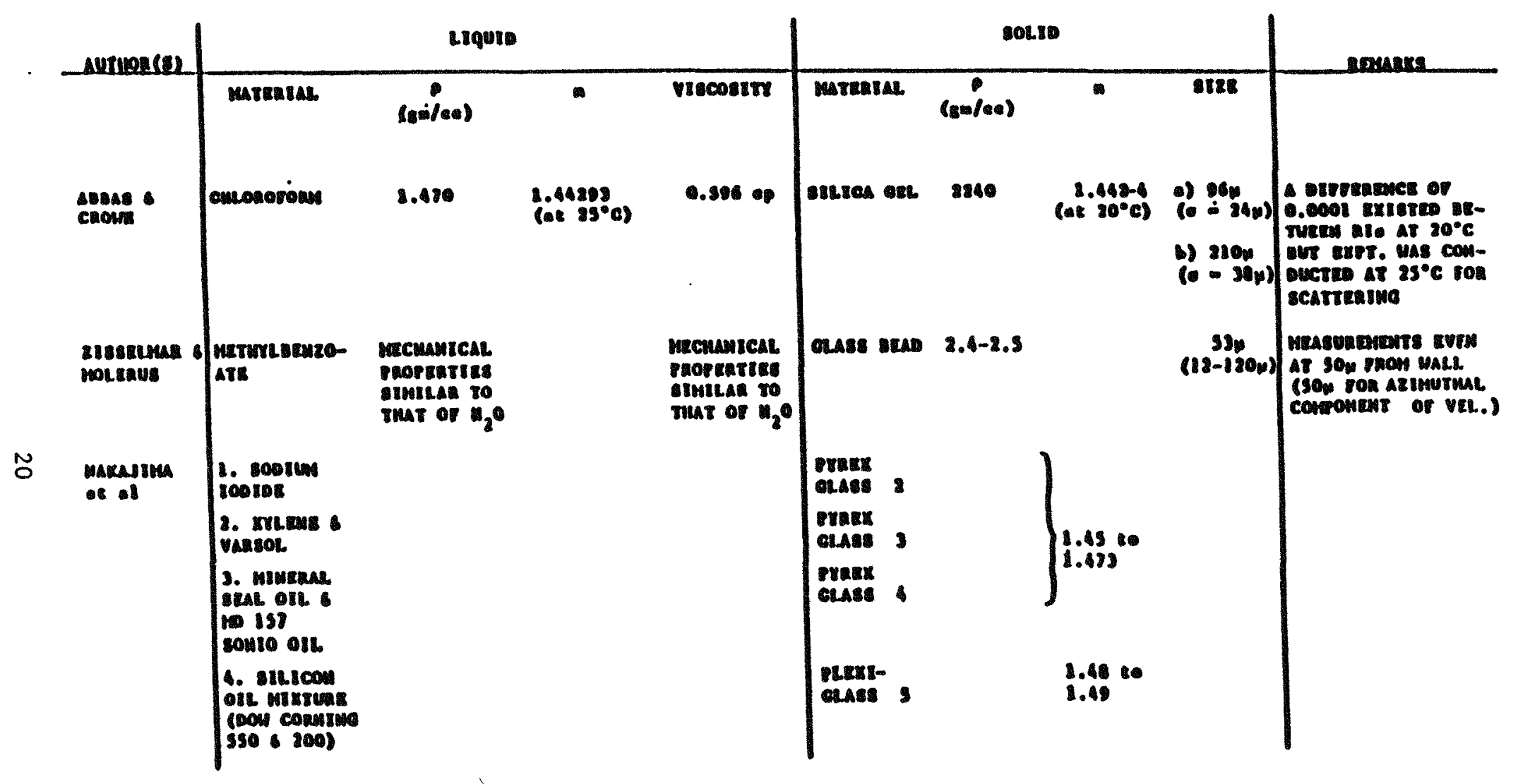




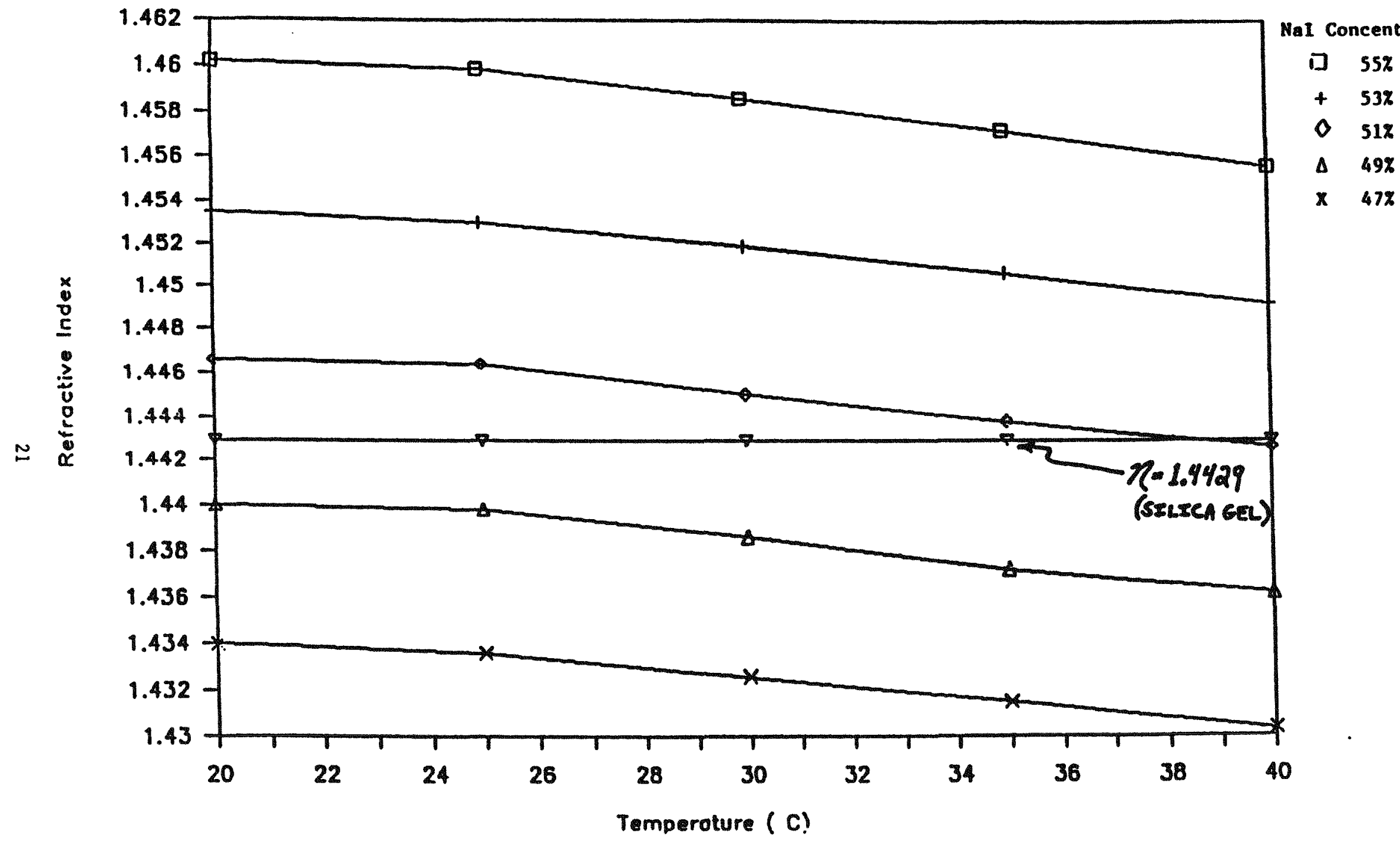

Figure 3.1. Variation in the refractive Index of wodium lodid solution as anction of temperature and concentration levels. 
the solution temperature from $20^{\circ}$ to $40^{\circ} \mathrm{C}$, a wide range of refractive indices $(1.33-1.487)$ can be covered. However due to the unavailability of sufficiently high quality glass beads (30 - 100 microns diameter) of uniform refractive index this combination did not yield good results. Annealing of the glass beads was tried without much success. A combination of chloroform and silica gel was then tried. The refractive indices matched very well. But the use of chloroform poses serious health and safety problems. So this combination was discarded. Next combination selected was silica gel and sodium iodide solution in water $\left(\mathrm{NaI} / \mathrm{H}_{2} \mathrm{O}\right)$. A very good match in refractive indices $(\approx 1.443)$ was observed at around $24^{\circ} \mathrm{C}$. Silica gel particles are porous. According to manufacturer's specifications its porosity is $0.75 \mathrm{cc} / \mathrm{gm}$. This matched well with our test results. In the slurry these pores get filled up with the liquid. The density ratio between hydrated silica gel and sodium iodide solution was calculated to be 1.15 (see appendix A). Samples of this slurry were kept over a time period of few weeks to observe any chemical change that may take place. The only visible change was a change in the color of the solution. This was due to the release of iodine from $\mathrm{NaI}$, which can be suppressed by the addition of small amount of sodium hydroxide or sodium thiosulphate. Sodium thiosulphate was chosen for use in this project since silica gel reacts with sodium hydroxide. Silica gel particles of average diameter of 40 microns with standard deviation of 20 microns were selected for these tests.

\subsection{Preliminarv Tests to Obtain Pressure Loss Data}

For the successful design of an experimental test loop, it is important to have some information regarding pressure losses due to friction in the solid-liquid flow consisting of silica gel and sodium jodide solution slurry. A simple set-up was constructed to obtain pressure drop data for silica gel-water slurry. Water was used instead of sodium iodide solution because of the prohibitive cost of sodium iodide. The viscosity of sodium iodide solution $(55 \% \mathrm{NaI})$ is 1.47 centipoise at $22^{\circ} \mathrm{C}$ compared to 1.0 centipoise for water. 


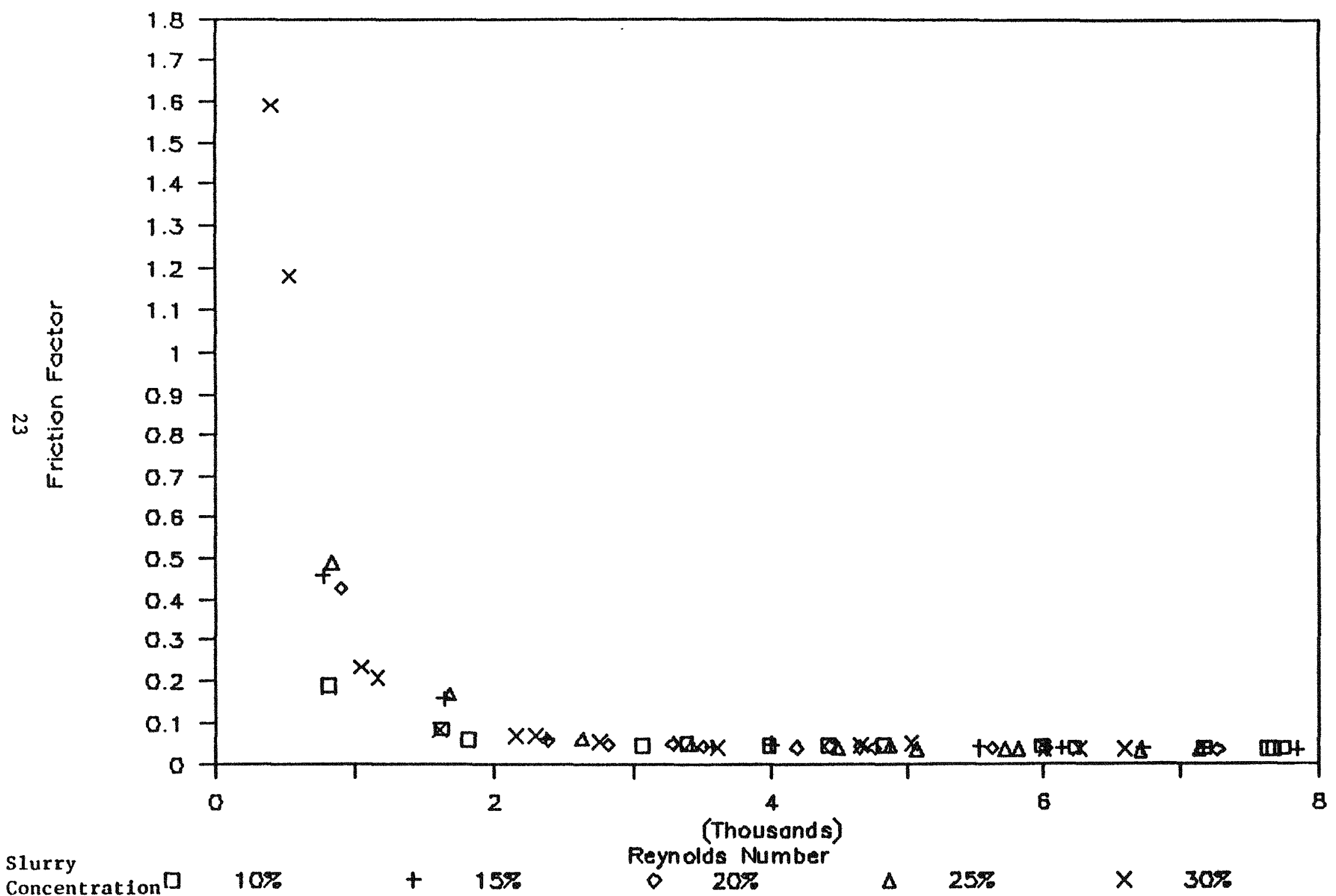

Figure 3.2: Friction Factor v8. Reynolds Number (9/32" ID plpe) 


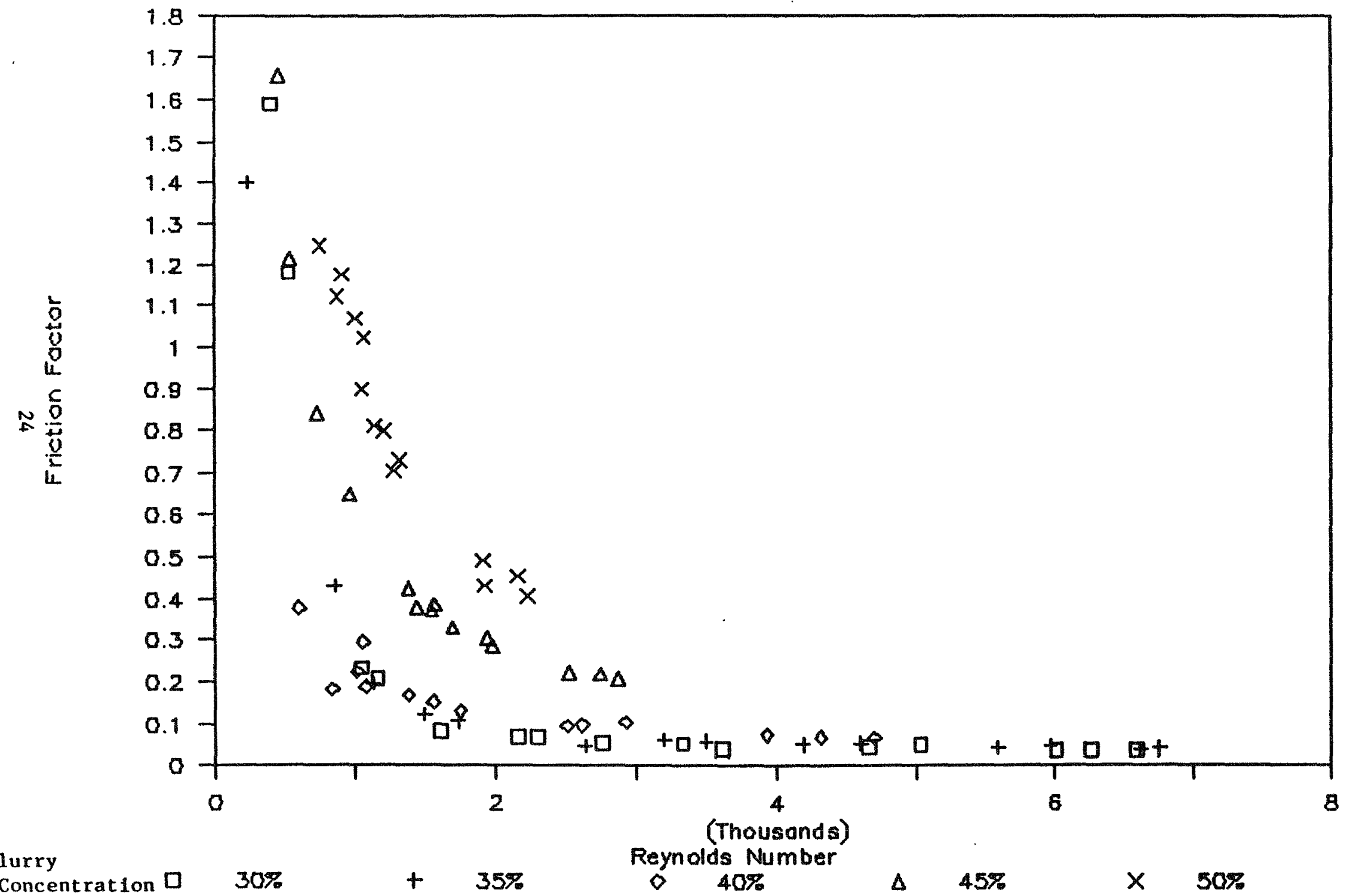

Figure 3.3: Friction Factor v8. Reynolds Number (9/32" ID pipe) 


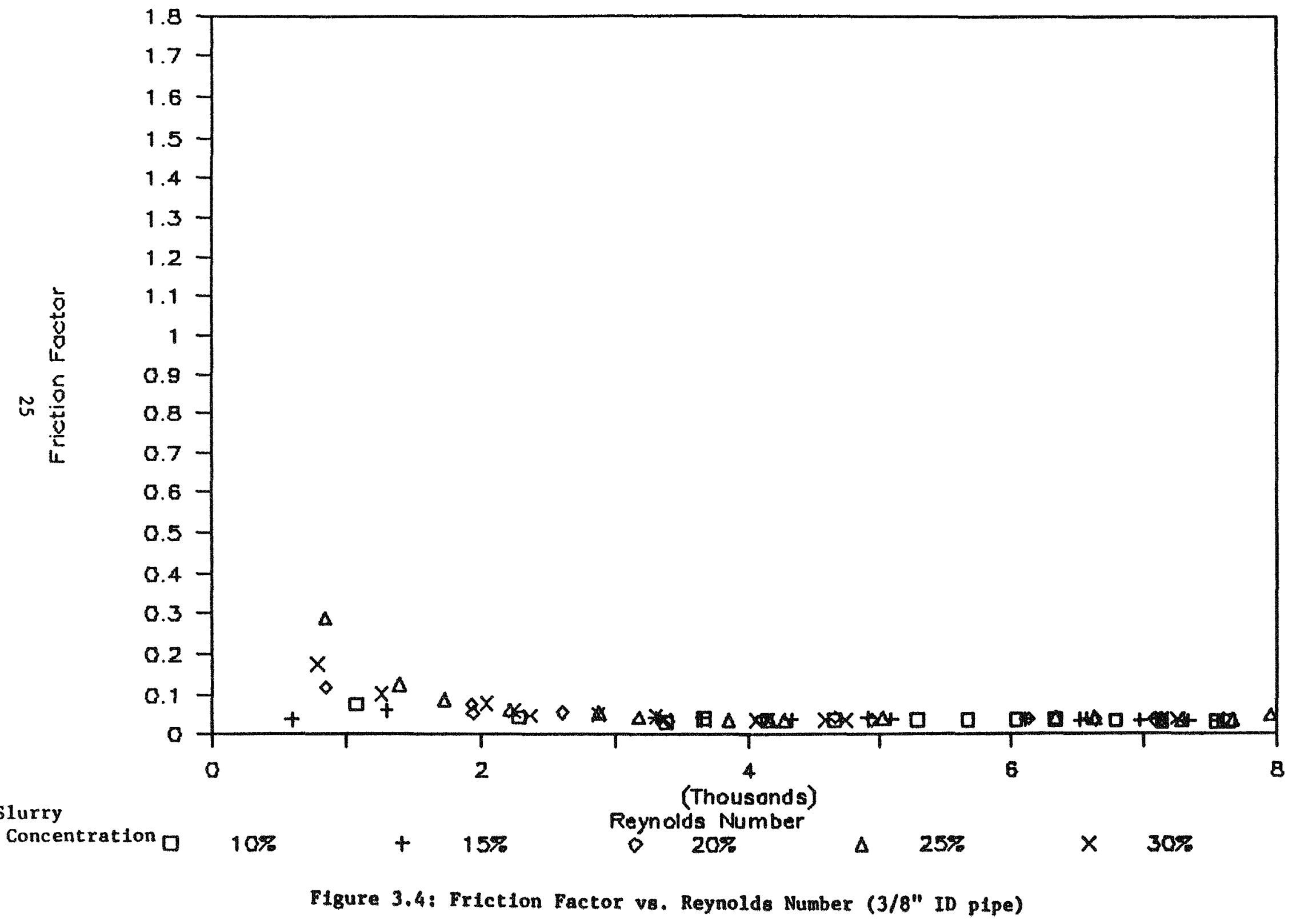




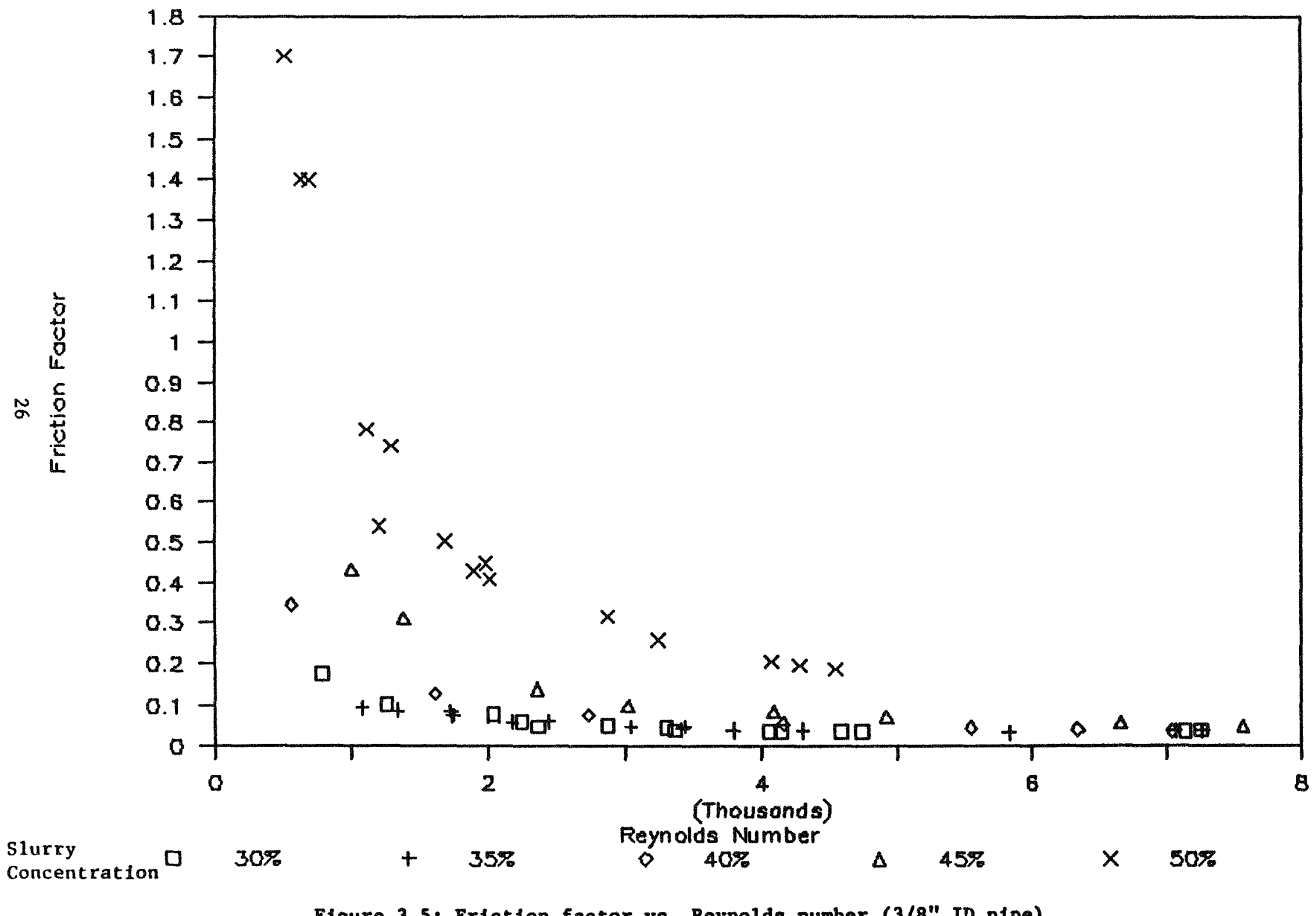

Figure 3.5: Friction factor v8. Reynolds number (3/8" ID p1pe) 


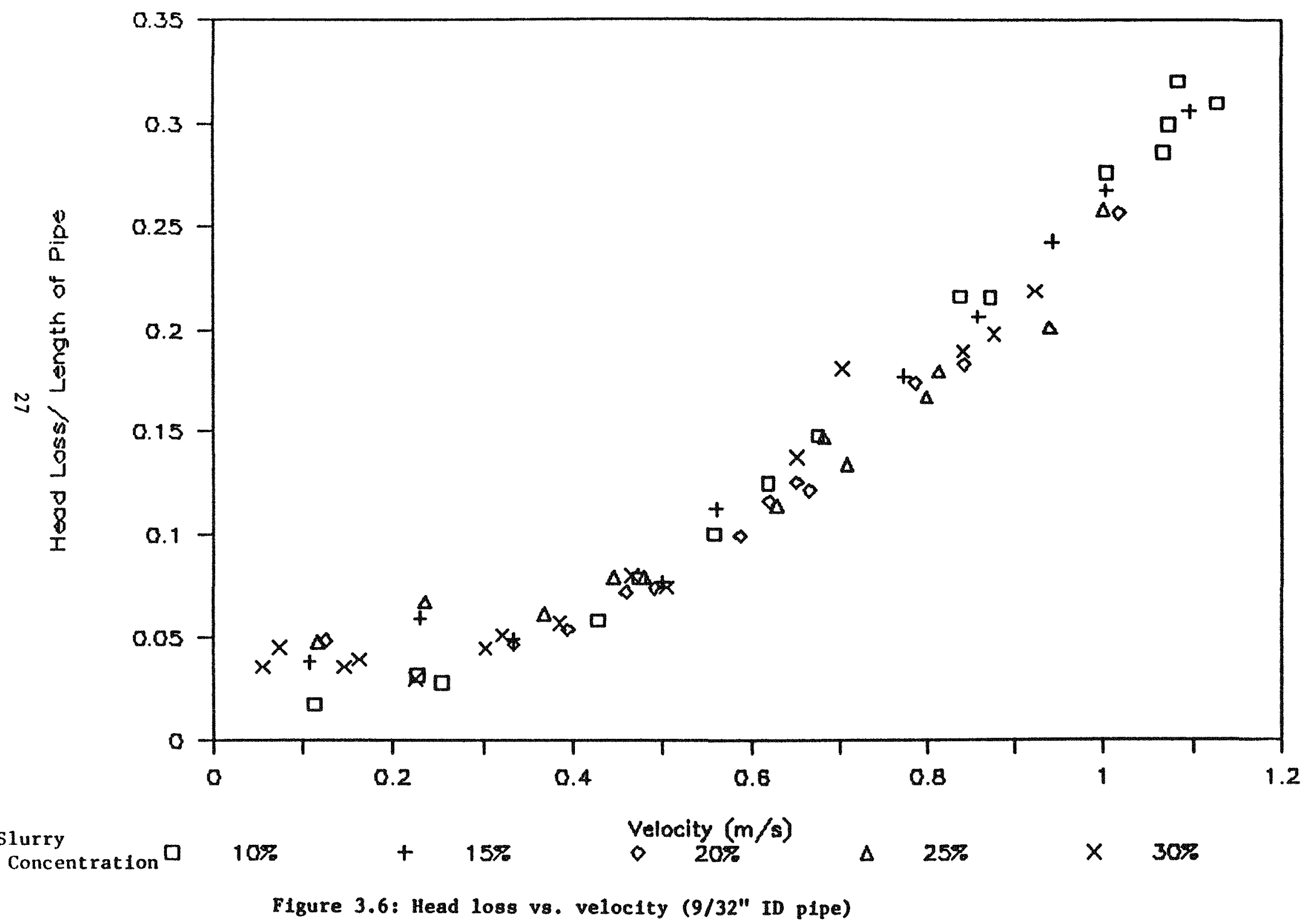




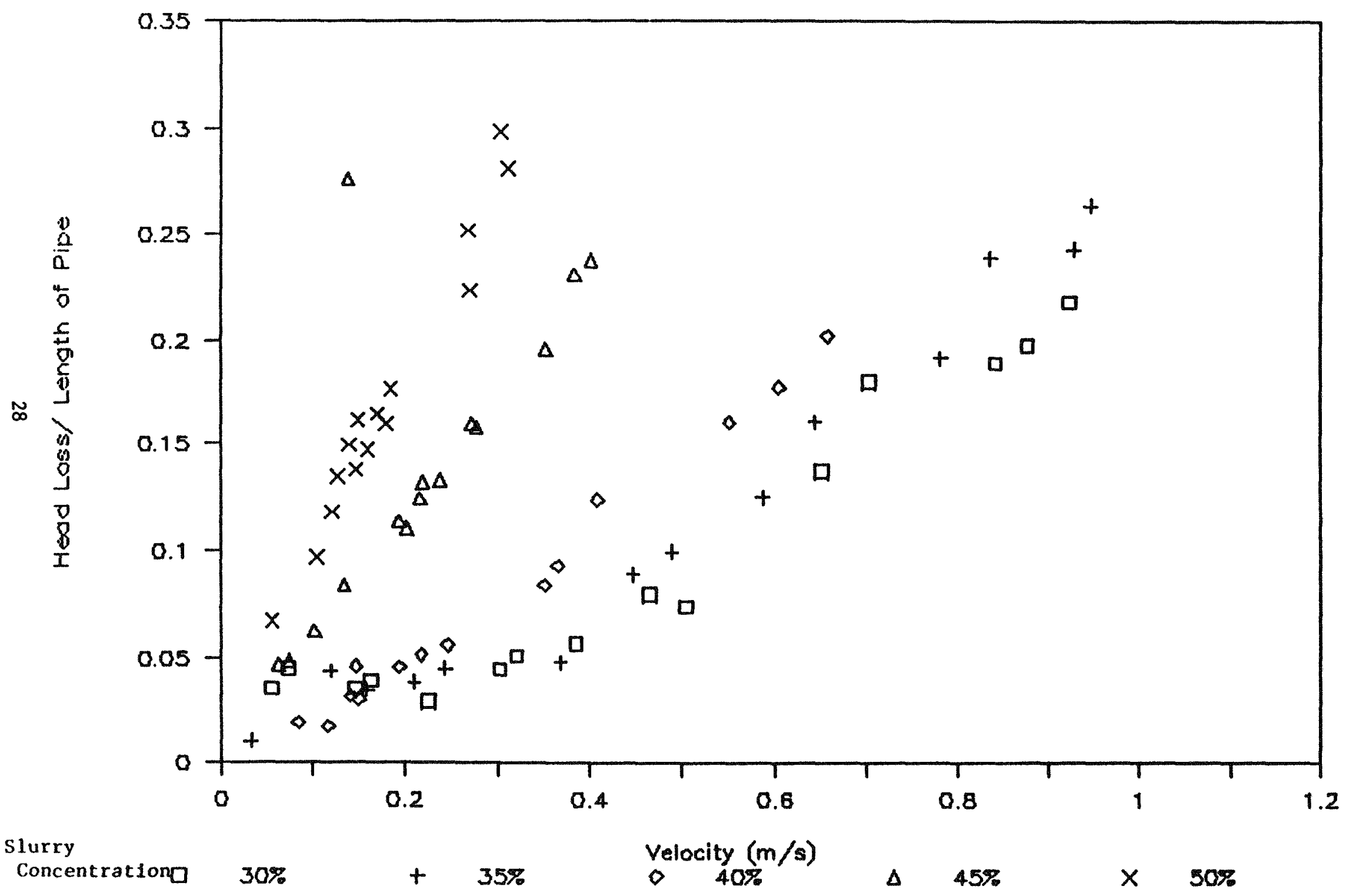

Figure 3.7 Head loss vs, velocity ( $9 / 32^{\prime \prime}$ ID pipe) 
Density of silica gel is $2.24 \mathrm{gm} / \mathrm{cc}$. For hydrated silica gel, i.e. pores filled with water, the average density is $1.45 \mathrm{gm} / \mathrm{cc}$. The tests were conducted in two different pipes, with internal diameters $8 / 32$ and $3 / 5$ inch, respectively. The solid concentration was varied from 0 to $50 \%$ by volume in steps of $5 \%$. The Reynolds number range was up to 8000 . Pressure measurements were made using open vertical tube manometers. Uncertainties in the pressure measurements were $\pm S \%$ for the $3 / S$ inch ID pipe and $\pm 11 \%$ for the $9 / 32$ inch ID pipe. The friction factor was calculated using Darcy-Weisbach equation (3.1).

$$
f=h \frac{D 2 g}{L}
$$

where, $h=$ head loss of the slurry

$\mathrm{D}=$ pipe diameter

$L=$ length over which head loss takes place

$\mathrm{g}=$ acceleration due to gravity

$v=$ average velocity of the slurry

The variation of the friction factor with Reynolds number for the data is shown in Figures 3.2 through 3.5. The solid particle concentration range from $10 \%$ to $50 \%$ by volume is covered in these figures. The Reynolds number is based upon average velocity of the slurry, pipe diameter and the kinematic viscosity of the fluid phase only.

The friction factor and head loss increase with concentration for the same Reynolds number, as expected. For low and medium concentration ( $<30 \%$ by volume of solid) this increase is very small, but for concentrations $>30 \%$, it becomes significant. Probably the critical concentration depends on particle size, solid to liquid density ratio and other factors like the properties of the fluid phase etc.

The variation of head loss per unit length of the pipe with velocity and the 
concentration is provided in Figures 3.6 and 3.7. The friction factors obtained from these preliminary tests were compared with the friction factors obtained from Turian and Yuan's correlation as shown in Table 3.

Results in Table 3 show that only at high velocities does Turian and Yuan's correlations predict friction factors fairly accurate.

Table 3.: Comparison of Friction Factors for the $9 / 32^{*}$ ID and $3 / 8^{\prime \prime}$ ID pipes $15 \%$ solid

\begin{tabular}{|c|c|c|c|}
\hline $\operatorname{Re}($ water visc.) & F1 & F2 & Fturian \\
\hline $\begin{array}{l}760 \\
1622 \\
2351 \\
3533 \\
3965 \\
5465 \\
6067 \\
6657 \\
7092 \\
7755\end{array}$ & $\begin{array}{l}0.676 \\
0.155 \\
0.067 \\
0.036 \\
0.045 \\
0.038 \\
0.035 \\
0.034 \\
0.034 \\
0.032\end{array}$ & $\begin{array}{l}0.240 \\
0.158 \\
0.055 \\
0.048 \\
0.054 \\
0.044 \\
0.042 \\
0.041 \\
0.039 \\
0.038\end{array}$ & $\begin{array}{l}0.107 \\
0.042 \\
0.041 \\
0.043 \\
0.042 \\
0.037 \\
0.035 \\
0.033 \\
0.033 \\
0.033\end{array}$ \\
\hline \multicolumn{4}{|c|}{$10 \%$ solid } \\
\hline $\operatorname{Re}($ water visc.) & $\mathrm{F} 1$ & $\mathrm{~F} 2$ & Fturian \\
\hline $\begin{array}{l}801 \\
1600 \\
3020 \\
3949 \\
4773 \\
5924 \\
7588 \\
1795 \\
334 \overline{1} \\
4375 \\
6162 \\
7099 \\
7975 \\
7663 \\
7548\end{array}$ & $\begin{array}{l}0.138 \\
0.062 \\
0.036 \\
0.040 \\
0.041 \\
0.039 \\
0.033 \\
0.038 \\
0.030 \\
0.041 \\
0.036 \\
0.033 \\
0.032 \\
0.046 \\
0.032\end{array}$ & $\begin{array}{l}0.237 \\
0.108 \\
0.051 \\
0.048 \\
0.049 \\
0.046 \\
0.039 \\
0.081 \\
0.068 \\
0.049 \\
0.042 \\
0.041 \\
0.035 \\
0.029 \\
0.037\end{array}$ & $\begin{array}{l}0.097 \\
0.043 \\
0.046 \\
0.042 \\
0.039 \\
0.037 \\
0.034 \\
0.035 \\
0.045 \\
0.040 \\
0.036 \\
0.034 \\
0.033 \\
0.034 \\
0.034\end{array}$ \\
\hline
\end{tabular}


$20 \%$ solid

\begin{tabular}{|c|c|c|c|}
\hline $\operatorname{Re}($ water visc) & $\mathrm{F} 1$ & $\mathrm{~F} 2$ & Fturian \\
\hline $\begin{array}{l}887 \\
4389 \\
3245 \\
2357 \\
4604 \\
3469 \\
4706 \\
5559 \\
7193 \\
5954 \\
415 \\
2786\end{array}$ & $\begin{array}{l}0.045 \\
0.039 \\
0.050 \\
0.051 \\
0.036 \\
0.044 \\
0.035 \\
0.034 \\
0.032 \\
0.032 \\
0.037 \\
0.045\end{array}$ & $\begin{array}{l}0.405 \\
0.044 \\
0.044 \\
0.064 \\
0.045 \\
0.041 \\
0.041 \\
0.043 \\
0.036 \\
0.039 \\
0.043 \\
0.050\end{array}$ & $\begin{array}{l}0.091 \\
0.041 \\
0.046 \\
0.052 \\
0.040 \\
0.045 \\
0.040 \\
0.037 \\
0.035 \\
0.037 \\
0.042 \\
0.048\end{array}$ \\
\hline \multicolumn{4}{|c|}{$25 \%$ solid } \\
\hline $\operatorname{Re}$ (water visc.) & $\mathrm{F} 1$ & F2 & Fturian \\
\hline $\begin{array}{l}\$ 23 \\
1662 \\
2603 \\
3382 \\
4445 \\
5007 \\
5649 \\
6638 \\
7064 \\
5750 \\
4822 \\
3144\end{array}$ & $\begin{array}{l}0.445 \\
0.167 \\
0.060 \\
0.048 \\
0.038 \\
0.034 \\
0.033 \\
0.027 \\
0.031 \\
0.033 \\
0.046 \\
0.055\end{array}$ & $\begin{array}{l}0.531 \\
0.170 \\
0.065 \\
0.048 \\
0.042 \\
0.039 \\
0.039 \\
0.035 \\
0.040 \\
0.041 \\
0.041 \\
0.056\end{array}$ & $\begin{array}{l}0.103 \\
0.060 \\
0.050 \\
0.046 \\
0.041 \\
0.039 \\
0.038 \\
0.036 \\
0.033 \\
0.038 \\
0.040 \\
0.048\end{array}$ \\
\hline
\end{tabular}

N.B - Re is based on water viscosity

F1 \& F2 are the friction factors for the $9 / 32$ inch and $3 / 8$ inch pipes respectively.

Fturian is the friction factor based on Turian \& Yuan's correlations.

For the purpose of modeling it is extremely important to know the behavior of the effective viscosity of the slurry. The effective or apparent viscosity of the slurry may be defined as the viscosity at a certain velocity if the slurry could be treated as an equivalent single phase fluid at that velocity. We can also define an apparent Reynolds number, $R e_{\text {ap }}$ based on this viscosity. According to this assumption, $\mathrm{Re}_{\text {ap }}$ should be related to the 
friction factor by,

$$
f=\frac{64}{\operatorname{Re}_{\text {ap }}}
$$

for low velocities and Colebrook's formula for high velocities. Apparent viscosity can be calculated knowing apparent Reynolds number (Figures 3.8 and 3.9). The variation of apparent viscosity with concentration at different velocities is shown in Figure 3.10. The apparent viscosity seens to vary exponentially with concentration at different velocities. This may be because, depending on the particle size and packing factor of the particle beyond a certain concentration the slurry may approach some kind of 'packed bed' state. These plots seem to support the model proposed by Chen et. al. and support the observations of Ekmann et. al. This pressure drop data were used in the design of the test loop.

\subsection{The Refractive Index Matched Multiphase Flow Loop}

A multiphase flow test loop was then designed and constructed. A schematic diagram of the flow loop is given in Fig. 3.11. In a slurry flow system it is best to avoid, as far as possible, sharp bends, expansion and contraction joints, or any object protruding into the flow. Such components and configurations can result in the accumulation of solid particles causing undesirable changes in the flow. There was no such component in the flow loop.

A 1 inch internal diameter flow loop was considered for this work. A horizontal flow path was chosen to minimize deposition of particles in different parts. Clear, rigid PVC (Polyvinyl chloride) tube was used to construct most of the flow loop except for a 10 foot long, 1 inch ID glass (pyrex glass) test section. Almost the entire flow path was supported on aluminum I-beams to prevent deflection.

A 1 HP Roper progressive cavity pump was used to circulate the slurry through the 


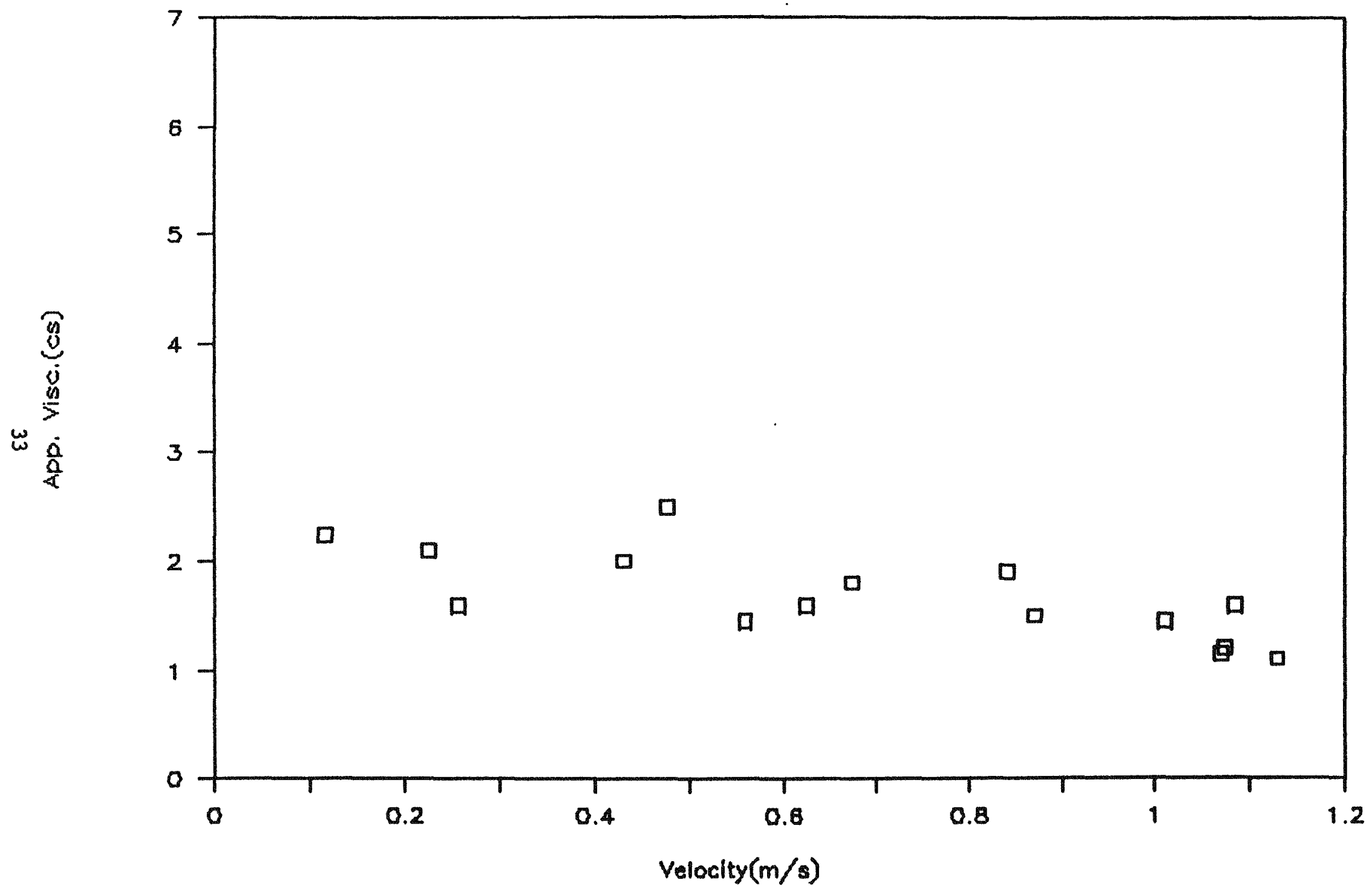

Figure 3.8: Apparent viscosity v8, velocity (10\% slurry, 3/8" ID pipe) 




Figure 3.9: Apparent viscosity v8. velocity ( $40 \%$ slurry, $3 / 8^{\prime \prime}$ ID pipe) 


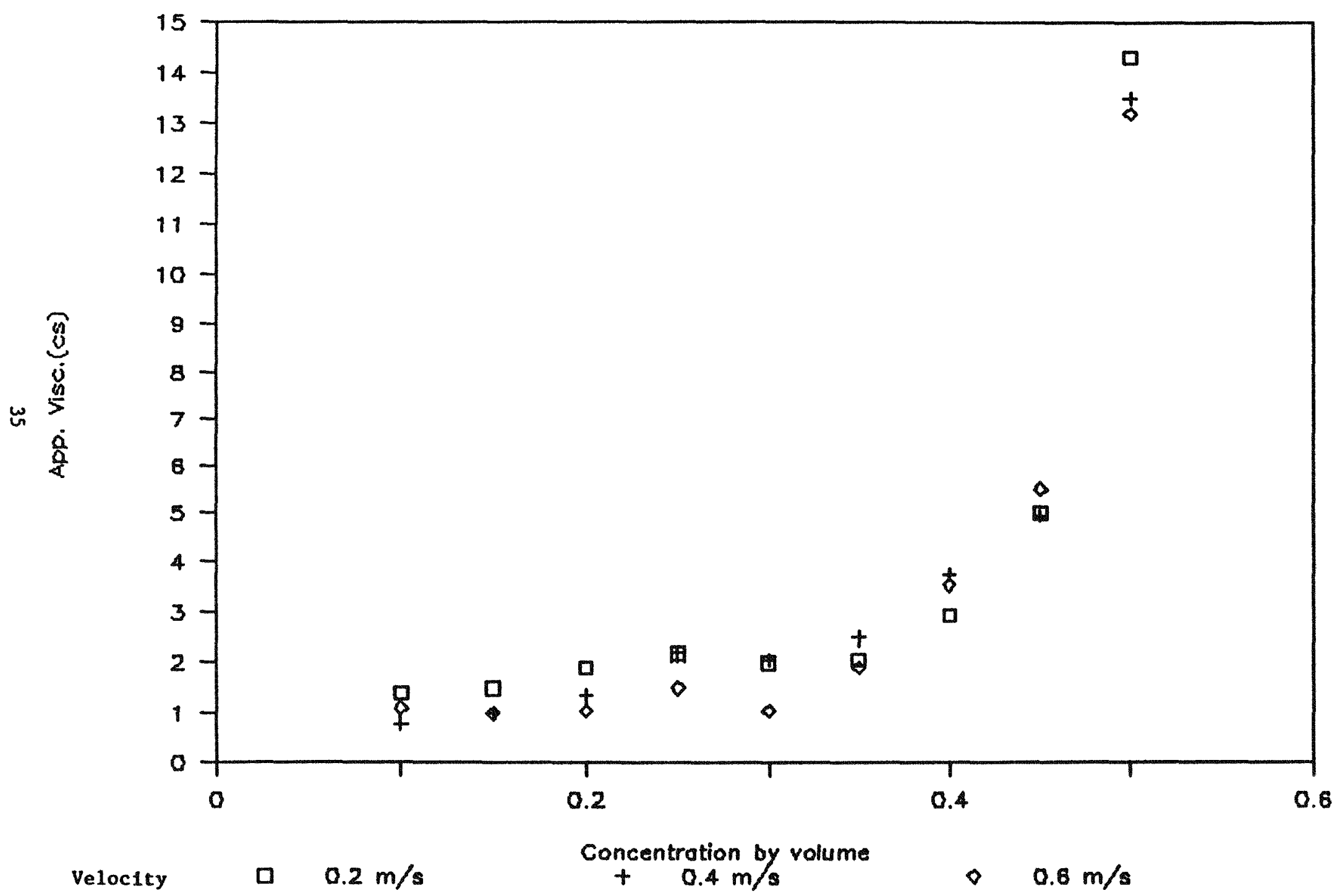

Figure 3.10: Apparent viscosity vs concentration of slurry (3/8" ID pipe) 


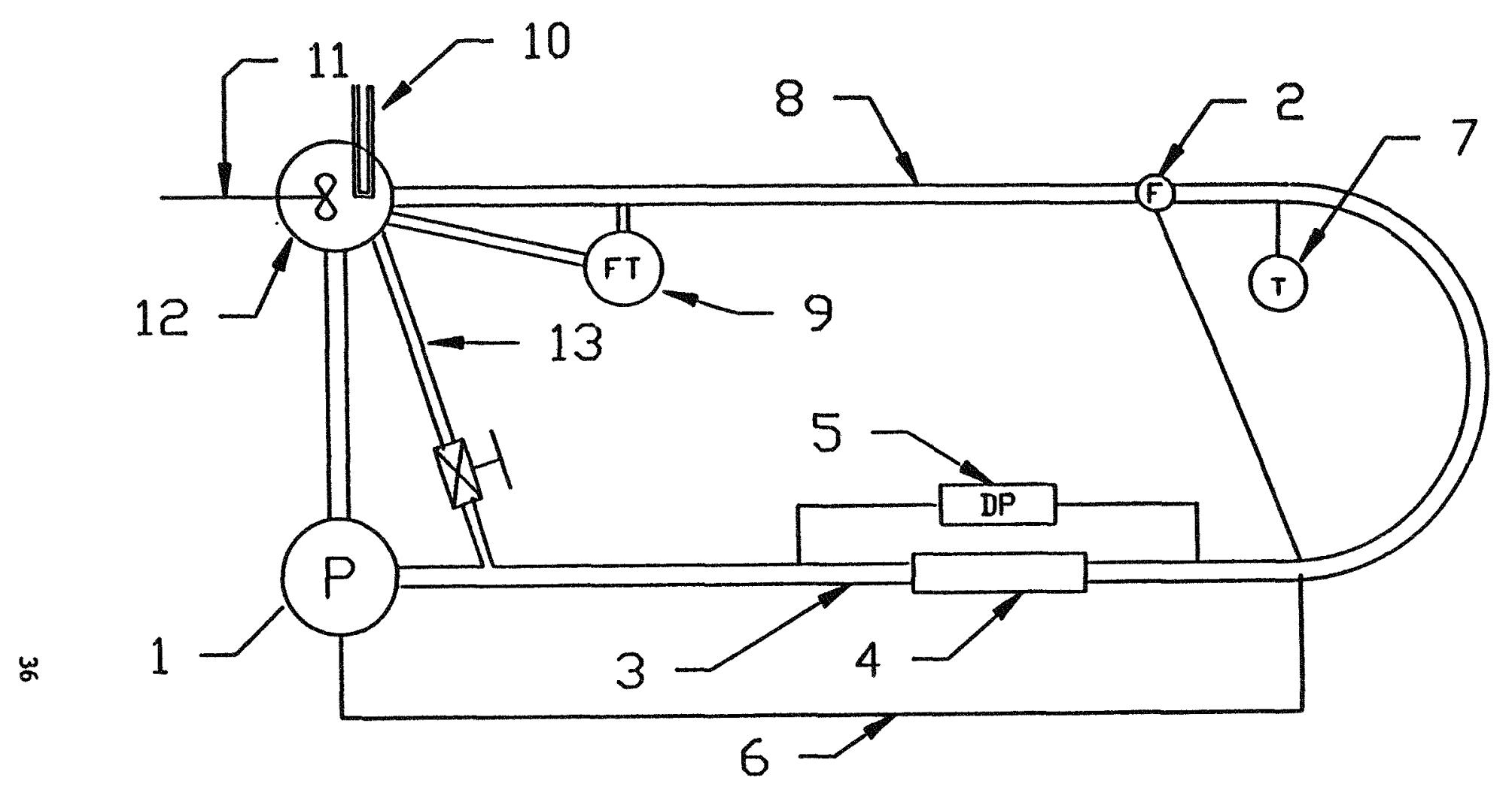

Figure 3.11: Schematic Diagram of Multiphase Flow syaten

1. Roper Progreselve Cavlty Pump, Model 172201

2. Poxboro slectromagnetic Flow Motex, Model Bo01-WRC-A6

3. 1" ID C1ase teat section

4. Square Box Around Test Section

3. Meriam Inclined Tube Manometer

6. Teedback Circuit

7. Temperature Probe

8. 1" ID PVC PIpe

9. Tlueh Tank

10. Heat Bxchanger

11. Stirrer

12. Reservolr

13. Bypass Line 
system. It is a modified form of screw pump. The rotor was made of stainless steel and the stator was coated with Buna-N. The rest of its inside was coated with PVC. This inhibited any interaction between the slurry and the metallic body of the pump. Our tests indicated that the swirl induced by the pump was completely dampened substantially upstream of the glass test section.

Nearly one foot downstream of the pump outlet a Bourdon type pressure gage and an over-pressure release valve was provided. The pressure drop was measured across a length of 14 feet 1.5 inches. First of the two pressure taps were located 11 feet downstream of the pump. Pressure tap hole size was $3 / 16$ inch diameter, appropriate for the pipe size (Shaw). A Meriam inclined tube manometer with indicating liquid of 2.8 specific density was used to obtain pressure drop.. Samples of Meriam indicating liquid and sodium iodide-Silica gel slurry were tested and found to be non reactive with each other.

Preliminary tests were conducted for single phase by using water. The results were compared with Moody chart of smooth wall; the comparisons were quite satisfactory. (Figure 3.12,3.13).

There was about ten feet of straight pipe before the entrance to the glass test section. This was meant to ensure 'fully developed' flow in the test section. An estimate about this length was made based on the requirement for a single phase flow.

The curvature of the glass tube could cause of problem in making LDV measurements. The curvature may bend the laser beams unequally and may cause total internal reflection depending on the refractive indices of mediums involved. Also for the back scattered light the glass wall acts as a diverging lens decreasing the amount of signal available to the photomultiplier tubes. Again to solve this problem a refractive index matching technique was used. A box with glass windows was constructel to fit around the glass tube. This box was filled with $\mathrm{NaI} / \mathrm{H}_{2} \mathrm{O}$ solution of same refractive index as that of 


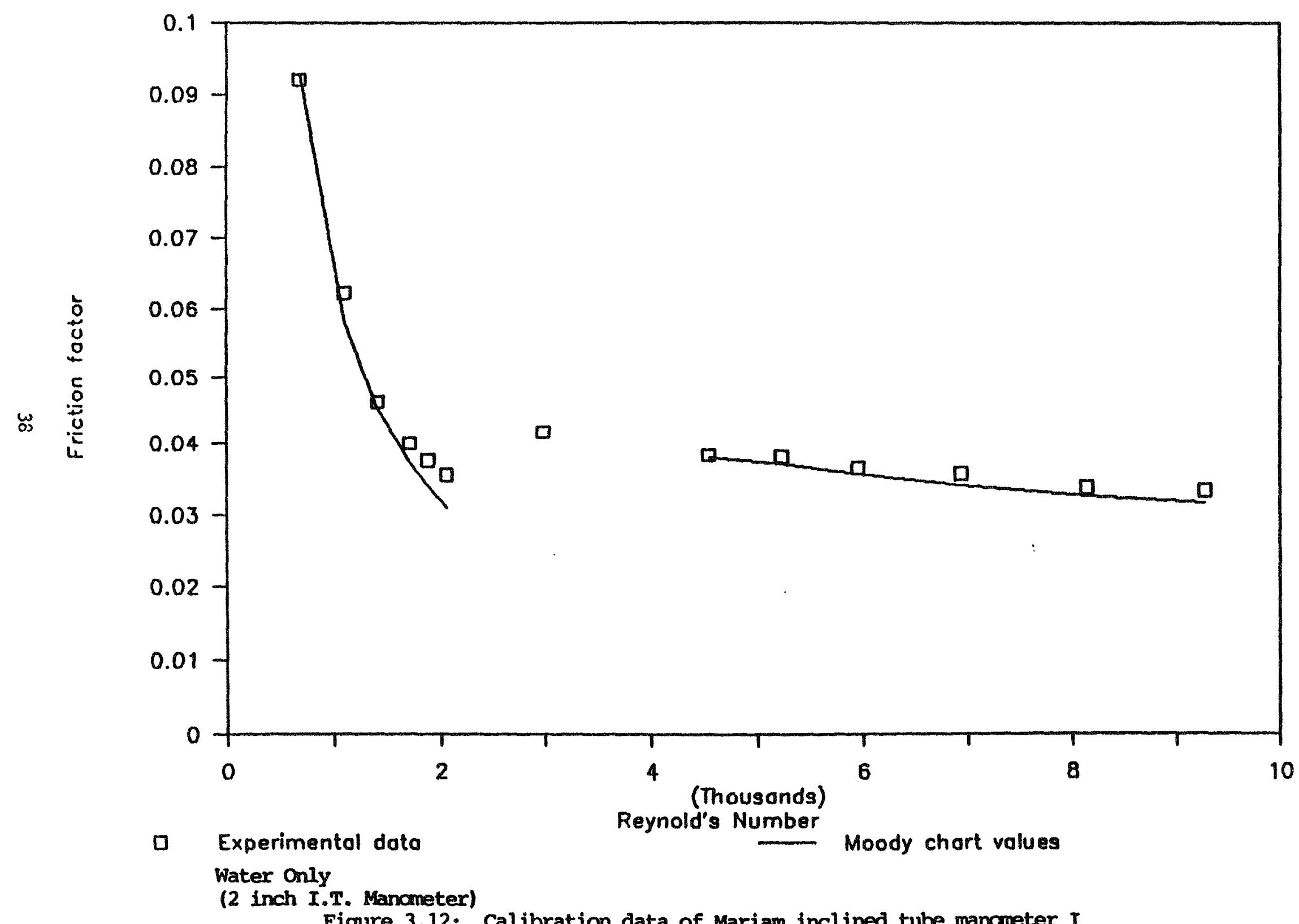

Figure 3.12: Calibration data of Mariam inclined tube manometer I 


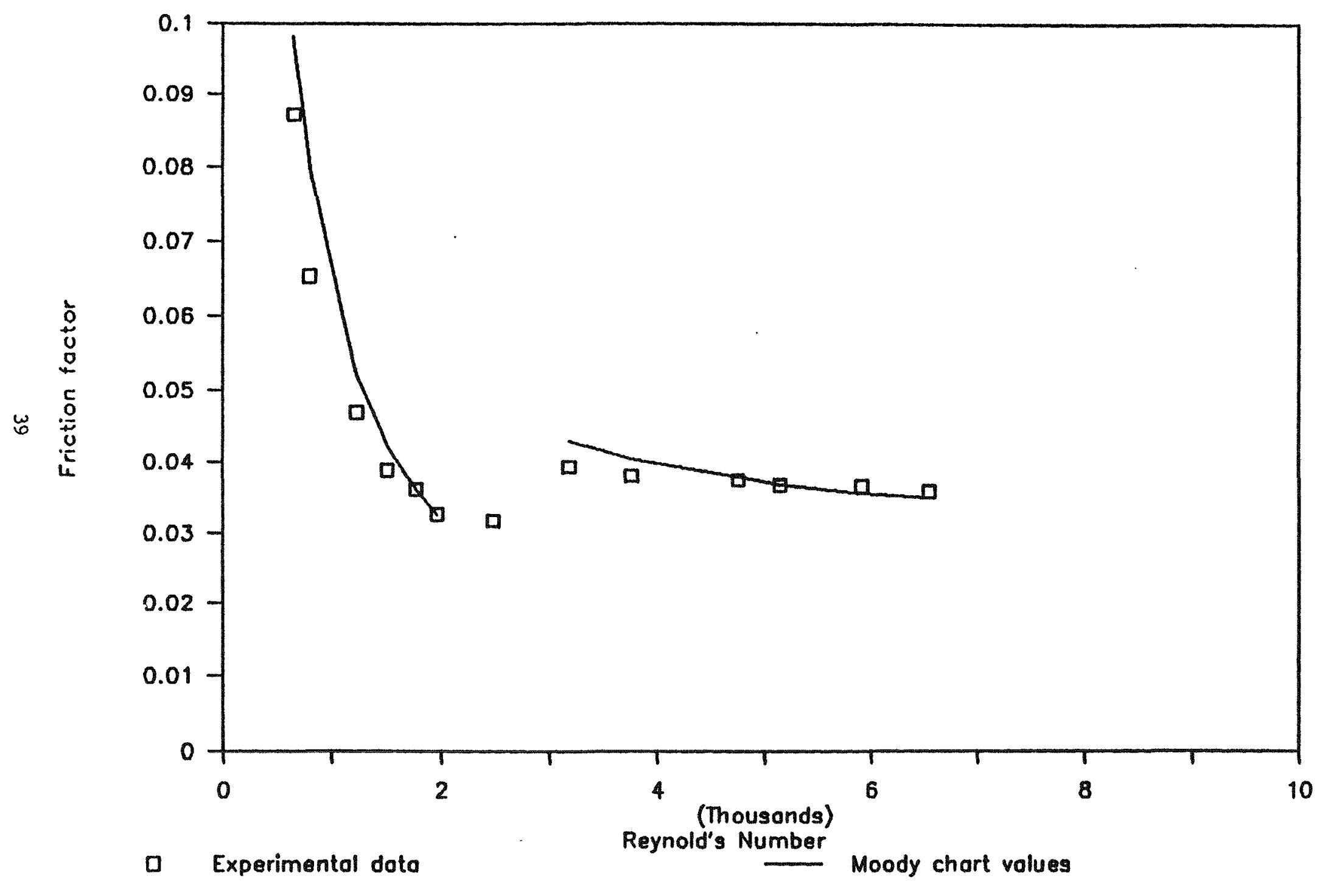

Water only

(1 inch I.T. Manameter)

Figure 3.13: Calibration data of Mariam inclined tube manometer II 
glass. Windows were kept vertical so that the incident laser beams were nearly normal to it.

The flow was turned around through a smooth bend (approximately 2 and $1 / 2$ feet radius, Figure 3.11). At the middle of the bend a valve was provided to release the air bubbles trapped in the flow. To facilitate removal of these bubbles and also to extend the capability of the facility to make measurements in an inclined tube an electric jack was attached to the supporting structure. The jack can lift the bent end of the flow system to make the test section inclined up to about $10^{\circ}$ with the horizontal. A pair of flexible couplings - one about 2 feet downstream of pump outlet and the other at the opposite side on the return flow path - were provided for this purpose.

Downstream of this bend a chromel-alumel thermocouple was installed to monitor the slurry temperature. A non-intrusive magnetic flowmeter, Foxboro model (80011 WRC - A6) was located downstream of the thermocouple.

A mixing tank was placed downstream of the flowmeter. The tank was provided with a power stirrer for mixing the solid and liquid and a heater for fine temperature control. A storage tank was placed between the mixing tank and the flow control valve. This tank would be useful during evacuation of the loop. Photographs of the test facility are provided in Figures 3.14 and 3.15. The test parameters are summarized in Table IV.

\subsection{LDV Instrumentation Set-up:}

Laser Doppler Velocimeter was used for measuring solid and liquid velocities at different locations inside the pipe. A dual beam LDV was used. Basic principle of operation of a dual beam LDV is as follows:

Intersection of two laser beams of the same polarization form a probe volume.(Figures $3.16,3.17$ ) A particle passing through the probe volume scatters light rays. These rays are Doppler shifted. There are different rays of two unequal shifts. Two 


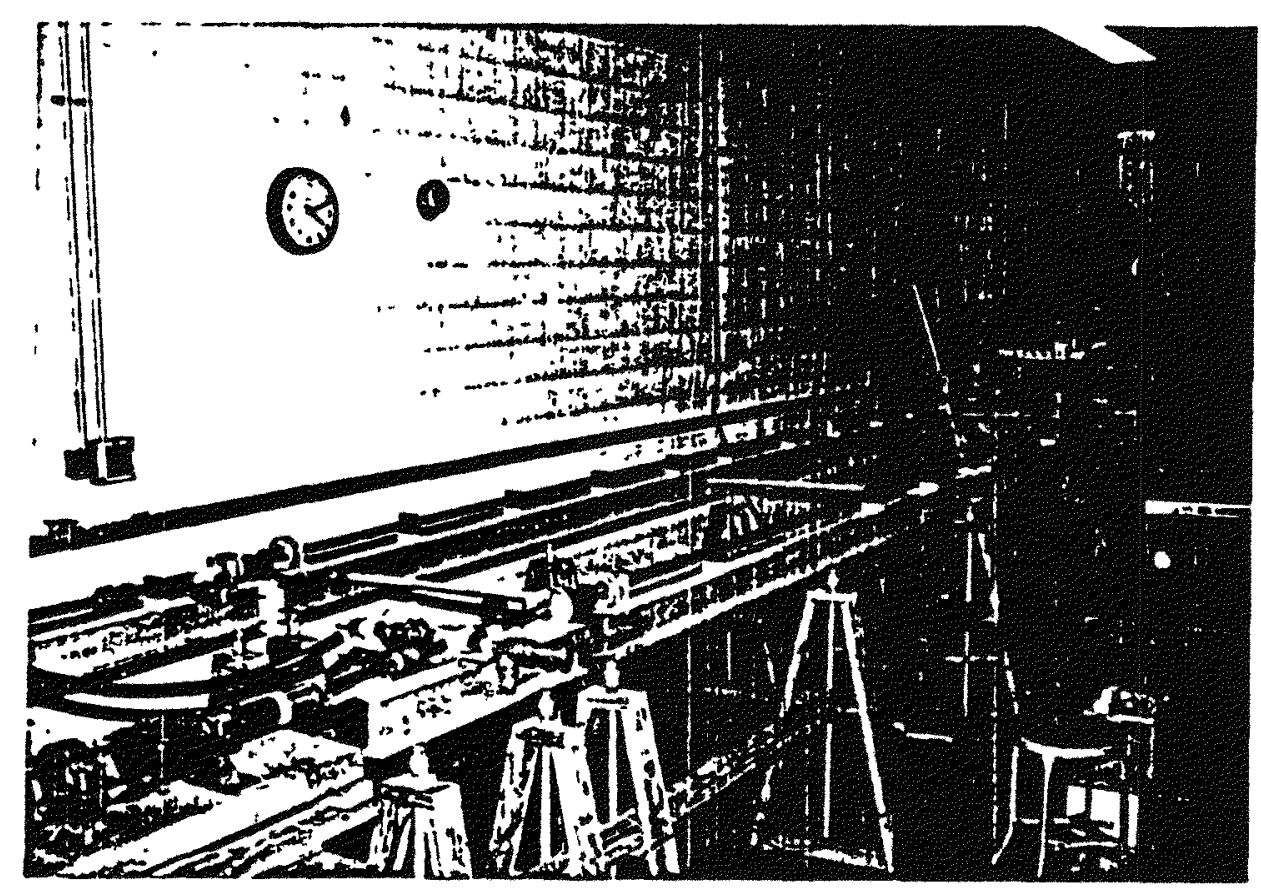

Figure 3.14: A view of the Matched Index of Refraction Flow System.

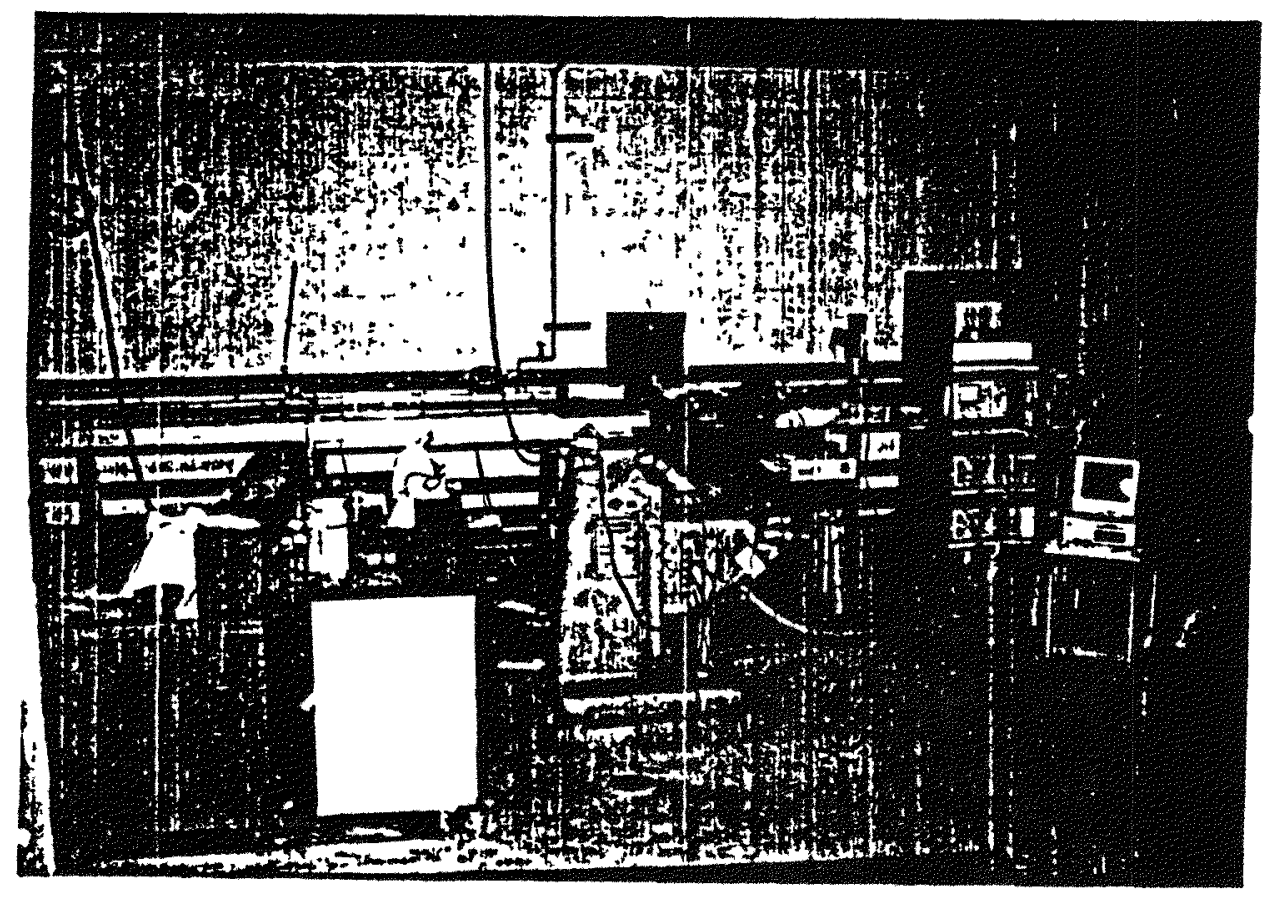

Figure 3.15: Laser Velocimeter anä Allied Instruments for the Matched Index of Refraction Flow System. 


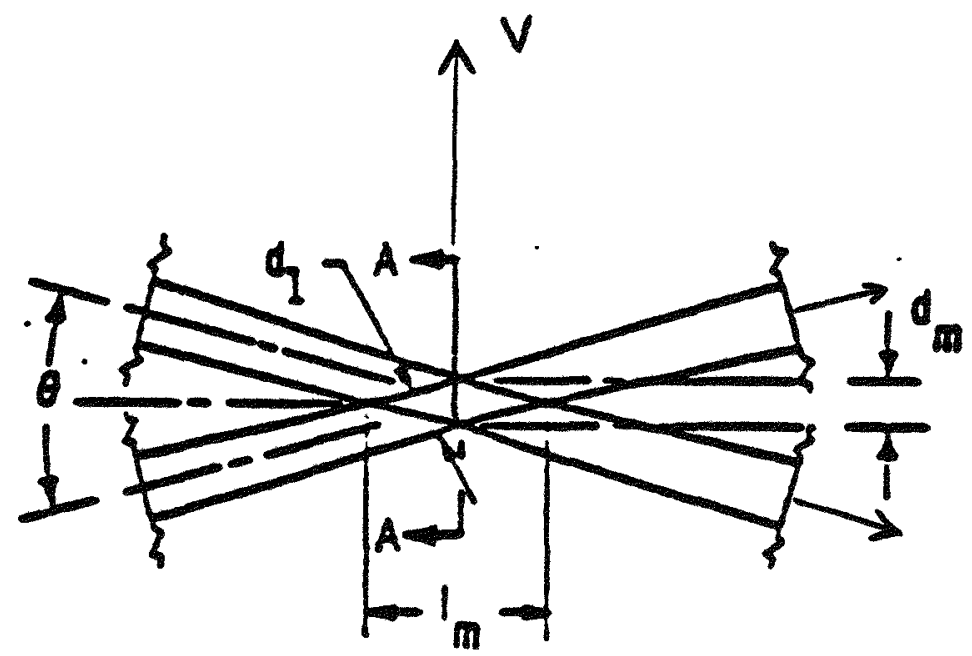

Figure 3:16: ' Iaser beams and the probe volume.

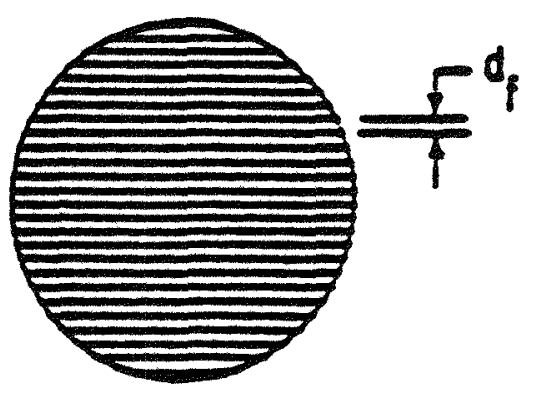

Figure 3.17: Interference fringes at the probe volume, section A-A. 
such unequally shifted rays interfere on a photomultiplier tube (PMT) to produce a signal of frequency $f_{d}$. This is related to the velocity of the particle as follows:

$$
v=\frac{\lambda f_{d}}{2 \sin (\theta / 2)}
$$

where $\mathrm{v}=$ component of velocity perpendicular to the bisector of the angle between the incident laser beams in the plane of the laser beams.

$\lambda=$ wave length of the incident laser beams.

$f_{d}=$ Doppler, frequency.

$\theta=$ angle between incident laser beams.

The LDV used in this study utilized a Coherent Innova 70 argon ion laser, TSI model $9100-7$ optical system including receiving optics assembly, photomultiplier tubes, and a Bragg cell in the green beam. It was a 2 color, 4 beam, back scatter mode LDV. For signal analysis both TSI counter processors model \# 1990 and a tracker designed and built in the Case Center for Complex Flow Measurements, C3FM (Edwards, Lading, Coffield), at Case Western Reserve University, were used. Software and hardware developed at C3FM (Edwards, Desai) was used for analyzing the data obtained from the counter processors. An HP 1725A oscilloscope was used for monitoring signals. The entire LDV arrangement was placed on a three dimensional traversing mechanism. The precision of positioning was 0.001 inch.

Intensity variations of the laser beams across the cross-section were measured using a photodiode. The photodiode was mounted on a micrometer controlled movable stand. Resolution of the micrometer was 10 microns. The photodiode was covered with a mask with a narrow slit. The slit allows only a slice of the beam to reach the photodiode surface, facilitating the measurement of intensity variation along the diameter perpendicular to the orientation of the narrow slit. Intensity variations in the blue beams were measured. 
The green beams were assumed to have same characteristics. However the Bragg cell shifted beam was slightly distorted.

TABLE 5: Parameters of optical system \& probe volume

a)

Focal Length of the focussing lens

Angle between each pair of incident beams,

$480 \mathrm{~mm}$

Wave length of blue beam

$9.82^{\circ}$

Wave length of green beam

$488 \mathrm{~nm}$

$514.5 \mathrm{~nm}$

b)

Laser beam waist before expansion (microns)

Probe volume diameter in the direction of velocity(microns)

On axis (laser axis) probe volume length (microns)

Fringe spacing (microns) $\frac{\text { Blue }}{446} \quad \frac{\text { Green }}{446}$

44.58

47.0

520

549

2.85

3.006

\subsection{Signal Processing}

Signals generated in a dual beam LDV are principally of two types. If there is only one particle in the measuring volume then the signal consists of a pedestal component and a sinusoidal component imposed on it (Figure 3.18). This is the so called 'Doppler burst'. When there are more than one particles in the probe volume simultaneously, which occurs when the number density of particles is quite high, there is an almost continuous sinusoidal signal, of varying amplitude, with occasional changes in phase of the signal. In this study both tracker and counter processors were used.

In a counter processor the time periods of the signals are measured. This is done using an electronic clock by measuring the time intervals between preassigned number of 
zero-crossings of the signal. Pedestal (Figure 3.18) is removed by passing the signal through a high pass filter and the high frequency noise is removed by using a low pass filter. Then the signal is amplified as required. The electronic clock is not activated unless the amplitude of the signal is above the threshold level which was set by user. There are other criteria the signal has to satisfy before being accepted for processing. It has to have a minimum number of zero-crossings which can be set by the user. Depending on the mode of operation (continuous, single burst etc.) time periods computed from two parts of the signal are compared and accepted only if they match within a certain accuracy set by the user. Periods of accepted signals are measured and averaged over certain durations adjustable by the user.

In a tracker, first the signal is sent through a bandpass filter to eliminate noise. Then it is amplified and compared with an existing frequency. The difference is amplified and fed to a circuit whose output is strongly frequency dependent. Output of this circuit controls the frequency of a voltage controlled oscillator with which the incoming signal and some noise are compared at the first place. So when this feedback loop attains a certain frequency with or without some small fluctuations around it it is 'tracking' the signal frequency (Drain). In this investigations the counter processors were used. 


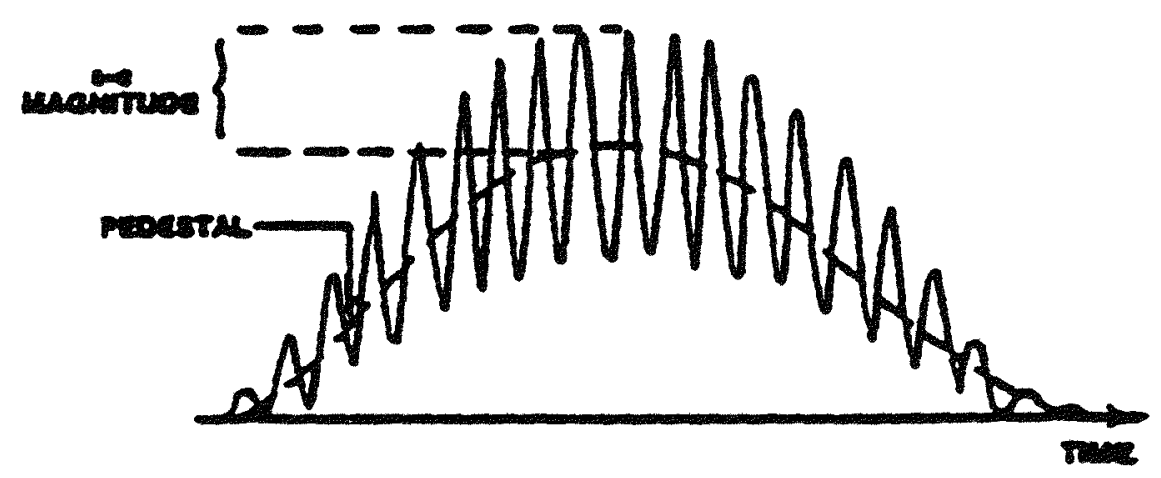

Figure 3.18: A Doppler Burst

46 


\section{TEST PROCEDURE}

In order to ensure the proper performance of the test loop and verify the flow was fully developed in the test section the first series of tests were conducted in single phase flow with water and $50 \%$ sodium iodide solution as the fluids. Analysis of this data (discussed in the next text section) confirmed that the flow was fully developed and the test loop performed satisfactorily. Then the second series of tests were conducted with sodium iodide-silica gel slurries with $5 \%$ and $15 \%$ solid concentration (by volume). These tests will be discussed in the next section.

The 50 percent sodium iodide solution was passed through a 5 micron size filter to ensure removal of particles larger than 5 microns prior to the addition of silica gel. The 5 microns or smaller size particles present in the solution provided adequate Doppler signals for following the liquid velocities. Prior to conducting the tests, viscosity of the $50 \%$ sodium iodide solution at different temperatures was obtained using a Brookfield viscosimeter. The values of viscosity and the slurry concentration calculation scheme are provided in Appendix B.

Prior to the start of a test run, any air bubbles trapped inside the pipe were purged through the air release valve. The test loop was run for at least one hour before taking any test data. This long waiting time ensured the steady state. Periodically the alignment of the LDV optics was checked by observing the signals produced by a thin wire attached radially to a rotating disk.

The LDV measurement procedure was the same for each test series. The laser beams were focused on the inside wall of the glass tube. After ascertaining the focal point location, the focusing lens was moved in predetermined steps to move the measuring volume to the desired location inside the pipe. The correlations for the measuring volume 
location to account for the refraction effects are provided in Appendix C.

The LDV measurement location are shown in Figure 4.1. Data were not only taken along vertical and horizontal diameter but also along several different vertical and horizontal lines. Thus, the slurry flow field was mapped thoroughly. The output of the photomultiplier tubes were observed on an oscilloscope for the Doppler signal by changing the range of filter settings till a clear signal was observed. An estimate of the expected frequency, from the flowrate, was used for initial setting the filters. Once a clear Doppler signal was observed on the oscilloscope the frequency was estimated. Final filter settings were made accordingly. The signal was also fed to the tracker.

In order to discriminate between the velocity of solid and liquid each set of data were taken once without any amplitude limit and once with an amplitude limit. As discussed later in the next section, amplitude discrimination technique and histogram of the data at a measurement location were utilized to obtain the solid and liquid velocities. All the data were saved on a floppy and analyzed afterward. Uncertainty level in velocity measurement was $\pm 0.23 \%$.

Pressure drop measurements were made by using a Meriam inclined tube manometer with indicating liquid of 2.95 specific density. Pressure drop measurements for water and sodium iodide solution showed very good agreements with Moody's diagram (Figure 3.12, 3.13) The uncertainty level in the friction factor was $5.8 \%$.

Temperature was monitored by a chromel alumel thermocouple before and during each test run. Tests were conducted only at steady state temperature.

The Foxboro magnetic flowmeter was used for measuring the flow rate. The flowmeter was calibrated for water and sodium iodide solution using a stopwatch and a weigh tank. The flow rates were also calculated by integrating the velocity along the tube cross section. The differences between the calculations and the flowmeter readings were 


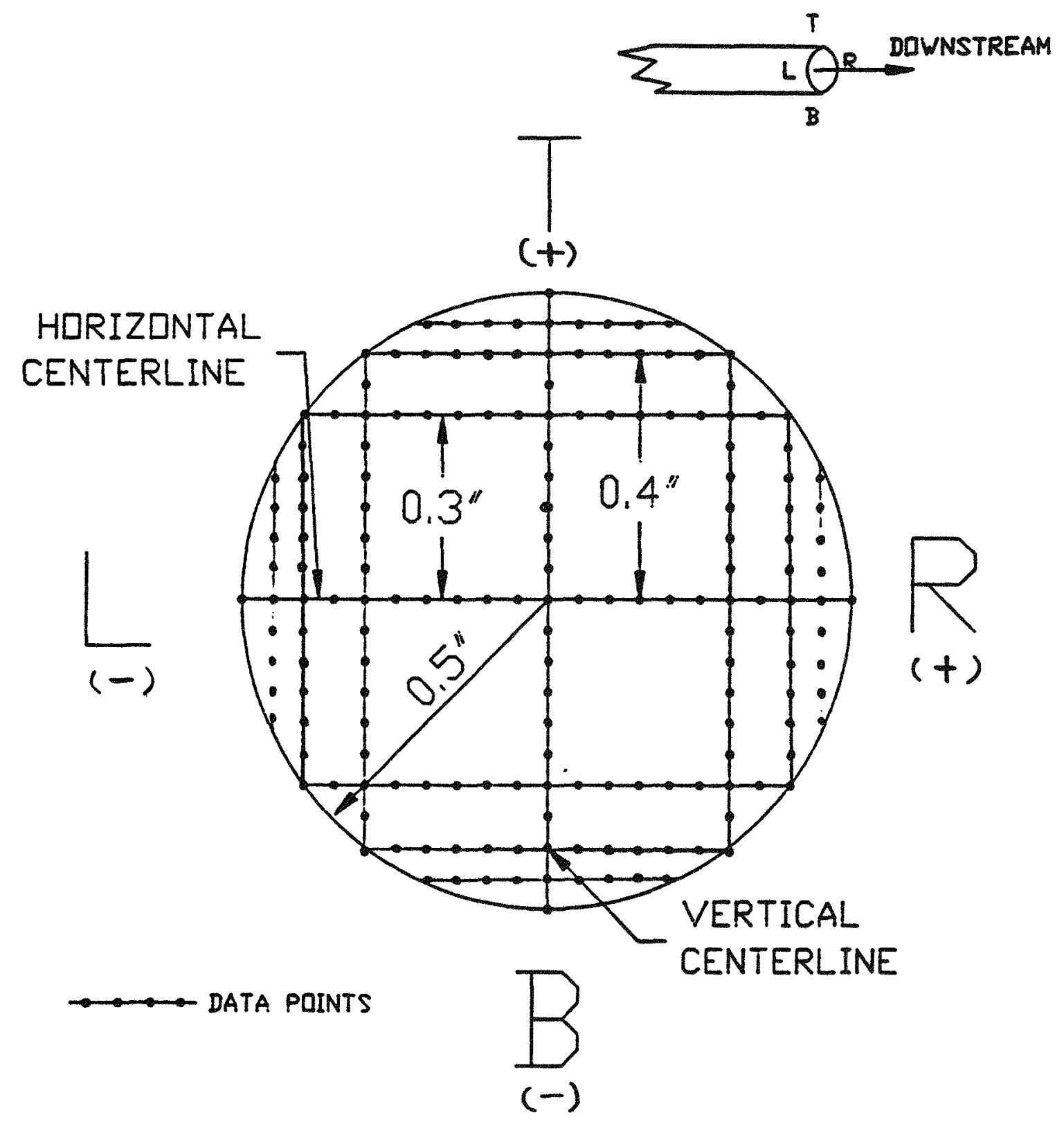

Figure 4.1: Schematic diagram of IDA measurement location. 
less than $\pm 0.5 \%$.

Average concentration was obtained based on the weight of silica gel and the volume of sodium iodide solution. We also tried to measure the concentration using an Auburn conductivity-meter. But it could not be used for the sodium iodide solution because the hardware of the instrument was designed for water, a comparatively low conductivity fluid and it could not handle the significantly more conductive sodium iodide solution. So the concentration-meter could not be used for on-line measurement of concentration of silica gel-sodium iodide solution slurry. 


\section{RESULTS AND DISCUSSIONS}

Tests were conducted in (a) Single phase flow of water and $50 \%$ sodium iodide solution in water and (b) Solid liquid slurries with $5 \%$ and $15 \%$ solid concentration by volume. Silica gel (average diameter 40 microns) and $50 \%$ sodium iodide solution were the solid and liquid respectively. Result of these tests are presented and discussed in this section.

\subsection{Single Phase Flow}

Tests in single phase fluid, i.e. in water and in 50 sodium iodide solution were conducted to ensure proper performance of the test loop and that the flow was fully developed in the test section. The axial velocity measurements were made in a plane at an axial location 240 diameters downstream of the pump exit. The number of velocity measurements made at each point were 1000.

No special seeding particles were added. Basically the LDV signals were obtained from the small particles ( $\leq 5 \mu \mathrm{m}$ ) which were naturally in the liquid and are presumed to follow the flow. Velocity profiles for water flow are presented in Figures 5.1, 5.2 and 5.3 for Reynolds numbers of 2530.8200 and 9870 respectively. The measurements were restricted to the half horizontal diametral plane. This was due to the difference in the refractive index of water (1.33) and glass tube (1.474). Without the refractive index matching the effect of curvature of the glass tube reduced the amount of scattered light available to the photomultiplier tubes, restricting the measurements beyond the center of the tube. The velocity profiles were integrated to obtain the flow rate and this flowrate was compared with the data measured by the flowmeter. The difference were always within $\pm 0.5 \%$. The Figures show the axial velocity profiles measured along the horizontal diameter. The square box represents experimental data and the solid line is the turbulent 


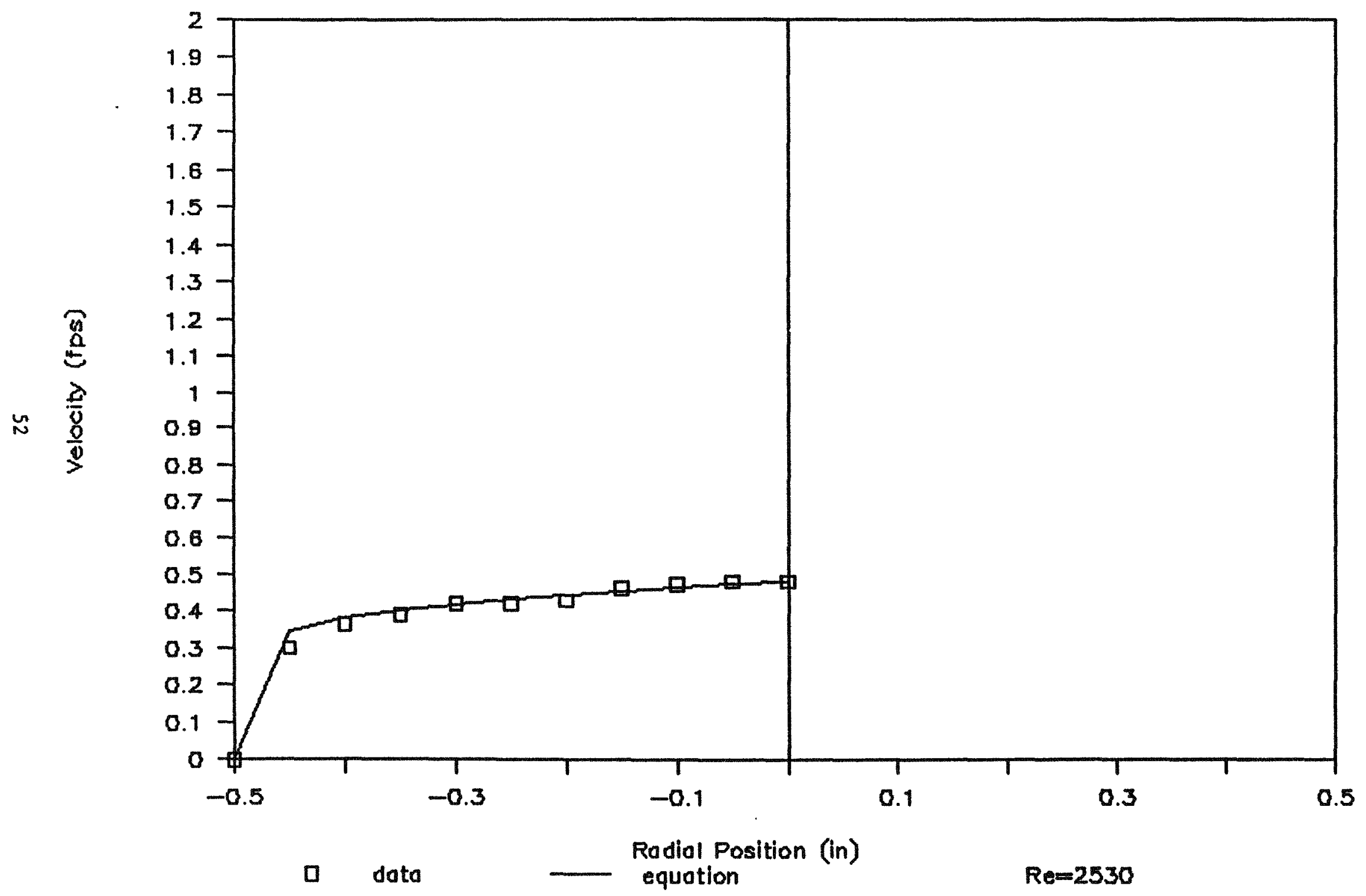

Figure 5.1: Axial velocity profile along the horizontal diameter for water flow at a Reynolds Mumber of 2350. 


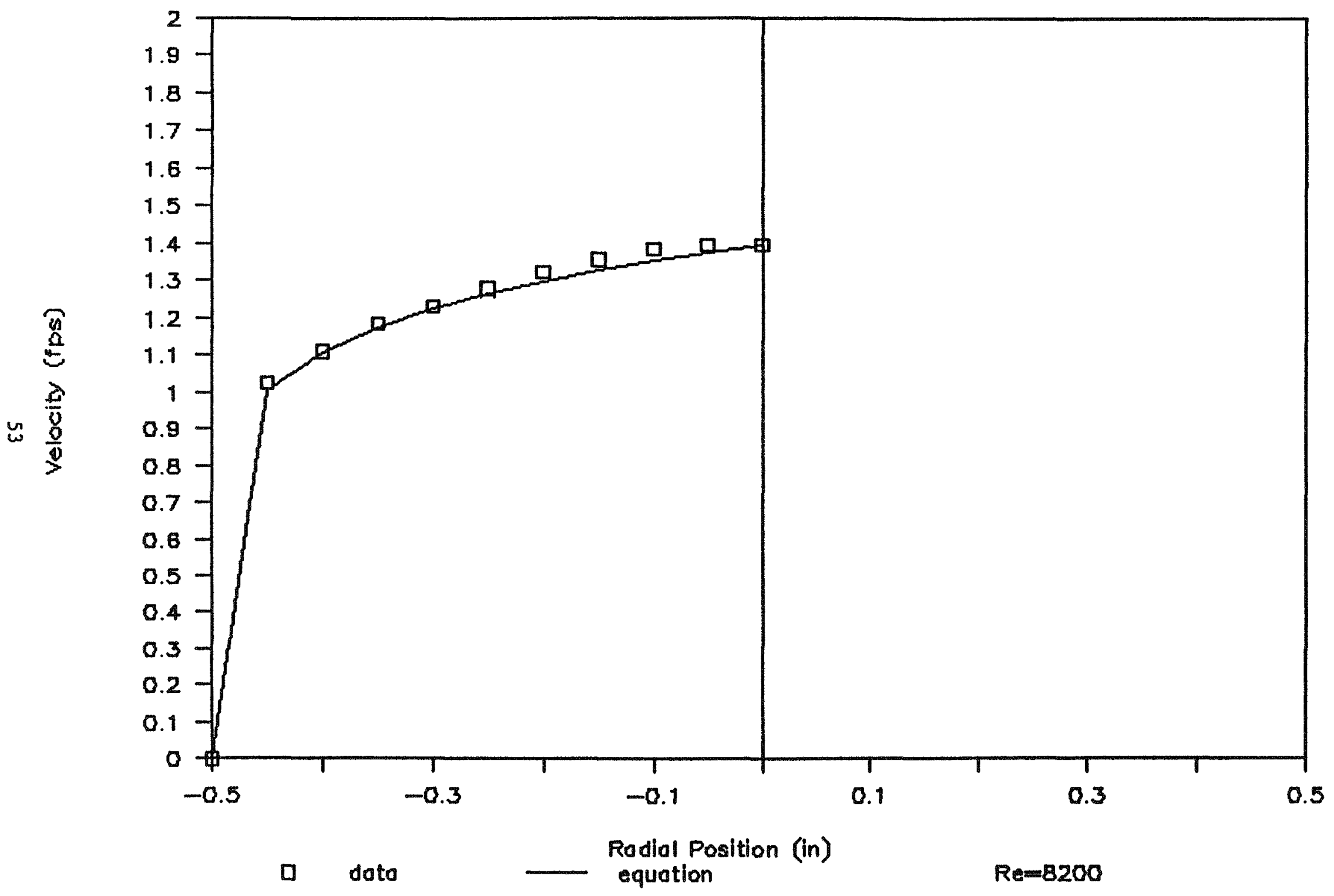

Figure 5.2: Axial velocity profile along the horizontal diameter for water flow at a Reymolds number of 8200 . 


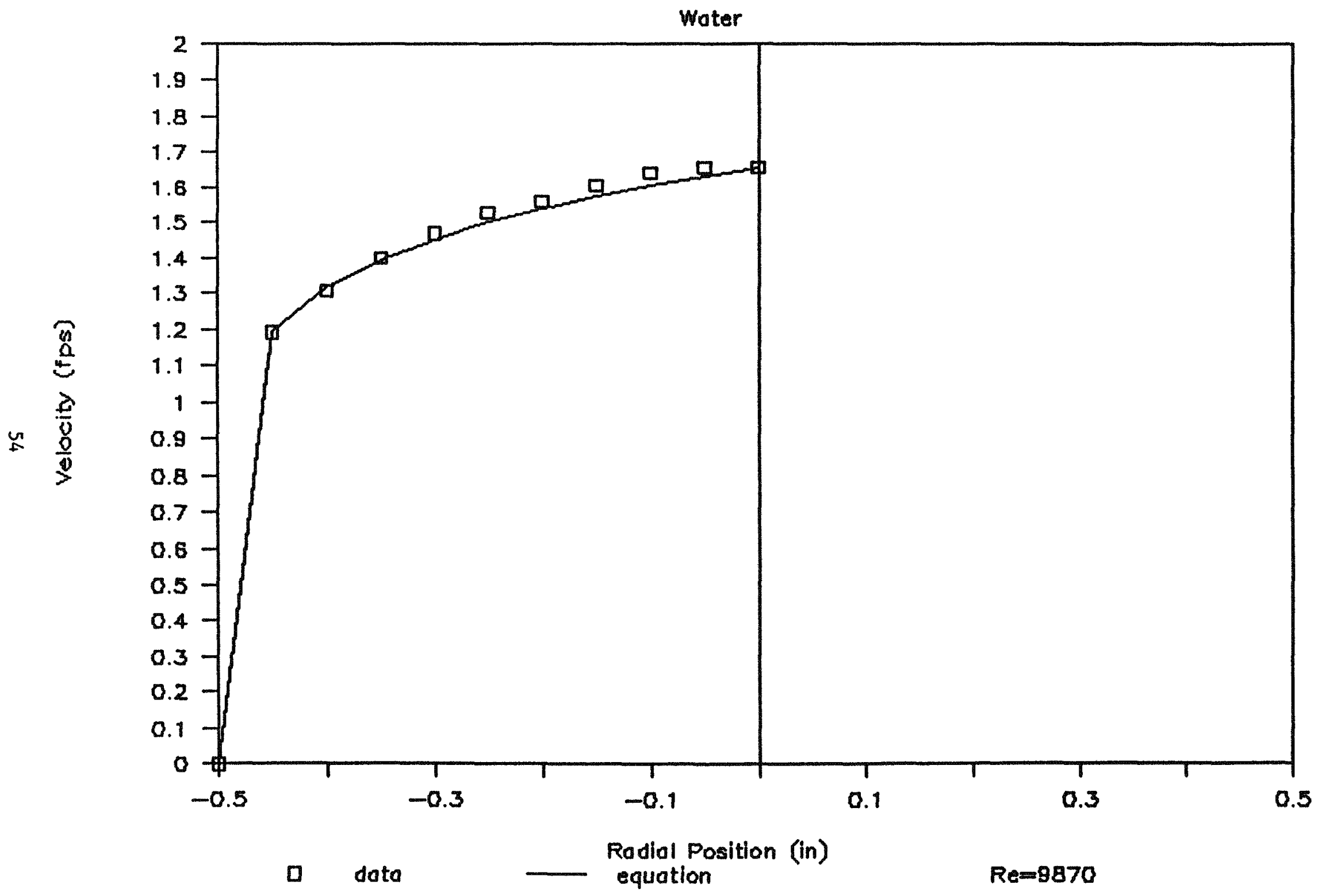

Figure 5.3: Axial velocity profile along the horizontal diameter for water flow at Reynolds number $=9870$. 
seventh power profile. Good agreement was obtained as shown in the Figures.

Results of test conducted in $50 \% \mathrm{NaI} / \mathrm{H}_{2} \mathrm{O}$ solution are shown in Figures 5.4 through 5.7 for different Reynolds numbers. Since the refractive index of $50 \% \mathrm{NaI} / \mathrm{H}_{2} \mathrm{O}$ solution (1.446) is close enough to that of glass (1.474), velocity measurement could be made at any location inside the pipe. In these figures we show the velocity profiles along the horizontal and the vertical diameter for different Reynolds numbers. We define the center point as the origin, and the side closer to the LDV as negative and the side away from the LDV as positive (sides $L$ and $R$ in Figure 4.1). Along the vertical diameter, height above the center is considered positive and below the center as negative, corresponding to $\mathrm{T}$ and $\mathrm{B}$ in Figure 4.1.

Tests were conducted in the Reynolds number range of 1000 to 7000 . Figure 5.4 shows very good agreement between the measured axial velocity profiles along the horizontal and vertical diameters for a Reynolds number of 1061 in the laminar flow regime. The solid line indicates the parabolic profile for laminar flow. Figure 5.7 shows equally good agreement between the axial velocity profiles along the horizontal and vertical diameters for turbulent flow at a Reynolds number of 6645 . The solid line indicates seventh power law profile. These figures are representative of the test data. The flow rates obtained by integrating the measured velocity profile were within \pm 0.5 percent of the flow rate indicated by the flow meter.

We can therefore conclude, that the single phase LDA data indicate a fully developed axisymmetric flow field in the test section and that the swirl introduced by the pump was dampened substantially upstream of the measurement location.

\subsection{Solid-liquid Slurrv Flow}

Test were conducted in solid-liquid slurry with 5 and 15 percent solid concentration by volume in the Reynolds number range of 400 to 9200 . The Reynolds number was based 


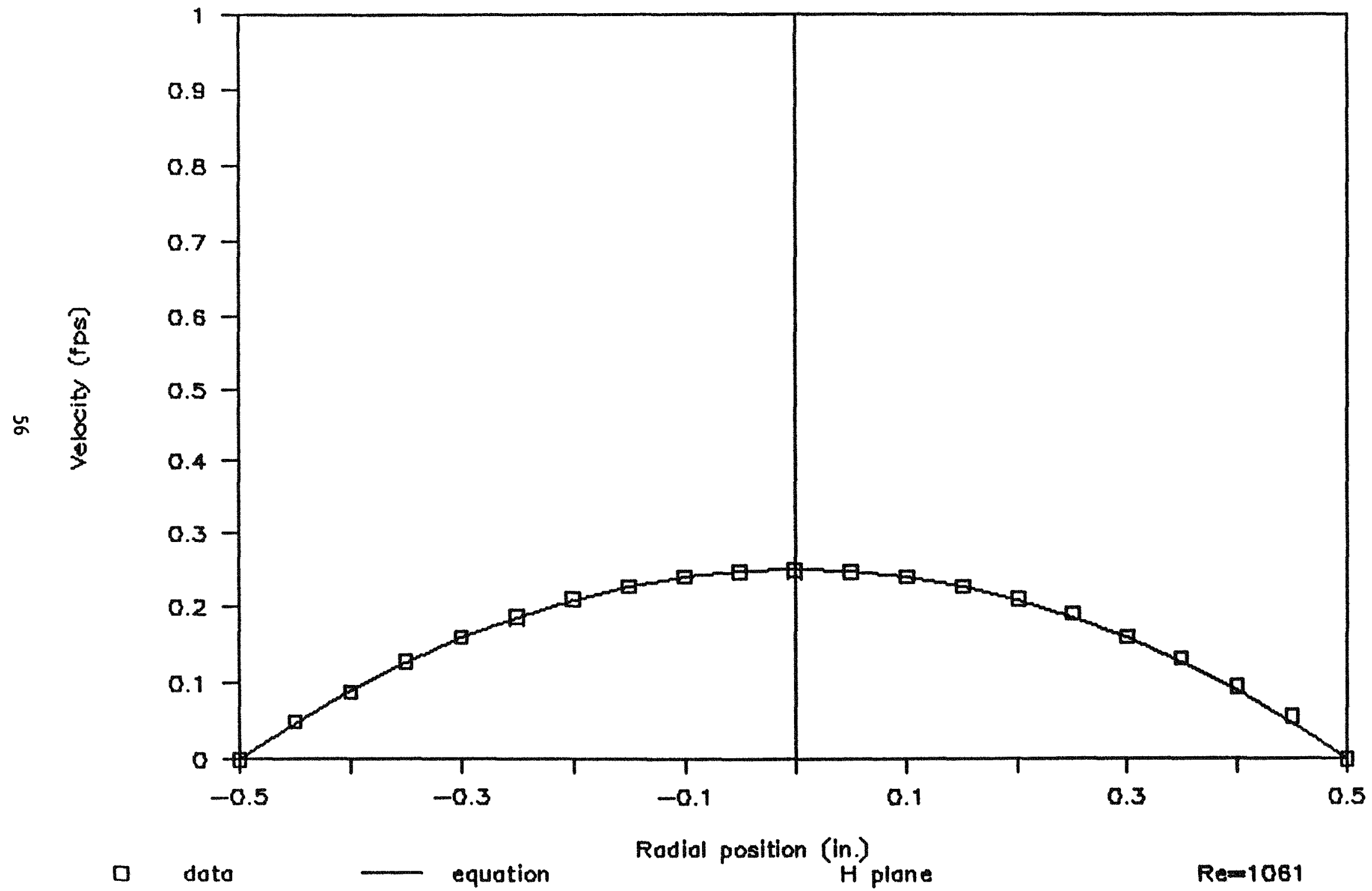

Figure 5.4: Axial velocity profile along the horizontal diameter for 508 sodium iodide solution flow at
Reymolds number $=1061$. 


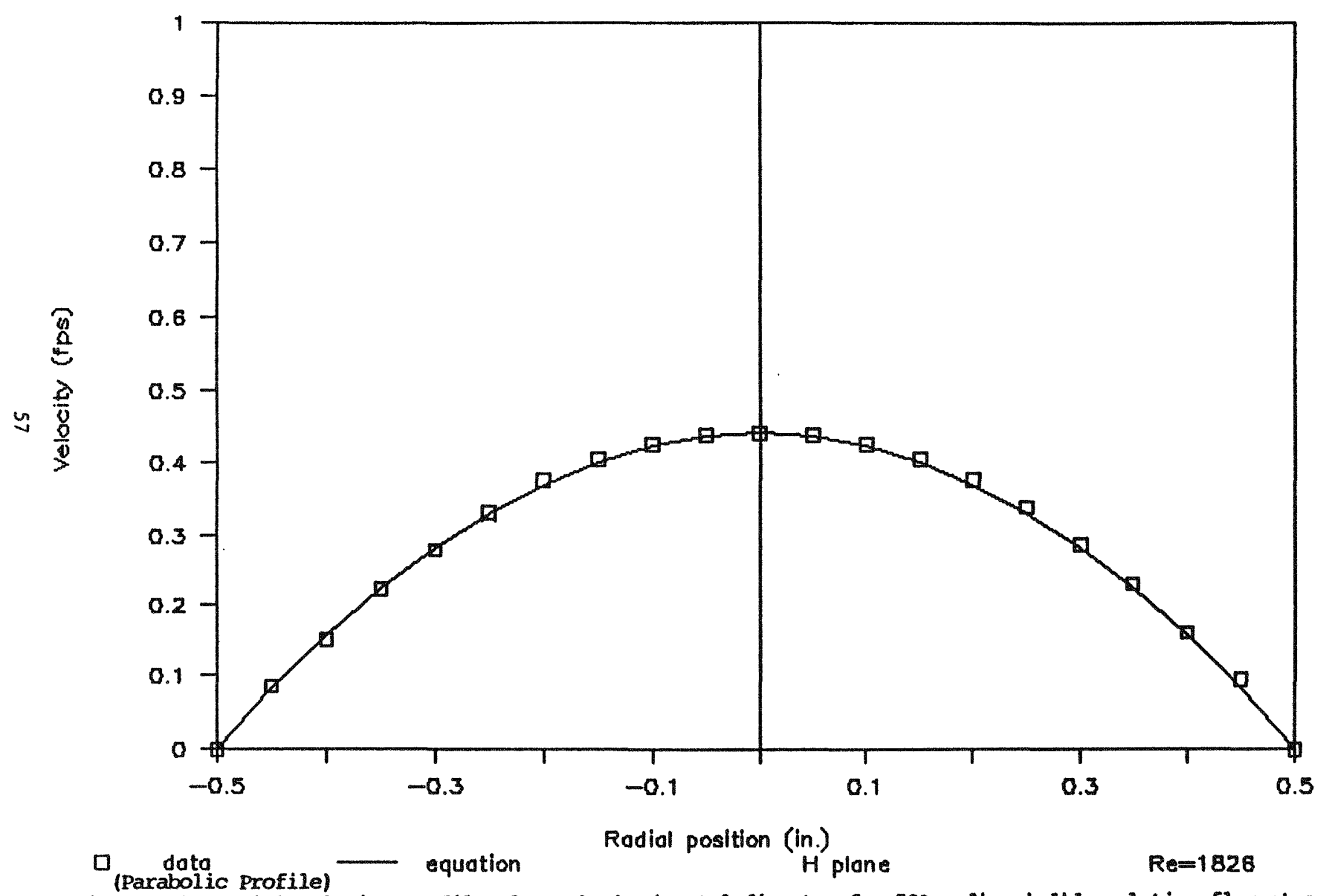

Figure 5.5: Axial velocity profile along the horizontal diameter for 508 sodium iodide solution flow at a Reynolds number $=1826$. 


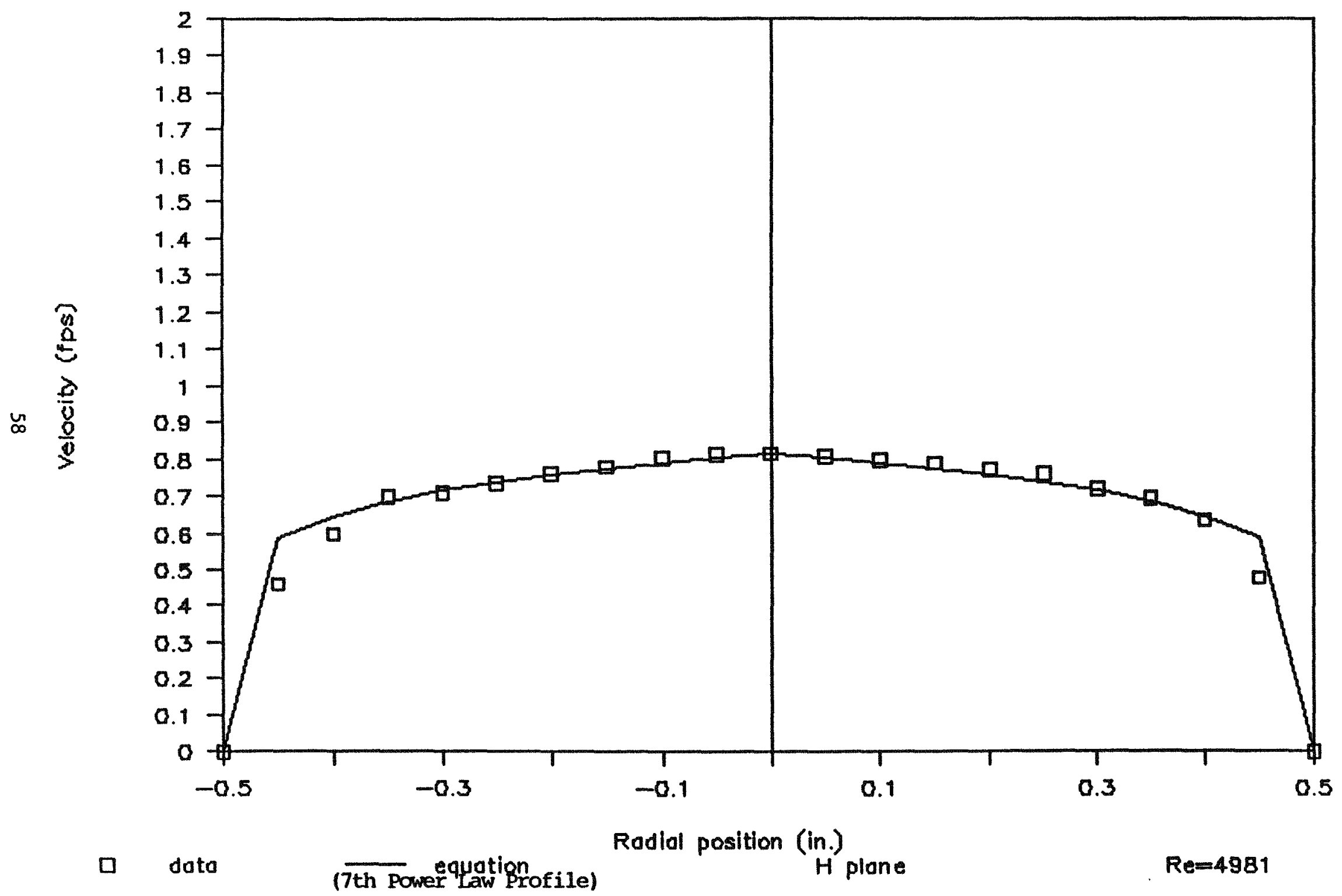
Figure 5.6: Axial velocity profile along the horizontal diameter for 508 sodium iodide solution at a
Reymolds number $=4981$. 


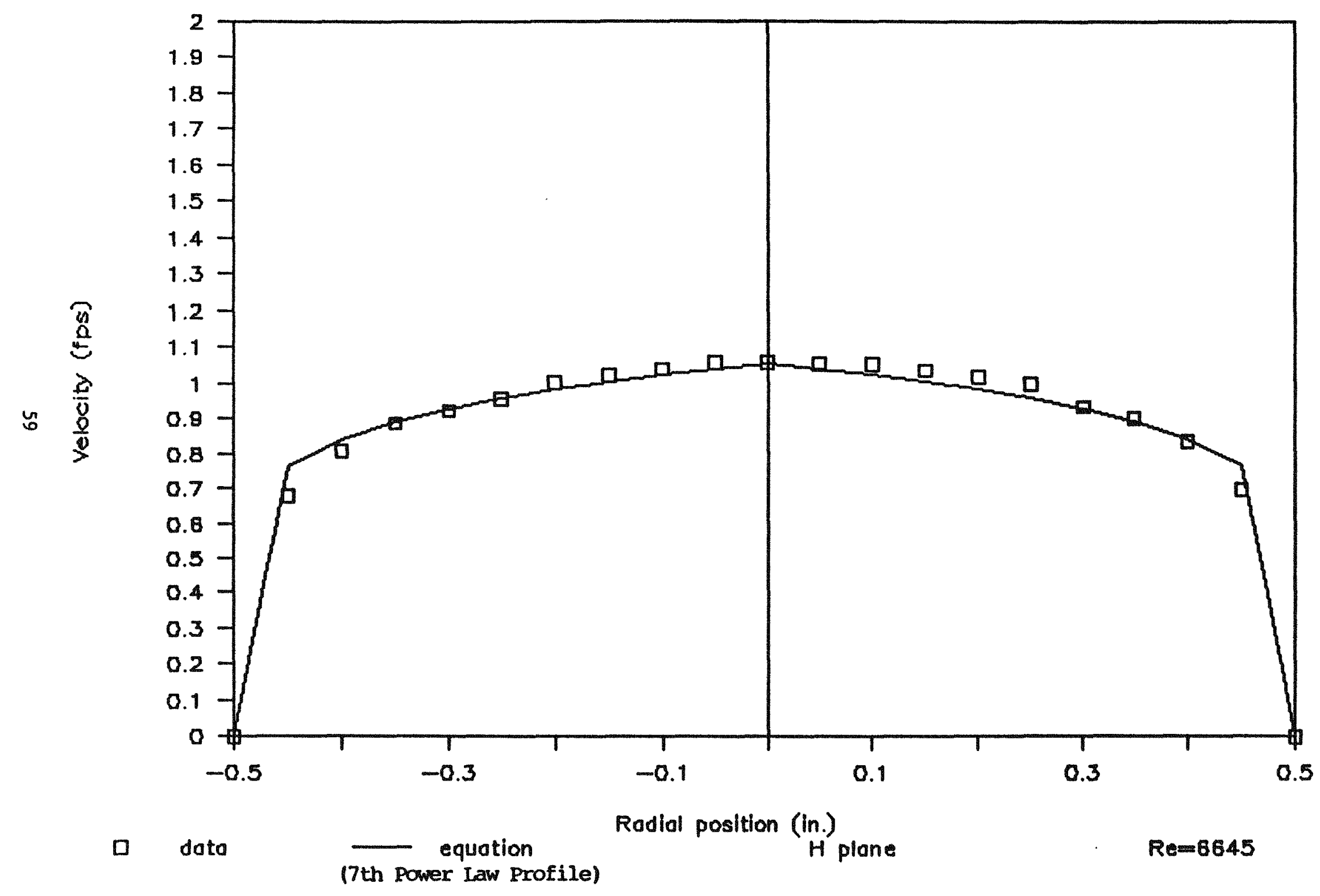

Figure 5.7: Axial velocity profile along the horizontal diameter for 508 sodium iodide solution at a Reynolds number $=6645$. 
upon liquid phase viscosity, pipe diameter and average velocity. Measurements were made at the location shown in Fig. 4.1. All the four flow regimes, i.e. stationary bed flow, saltation flow, heterogeneous flow and homogeneous flow were encountered in these tests.

\subsubsection{5\% Sodium Iodide Solution - Silica gel Slurrv}

Figures 5.8 through 5.12 show the velocity data obtained for the $5 \%$ slurry along the vertical and horizontal diameters in the Reynolds number range of 1745 to 8000 . The axial velocities along the horizontal and vertical diameters at Reynolds number of 1745 are shown in Figure 5.8. Obviously, the two profiles are not similar, however, the velocities at the center are the same. Also, while conducting the test, we could observe that the solid, i.e. silica gel had collected at the bottom of the pipe. The height of solid settled down on the bottom of pipe was observed not to change up to a Reynolds number of 2000 . However, the figure indicates that thickness of concentration along the vertical diameter was nearly 0.3 inch. A five percent volumetric solid concentration can only result in a thickness of 0.15 inch by considering "perfect" packing. However considering the effect of nonperfect packing due to irregular particle shape and the liquid entrained between the particles, it would be reasonable to expect a larger thickness. We observed that bringing homogeneous slurry flow to a sudden stop by turning off the pump resulted in the deposition of silica gel in a uniform layer nearly 0.17 inch thick at the bottom of the pipe, which is in agreement with the preceding discussion. It needs to be pointed out that the volumes of slurry in the reservoir and in the pipe were almost equal. The stirrer in the reservoir ensured that homogeneous slurry entered the pump, however, at lower Reynolds numbers $(\leq 2000)$ the fluid flow could not sustain the solids resulting in the deposition of the solids in the pipe downstream of the pump. Observations revealed that for Reynolds numbers less than 2000 , i.e. stationary bed flow regime, nearly all of the silica gel got collected at the bottom of the pipe along its entire length forming a layer approximately 


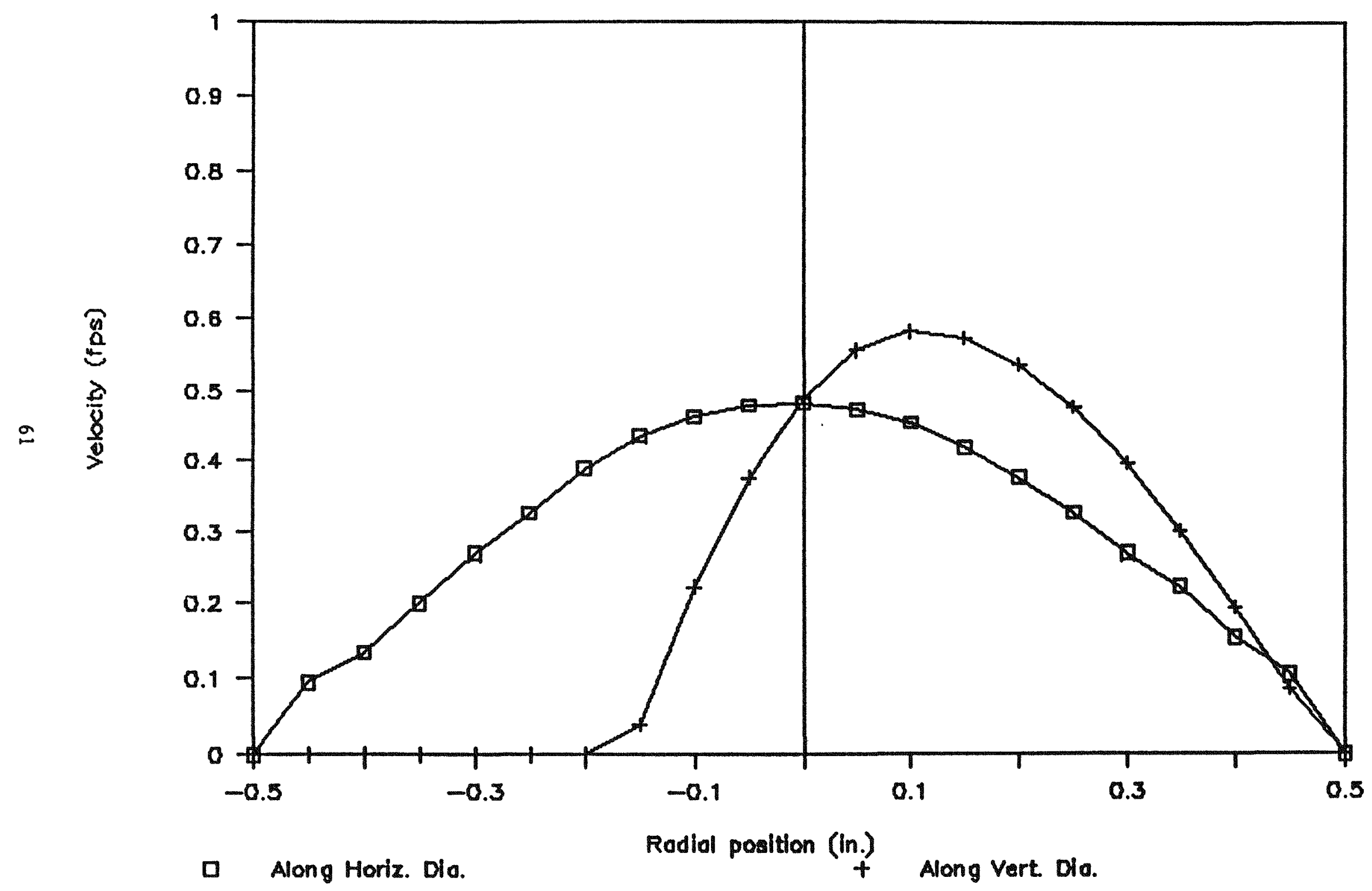

Figure 5.8: Axial velocity profiles along the horizontal and vertical diameters for 58 silica gel-sodium iodide solution slurry at a Reynolds number $=1745$. 


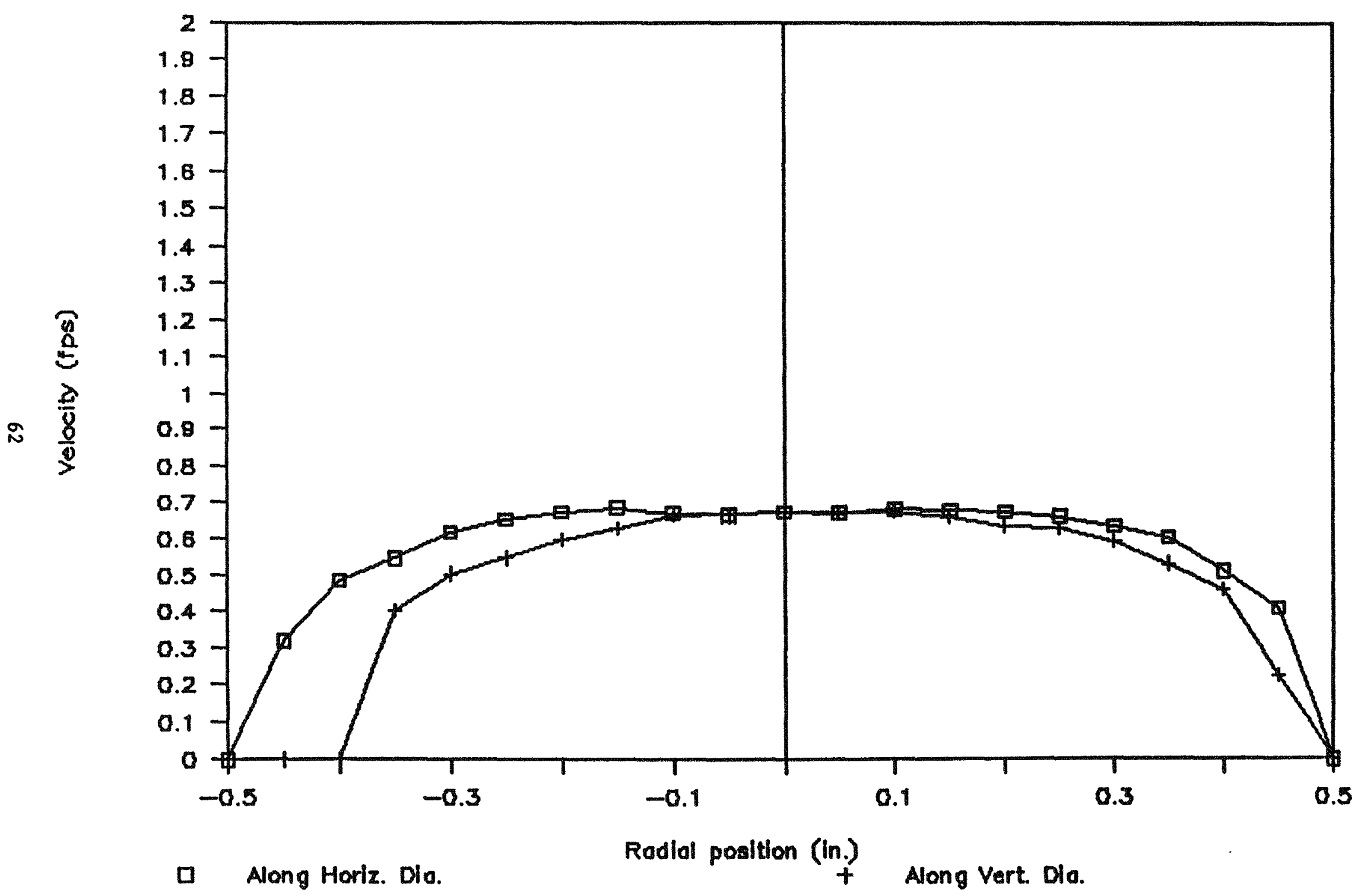

Figure 5.9: Axial velocity profiles along the horizontal and vertical älameters for 58 silica gelsodium iodide solution slurry at a Reymolds number $=4014$. 


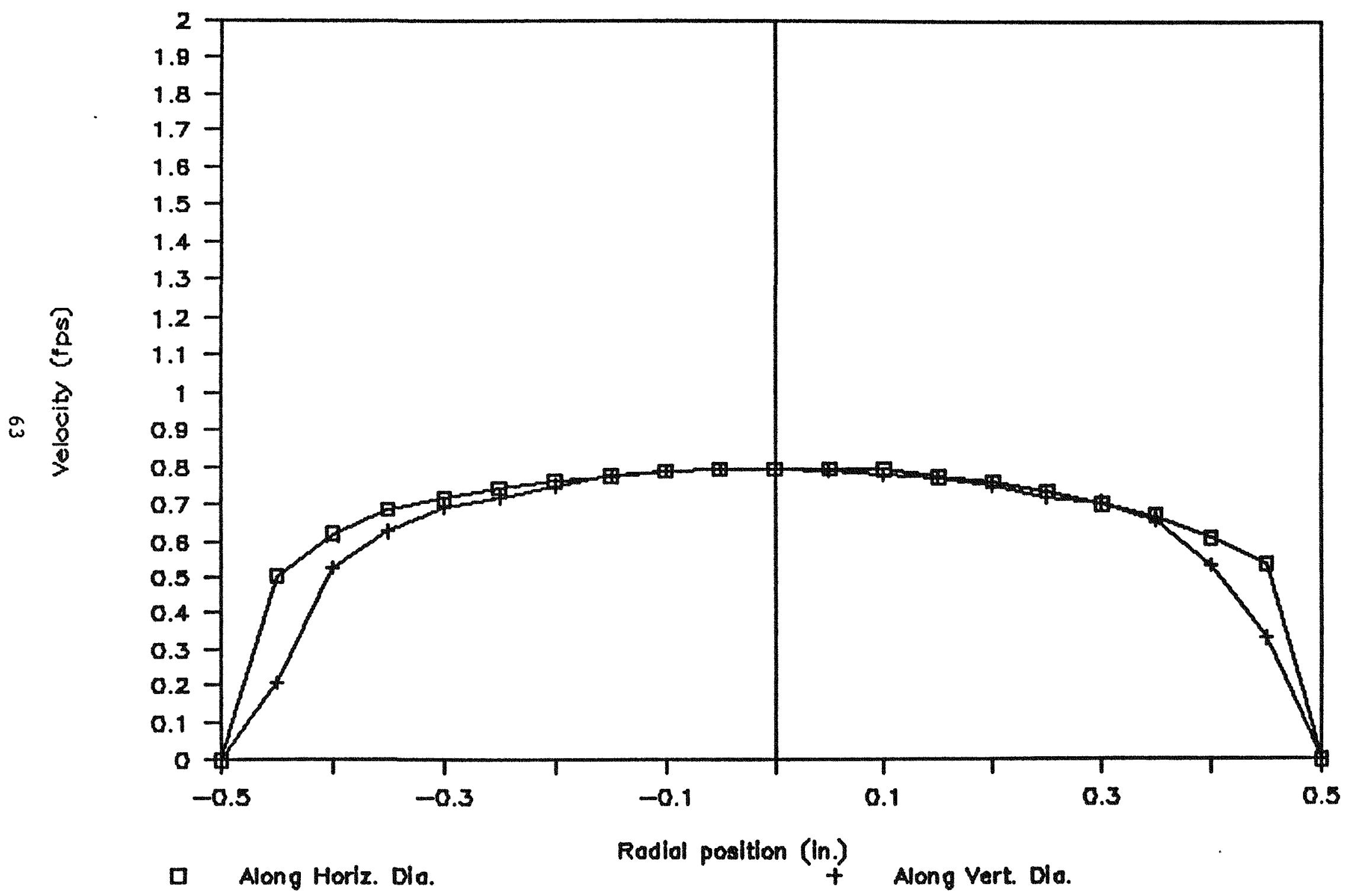

Figure 5.10: Axial velocity profiles along the horizontal and vertical diameters for 58 silica gelsodium iodide solution slurry at a Reynolds number $=4766$. 


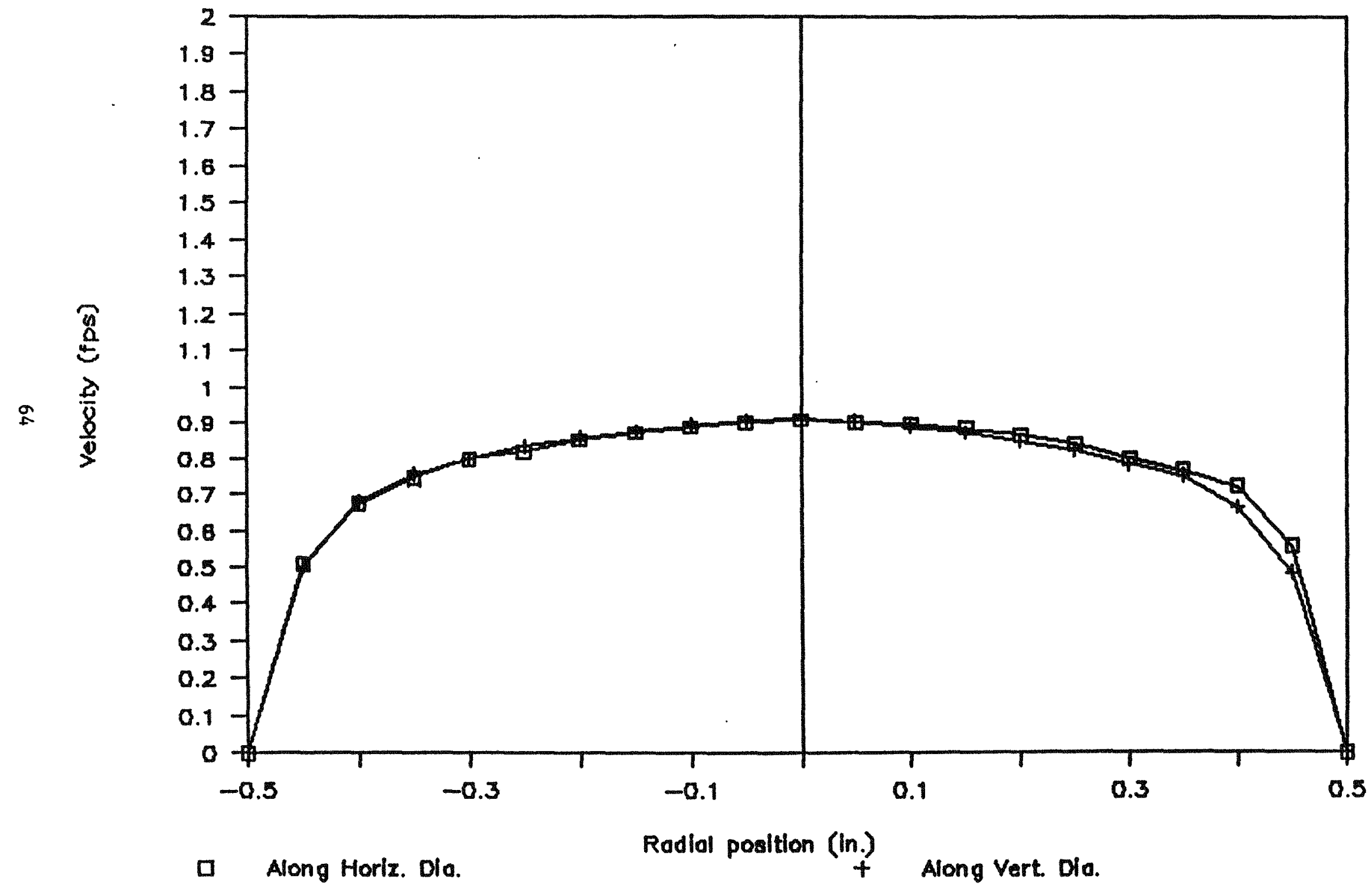

Figure 5.11: Axial velocity jrofiles along the horizontal and vertical diameters for 5\% silica gelsodium iodide solution slurry at a Reynolds number $=5544$ 


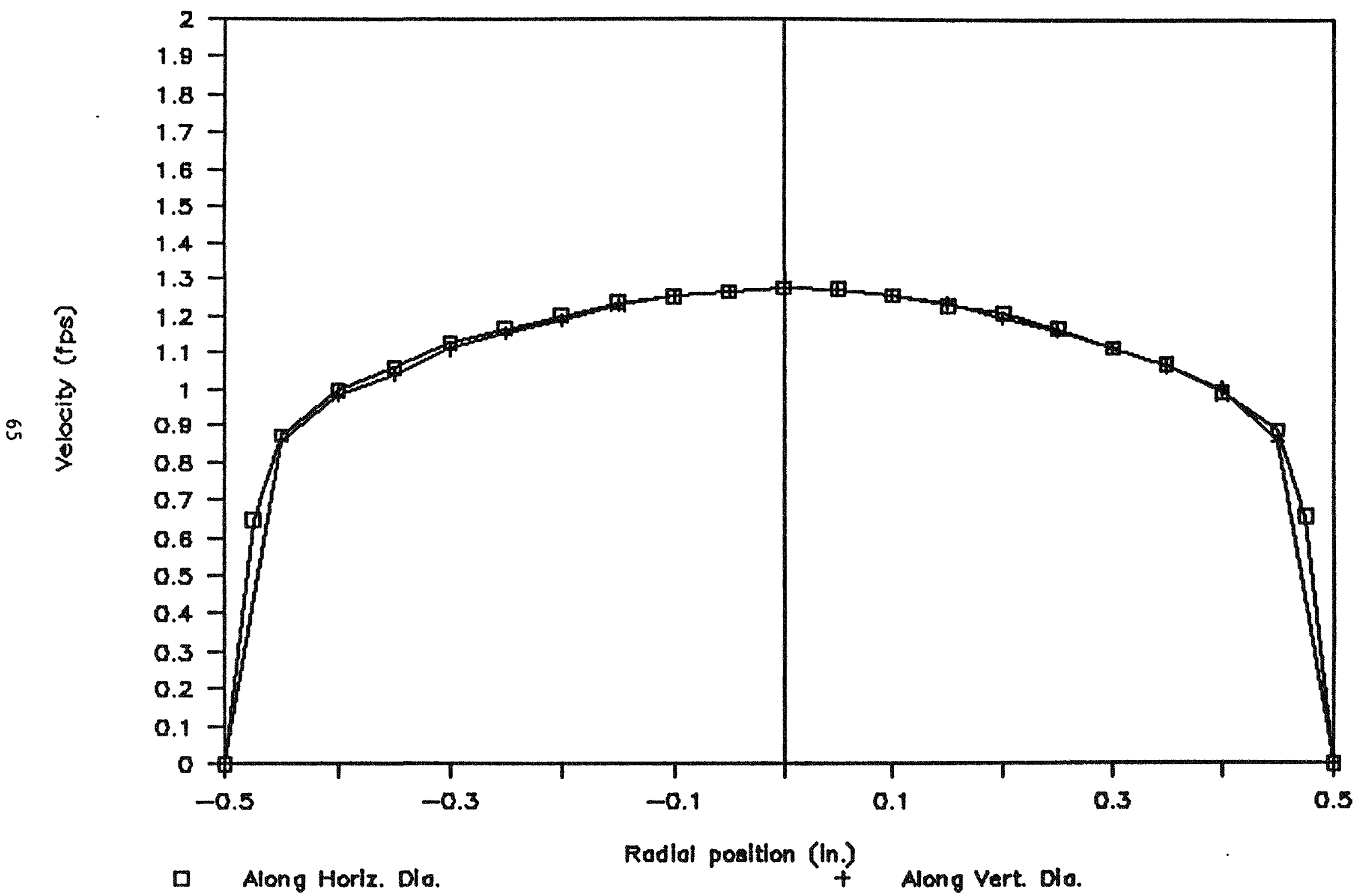

Figure 5.12: Axial velocity profiles along the horizontal and vertical diameters for 58 silica gelsodium iodide solution slurry at a Reynolds number $=8001$. 
0.3 inch thick. Further increase in flow velocities resulted in the flow regime changing to saltation flow in the Reynolds number range of 2000 to approximately 4000 . As can be observed from Figure 5.9, at Reynolds number of 4014, the difference between the axial velocity profiles along the horizontal and the vertical diameter becomes smaller than that at a Reynolds number of 1745 (Figure 5.8). Higher flow velocities resulted in the flow becoming beterogeneous, i.e. all the solid particles were now moving with the fluid however the solid-liquid mixture was not homogeneous, with a higher concentration and lower local velocity of the solids near the bottom of the pipe. The heterogeneous flow regime was observed in the Reynolds number range of 4000 to about 5500. Figure 5.10 is a typical example. In this figure, the axial velocity profile taken along the horizontal and the vertical diameters at a Reynolds number of 4766 , we can see that though the axial velocities near the center of pipe are similar, the difference in the velocities near the pipe wall is still observable. For Reynolds number greater than 5500 the flow regime was homogeneous. One can observe from Figures 5.11 and 5.12 that axial velocity profile along vertical and horizontal diameters become exactly similar at Reynolds numbers of 5544 and 8001. Figure 5.13 which shows the axial velocity profiles along the several vertical and horizontal lines (as indicated in Figure 4.1), also indicates that the flow is axisymmetric.

Figure 5.14 shows the axial velocity profile along the horizontal and the vertical diameters for the Reynolds number range of 1745 to 8000 , while Figure 5.15 shows the axial velocity profile along the vertical diameter. The change in flow regime from stationary bed flow to saltation flow to heterogeneous flow to finally homogeneous flow can be observed in these figures as the Reynolds number increases from 750 to 5500 . The flow was initially highly non-axisymmetric in the stationary bed flow regime with substantial difference in the velocity profile along the horizontal and the vertical diameters. These velocity differences reduce as the Reynolds number increases and finally for the homogeneous 


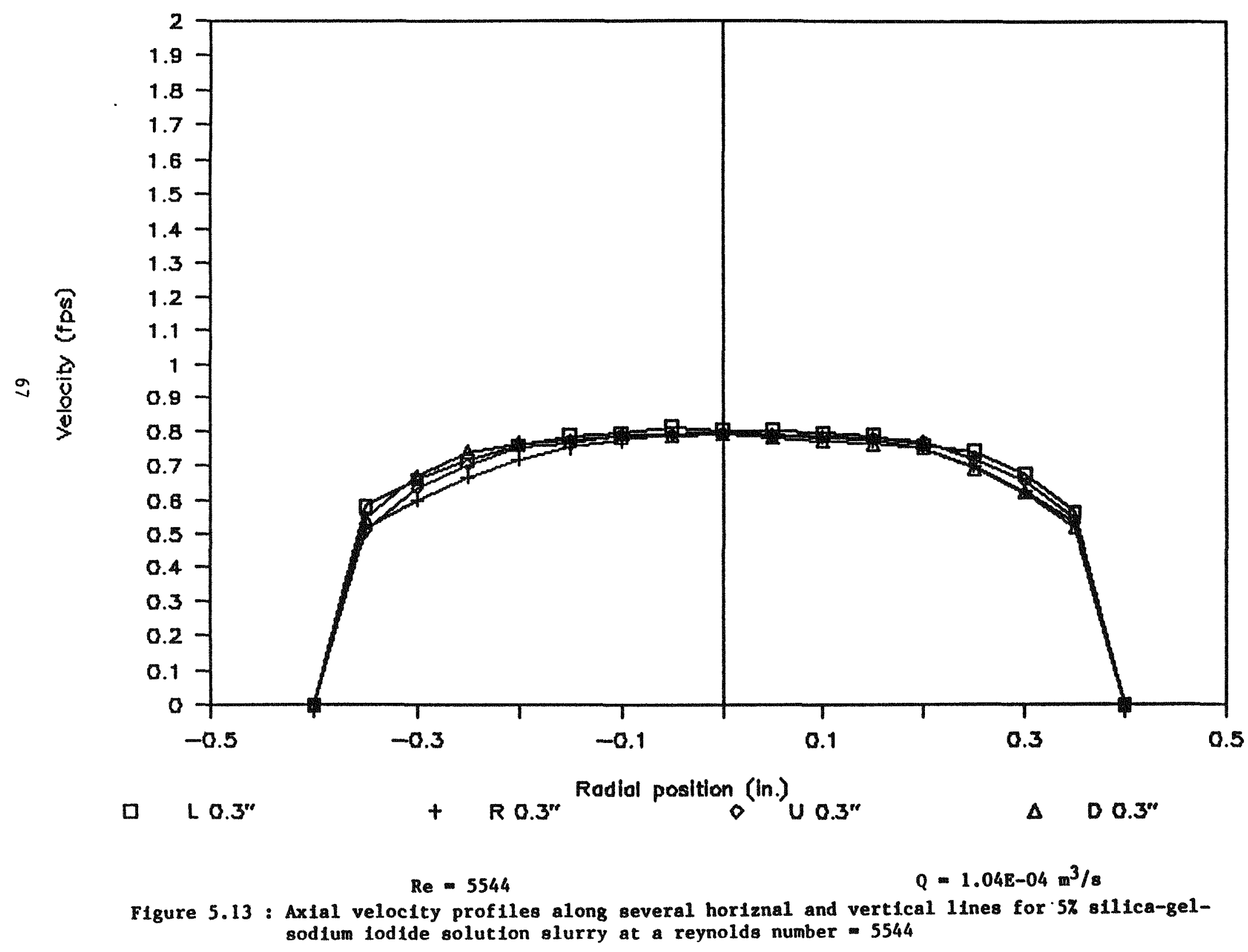




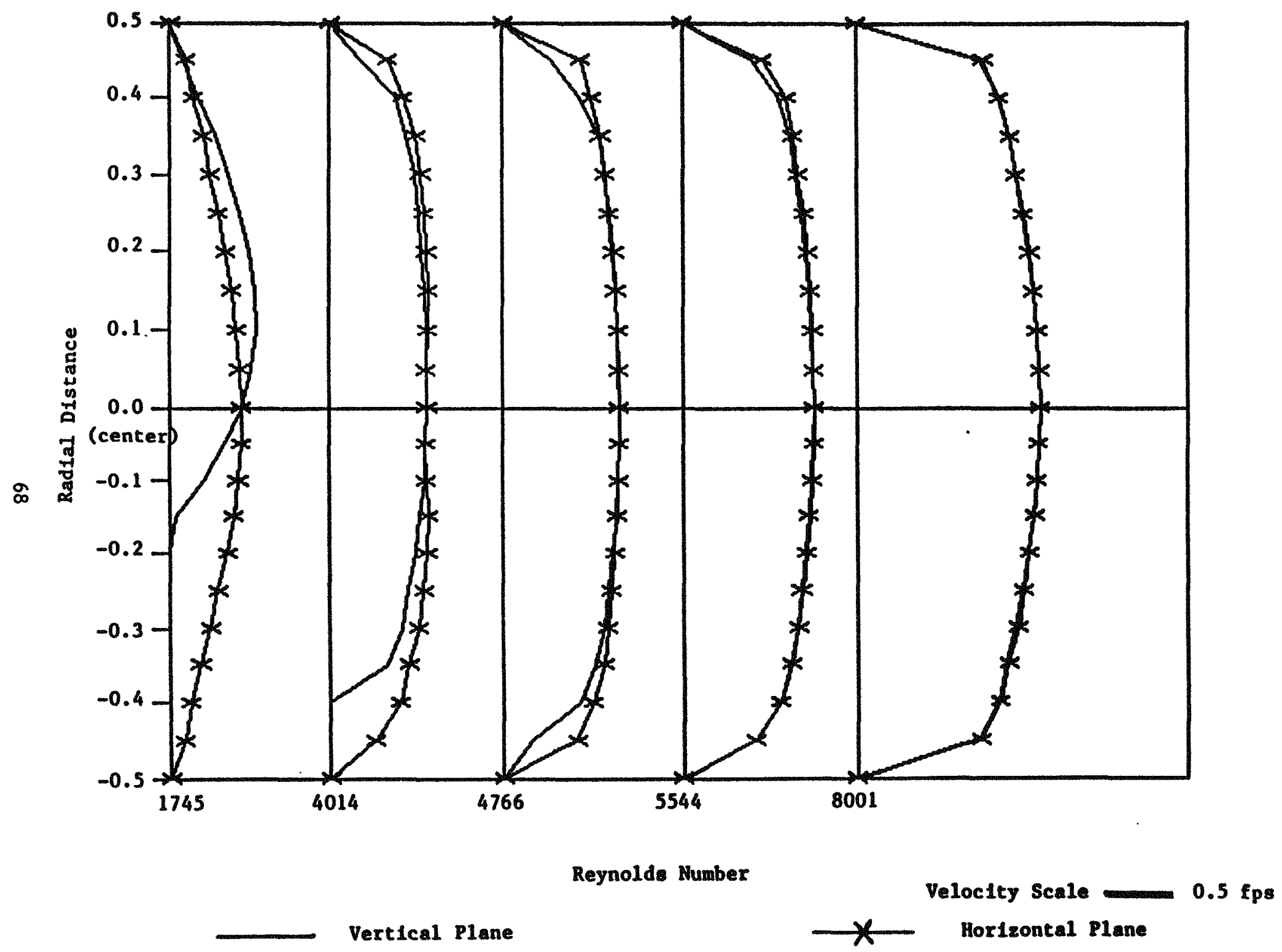

Figure 5.14. Axial velocity profiles along the horizontal and vertical diameters for 58 silica gelsodium iodide solution slurry at various Reynolds Numbers. 


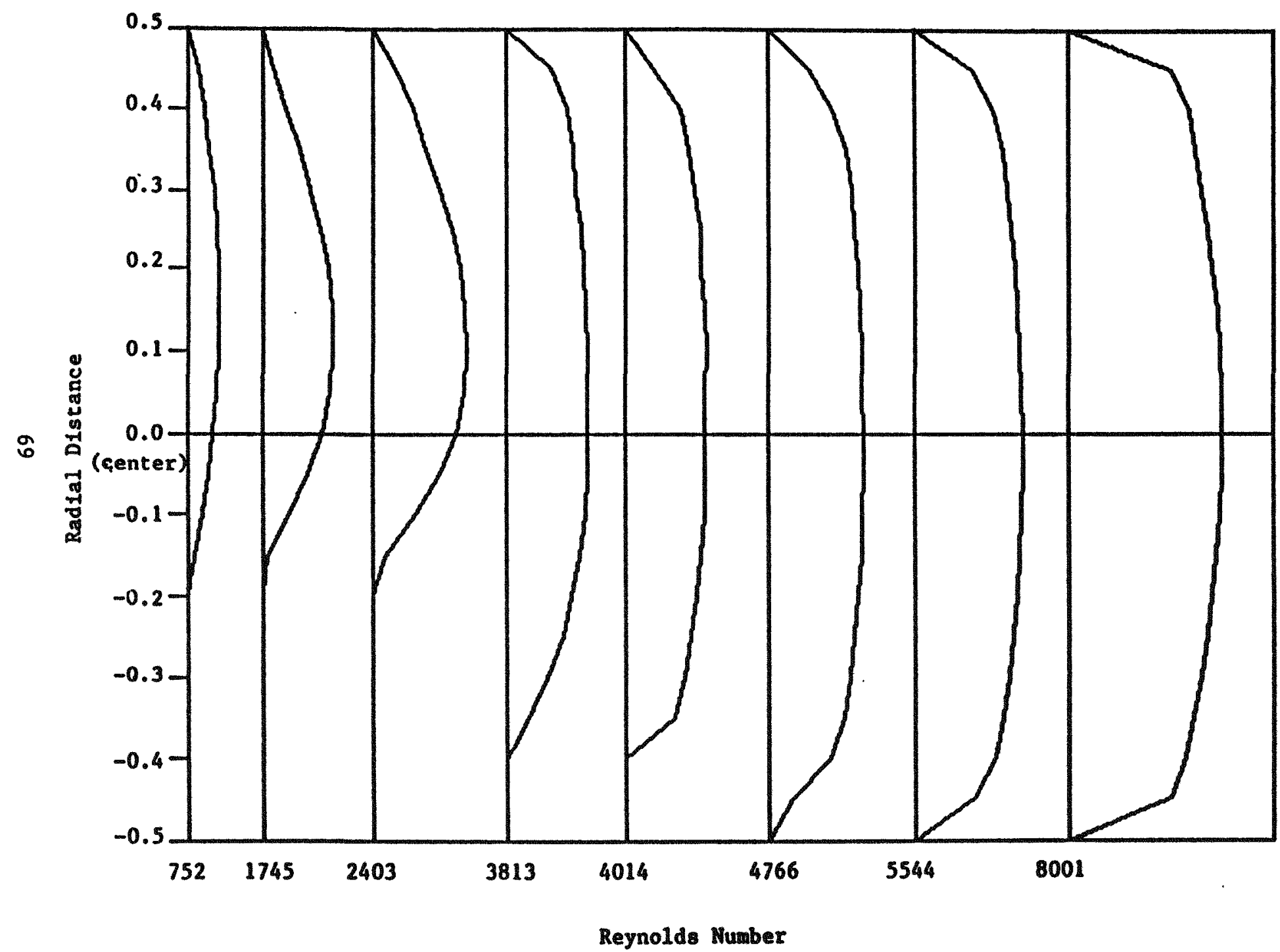

Velocity Scale $0.5 \mathrm{fps}$ Figure 5.15: Axial velocity profiles along the vertical diameters for 58 silica gel-sodium iodide solution slurry at various Reynolds Numbers. 
regime $(\operatorname{Re}>5500)$ the velocity profiles along the horizontal and vertical diameters are exactly similar.

A comparison of the 5 percent slurry velocity profile was made with the theoretical velocity profiles for single phase flows. These comparisons are shown in Figures 5.16 through 5.20. The comparison at Reynolds number of 1745 , saltation flow regime, shown in Figure 5.16 is relatively poor. Also the figure shows comparison along the horizontal diameter only, since along the vertical diameter the flow is not axisymmetric (Figure 5.8). For the heterogeneous flow at Reynolds number of 4766 , the 7 th power law profile matches well for the profile along the horizontal diameter (Figure 5.18) but the comparison is not good along the vertical diameter (Figure 5.17) because of the variation in the concentration along the vertical diameter. For homogeneous flow, good agreement is obtained between the 7 th power law profile and the velocity profiles along the horizontal and the vertical diameters as shown in Figures 5.19 and 5.20 for a Reynolds number of 8001 . This implies that for solid concentrations of 5 percent and less, the velocity profiles for the homogeneous flow regime (Reynolds no. $>5500$ ) are the same as that for single phase turbulent flow.

It was very difficult to discriminate between the solid particle and liquid velocities for $5 \%$ solid concentration. In most cases the solid particle and liquid velocities were identical. Only in the overlapping region of the saltation and heterogeneous flow regime did we observe velocity a difference between the solid and the liquid. The differences, however, were small and non-steady. The histogram-signal amplitude discrimination technique utilized to obtain the solid-liquid velocity discrimination is discussed later in this section. In general, we can conclude that for the slurry with $5 \%$ solid concentration, the liquid and solid velocities are identical.

\subsection{2 $15 \%$ Sodium Iodide-Silica Gel Slurrv.}

Axial velocity profiles were obtained for slurry with $15 \%$ solid concentration in the 


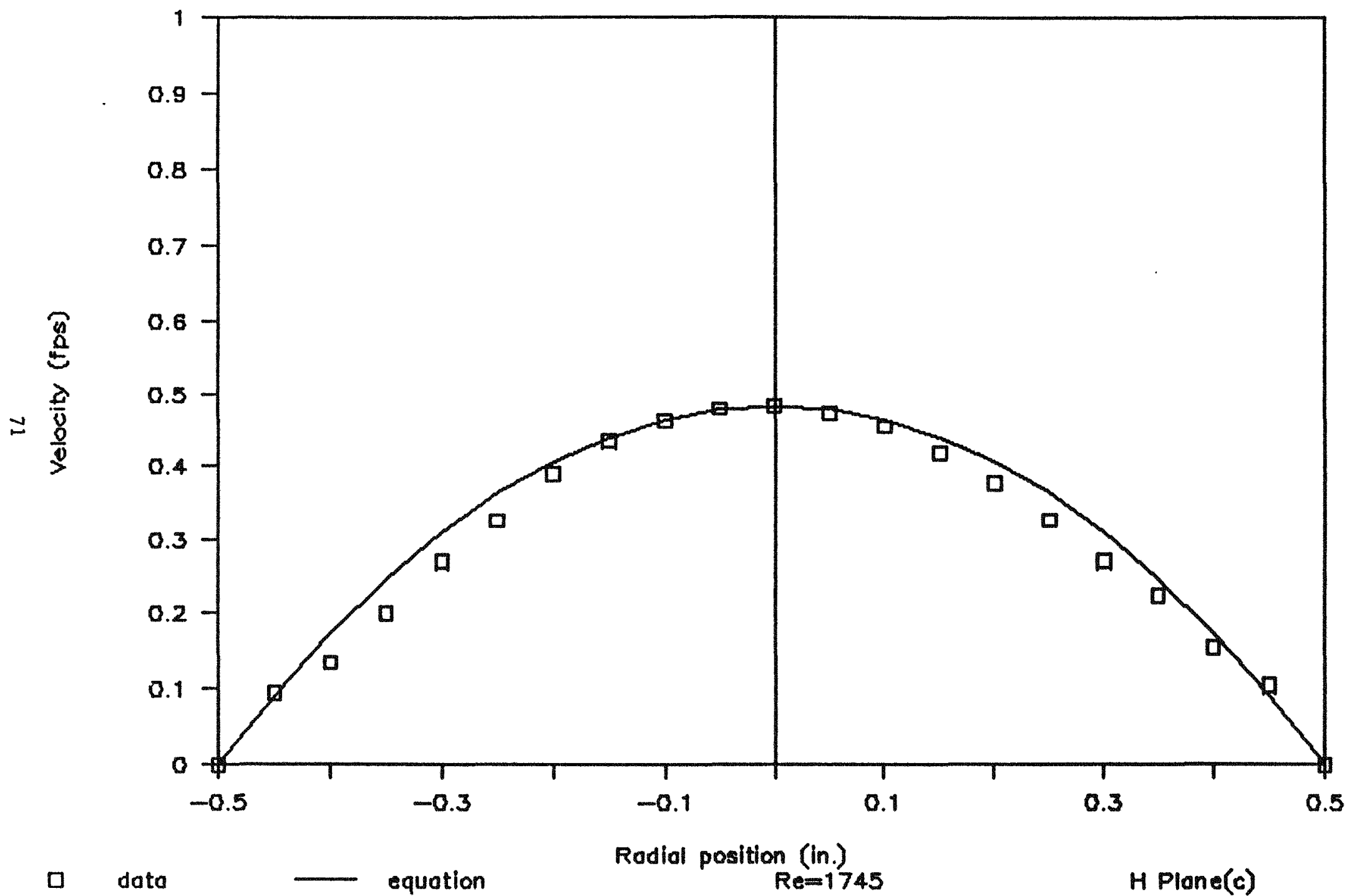

Figure 5.16: Axial velocity profile along the horizontal diameter for 58 silica gel-sodium iodide solution slurry flow at a Reymolds number $=1745$. 


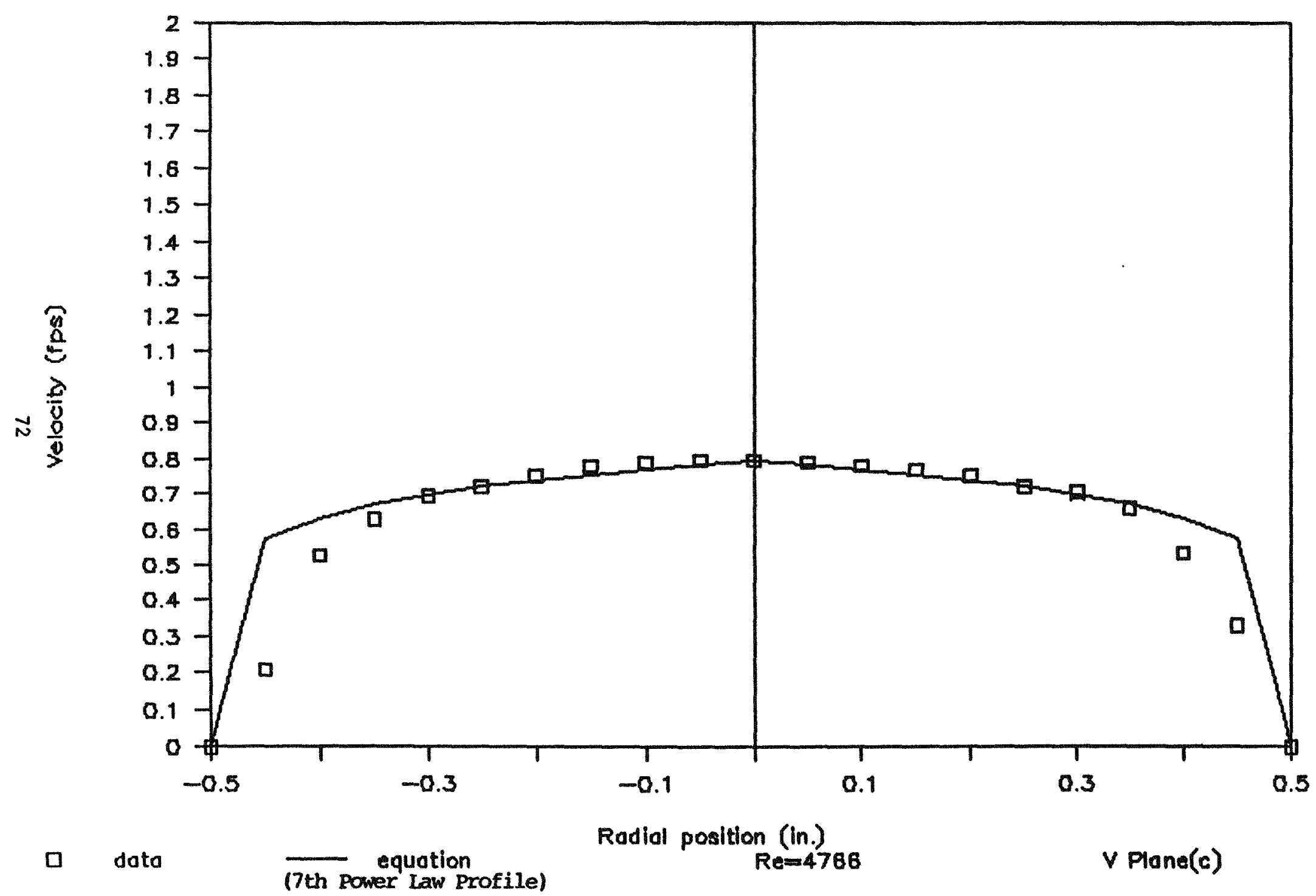

Figure 5.17: Axial velocity profile along the vertical diameter for 58 silica gel-sodium iodide solution slurry flow at a Reynolds number $=4766$. 


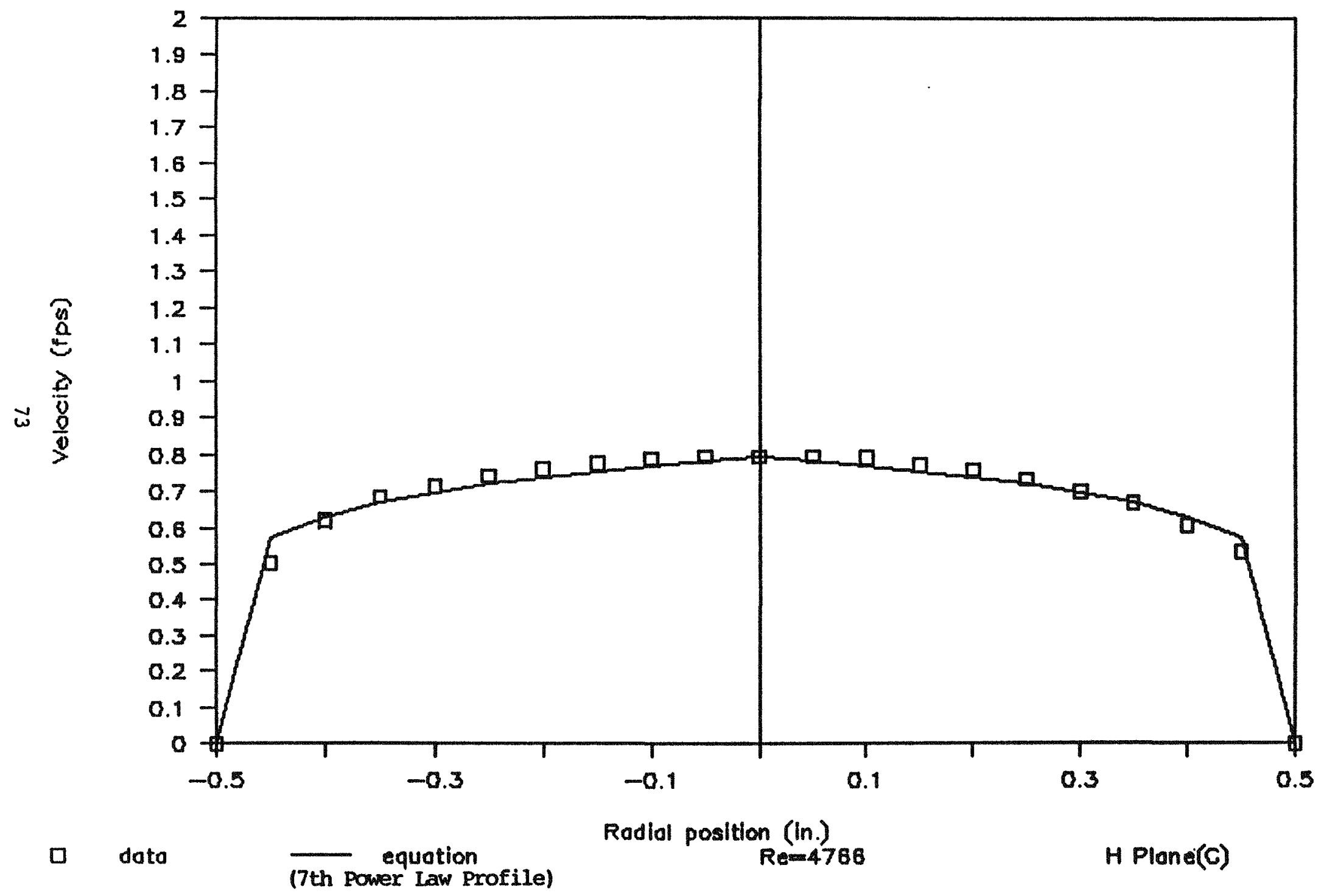

Figure 5.18: Axial velocity profile along the horizontal diameter for 58 silica gel-sodium iodide solution slurxy flow at a Reynolds number $=4766$. 


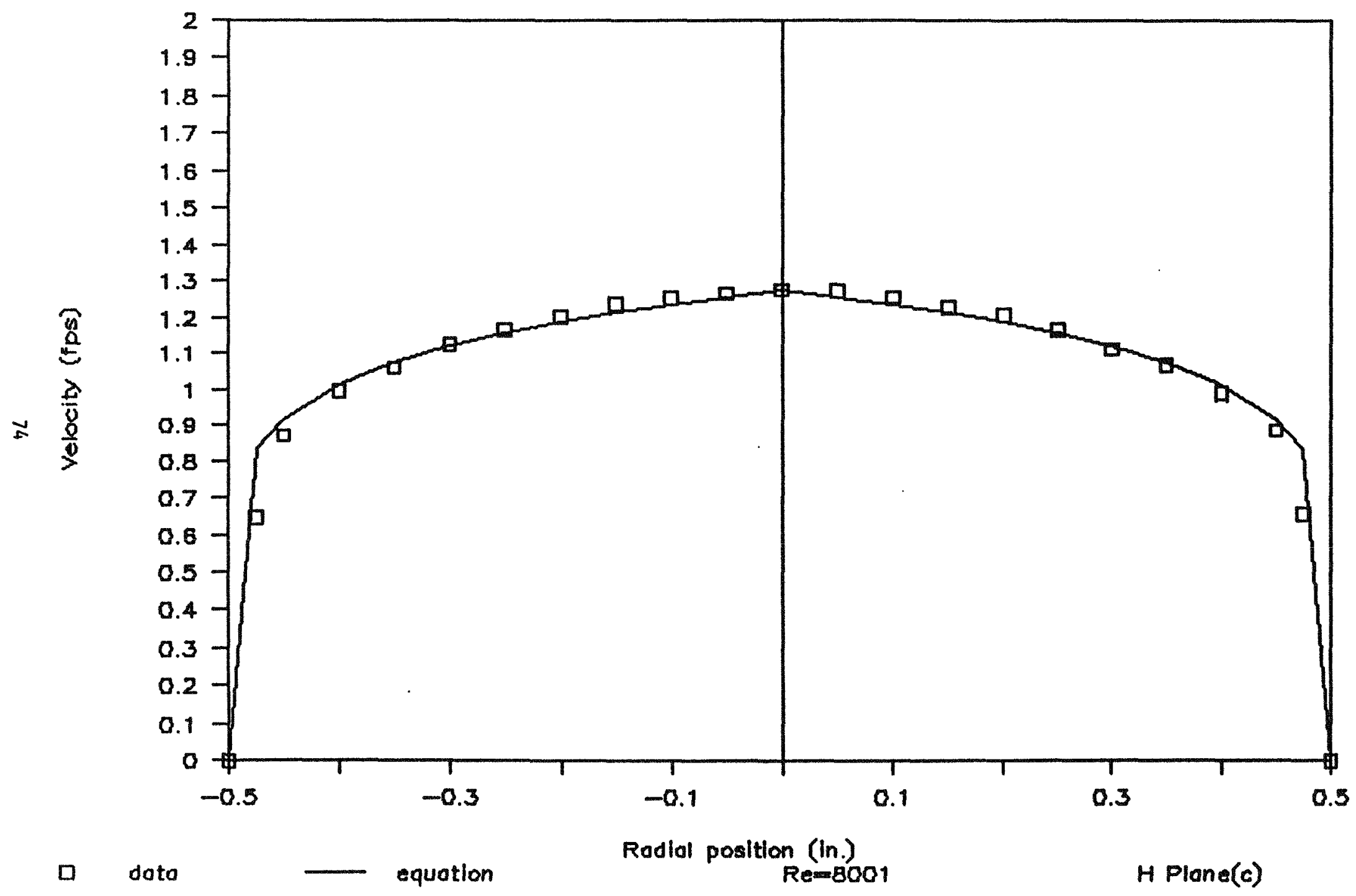

Figure 5.19: Axial velocity profile along the horizontal diameter for 58 silica gel-sodium iodide solution slurry flow at a peynolds number $=8001$. 


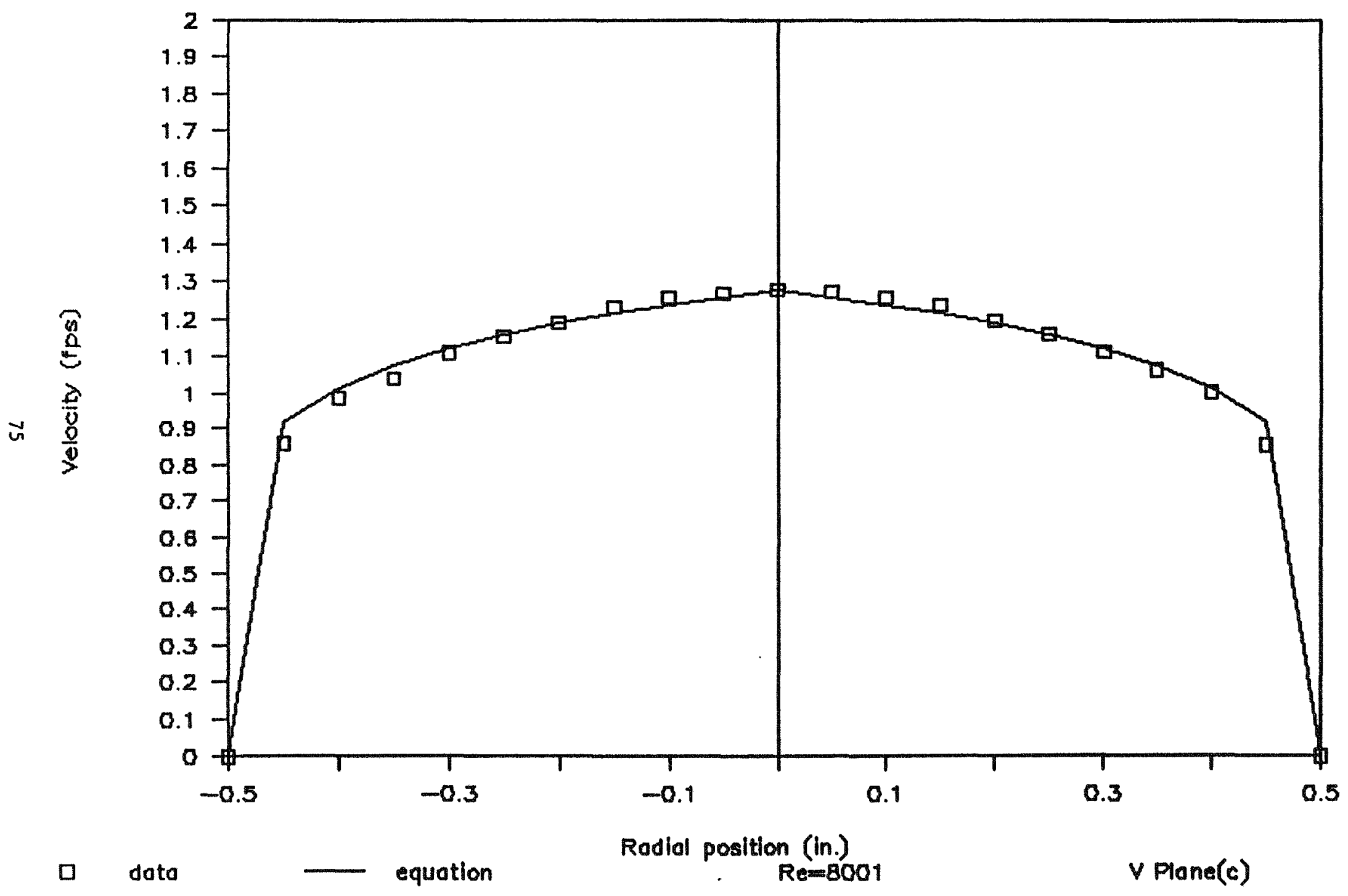

Figure 5.20: Axial velocity profile along the vertical diameter for 5 silica gel-sodium iodide solution slurry flow at a Reynolds number $=8001$. 
Reynolds number range of 700 to 9200 . Figure 5.21 shows the axial velocity profiles along the horizontal and vertical diameters for Reynolds number range of 1700 to 8000 . The figure provides the solid velocities. We observed that for stationery bed flow (Reynolds \# $<2000$ ) and homogeneous flow (Reynolds \# $>5500$ ) the solid and liquid velocities were the same. The critical Reynolds number for identifying the four flow regimes are identical to the $5 \%$ slurry. Figure 5.22 shows the solid particle axial velocity profiles along the vertical diameter for a Reynolds number range of 700 to 8000 . Due to the phenomena as explained in the case of $5 \%$ slurry, we observed a solid layer thickness of nearly 0.55 inch in the stationary bed flow regime (Reynolds \# $<2000$ ). Apparently all the solid particles were deposited in the pipe, resulting in a depth corresponding to $30 \%$ solid concentration and non perfect packing. Further increase in the velocity resulted in the flow regime changing to saltation $(2000<\operatorname{Re}<4000)$, heterogeneous $(4.000<\operatorname{Re}<5000)$ and homogeneous flow regimes (Re>5200) progressively. Figures 5.23 and 5.24 show the velocity profiles not along the diameters but along the vertical and horizontal lines (Figure 4.1) for Reynolds number of 3960 and 5665 . We can observe that flow is not axisymmetric for saltation flow $(\mathrm{Re}=3960)$ but is axisymmetric for the homogeneous flow ( $R e=5665)$.

It was relatively easy to obtain solid and liquid velocities for the $15 \%$ concentration as compared to the $5 \%$ concentration slurry. Figures 5.25 and 5.26 show the axial velocity profiles for the solid particles and the fluid along the horizontal and vertical diameters respectively in the heterogeneous flow regime $(\operatorname{Re}=4497)$. However, the solid particle and fluid velocities were identical in the homogeneous flow regime. The velocity profiles obtained along the horizontal as well as the vertical diameters for homogeneous flow regime agreed very well with the single phase turbulent flow profile obtained by using the seventh power law as shown in Figures 5.27 and 5.28 . Thus for both $5 \%$ and $15 \%$ slurry the velocity profile for homogeneous flow regime $(\operatorname{Re}>5200$ ) is similar to the profile for single 


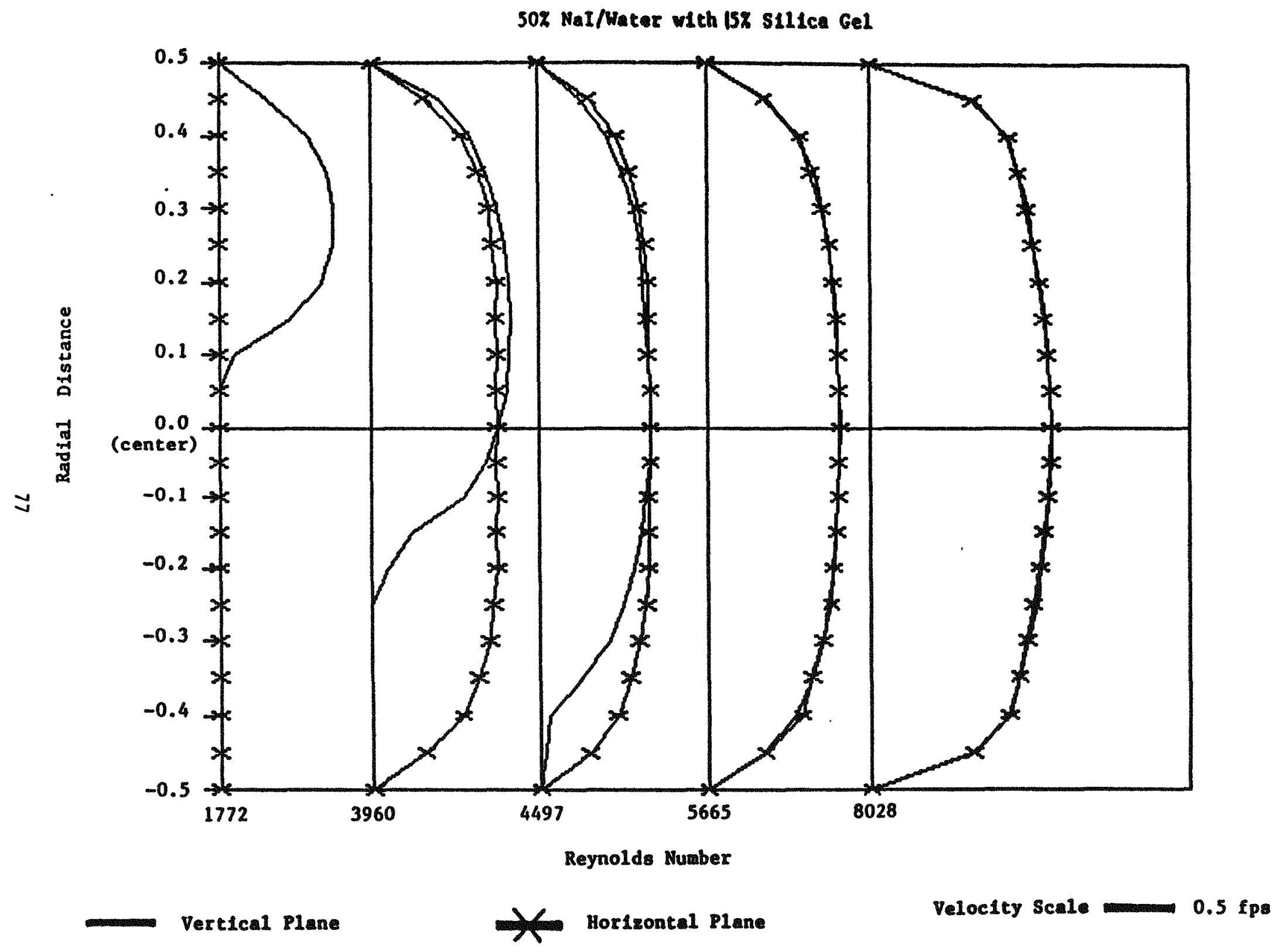

Figure 5.21: Axial velocity profiles along the horizontal and vertical diameters for 158 silica gelsodium iodide solution slurry at various Reymolds numbers. 


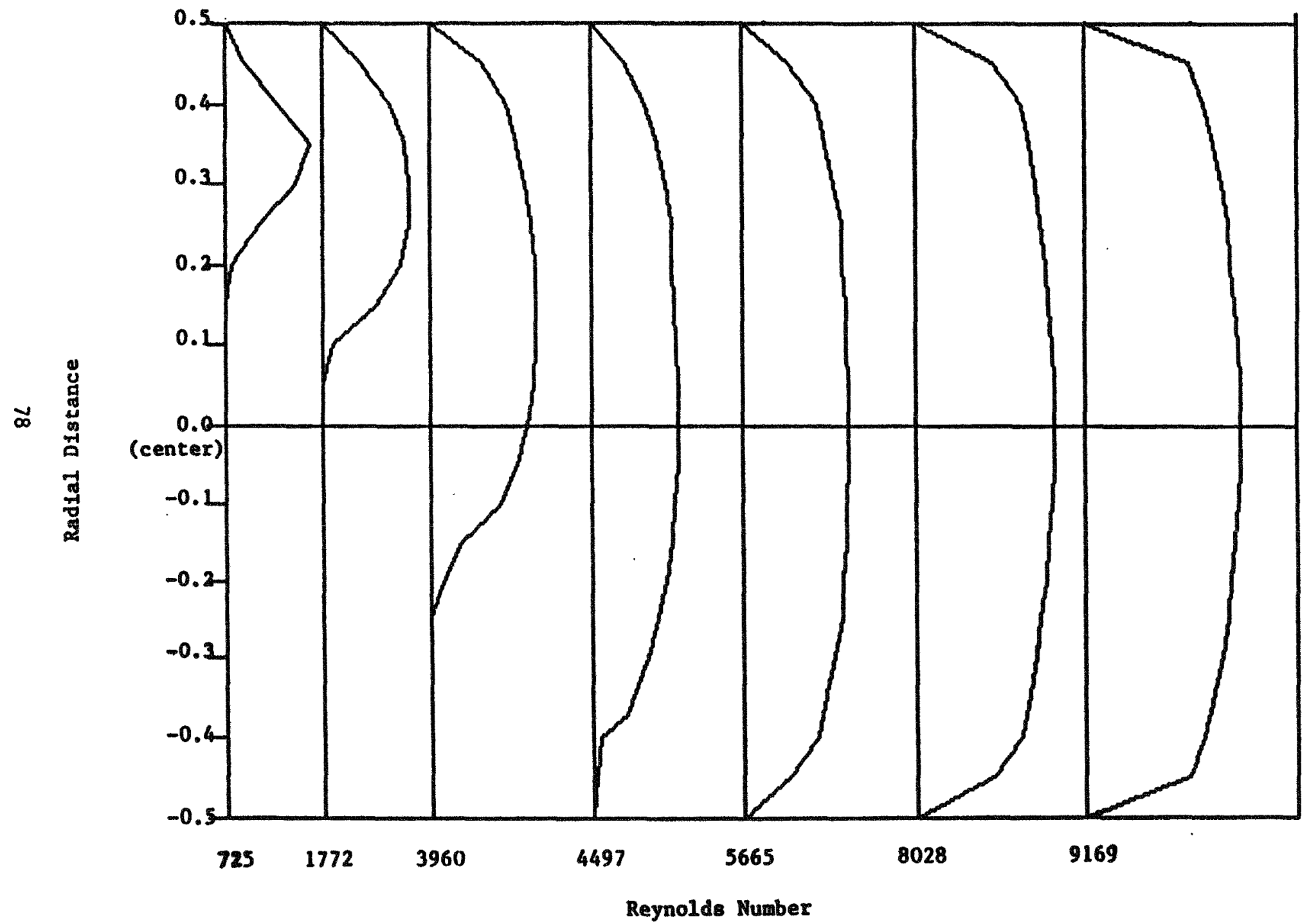

Figure 5.22: Axial velocity profiles along the vertical diameters for 158 silica gel-sodium iodide solution slurry at various Reynolds numbers. 


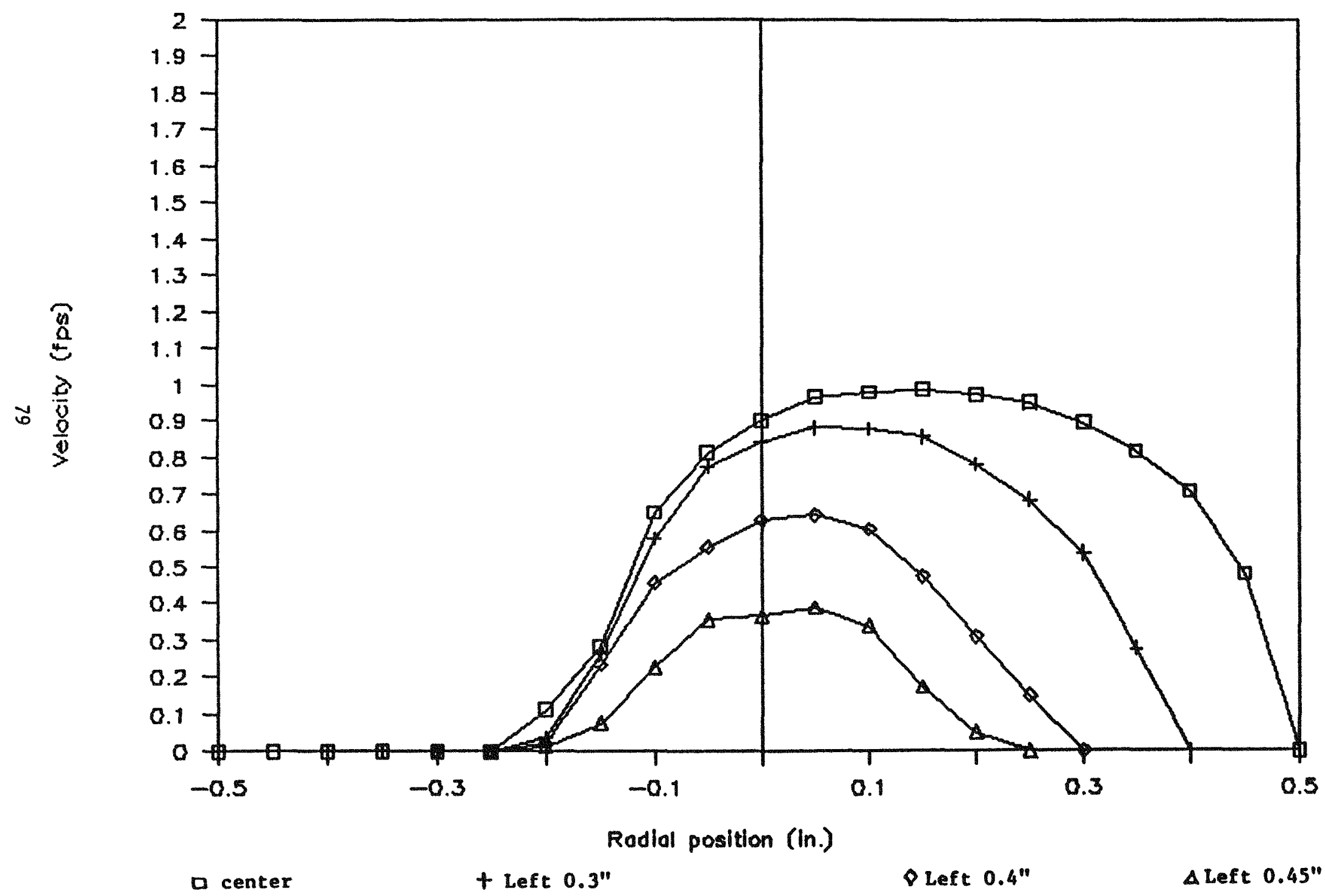

Figure 5.23: Axial velocity profiles along several vertical 11 eses for $15 \%$ silica gel-sodium lodide solution slurry at a $R e=3960$ 


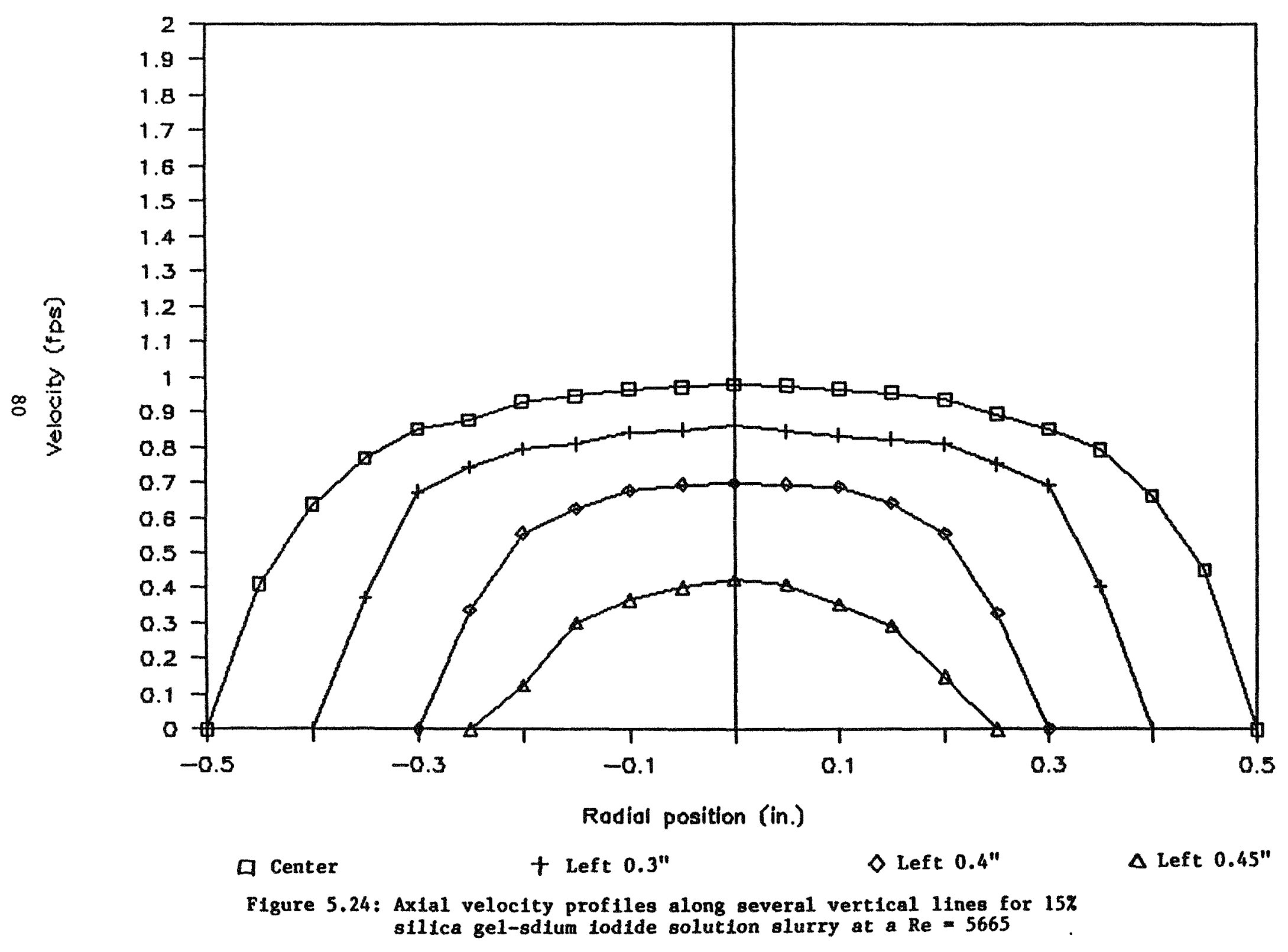




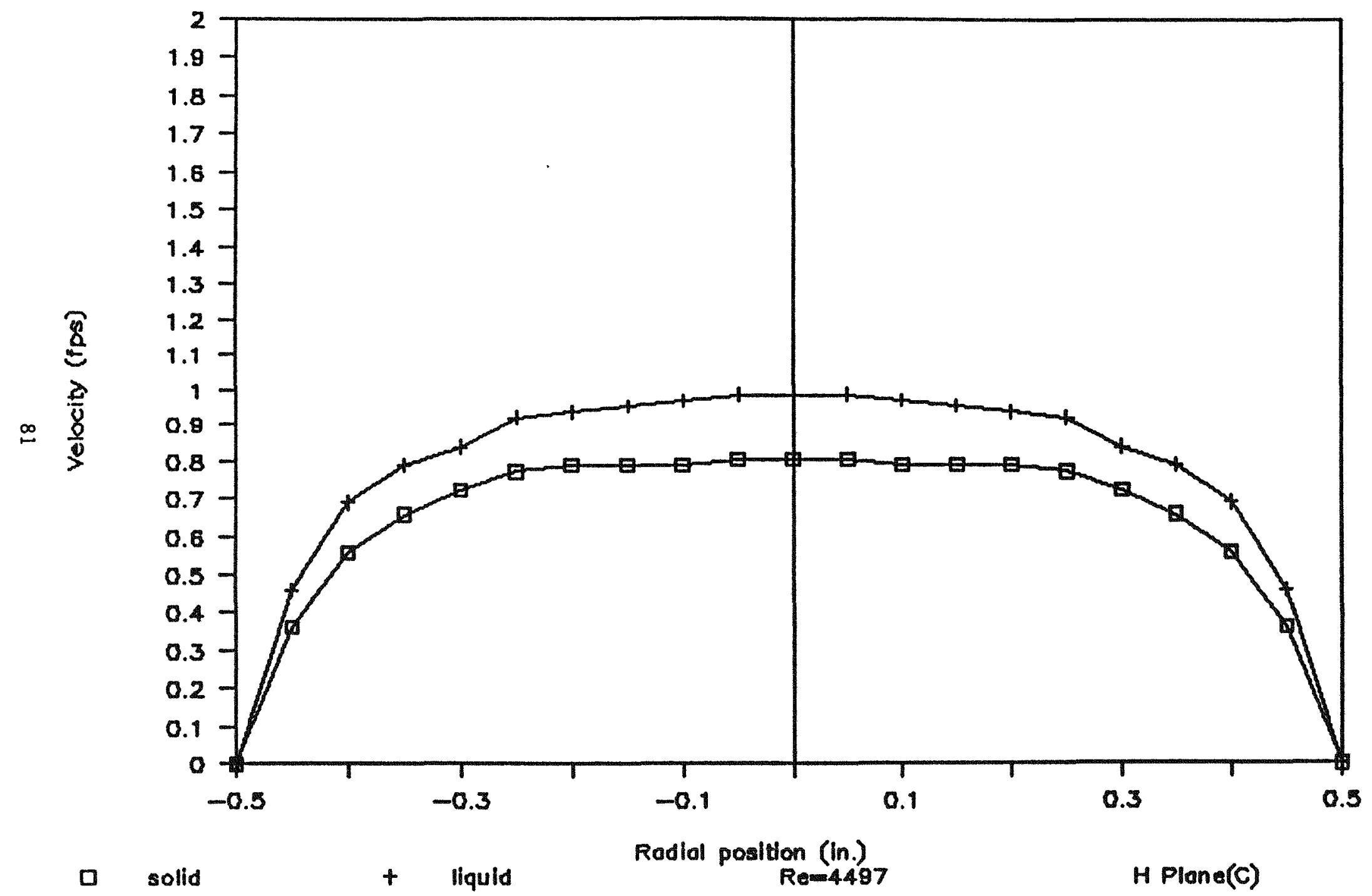

Figure 5.25: Axial velocity profiles along the horizontal diameter for liquid and solid phase for 158 silica gel-sodium iodide solution slurry at a Reynolds number $=4497$. 


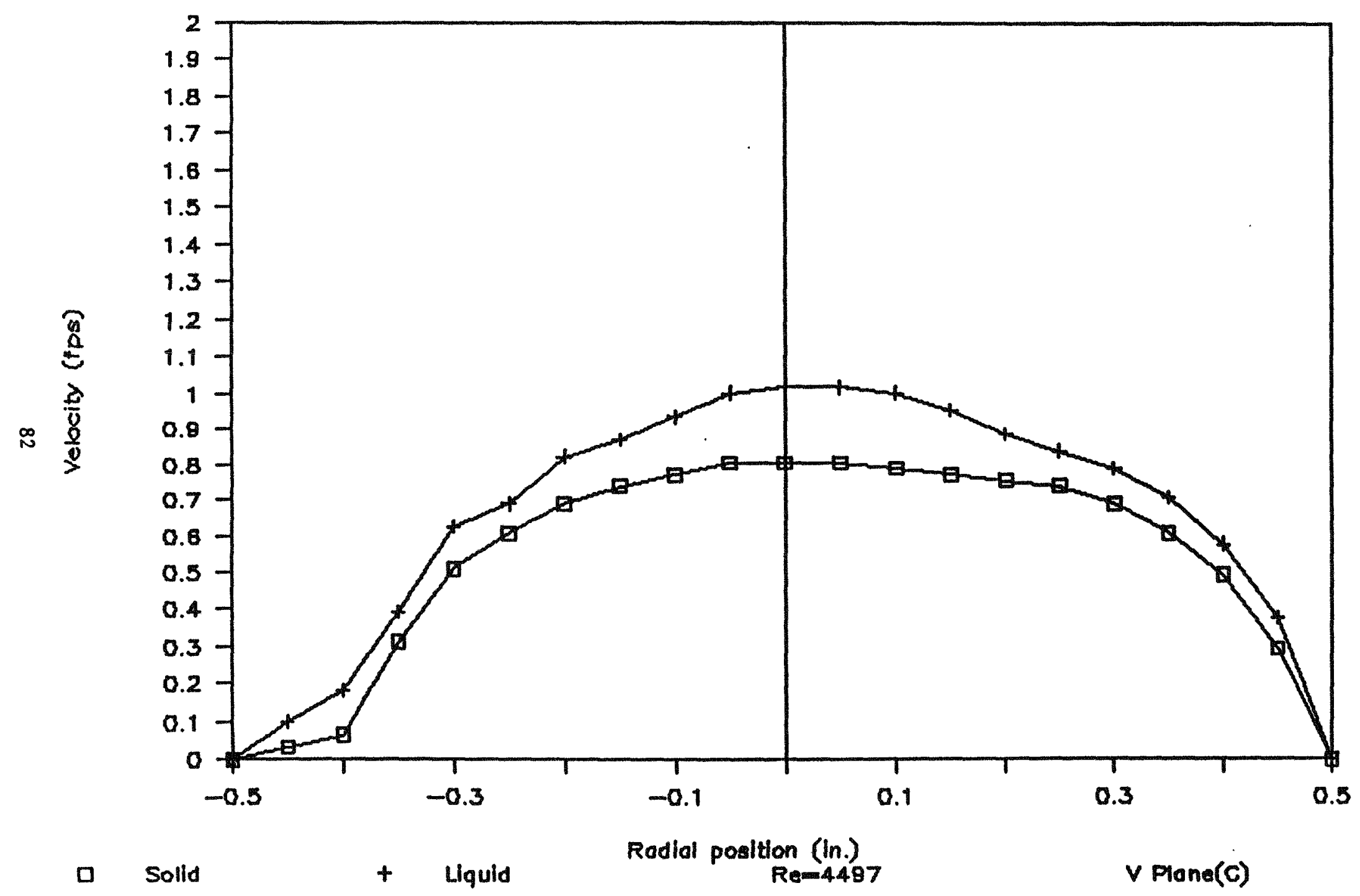

Figure 5.26: Axial velocity profiles along the vertical diameter for liquid and solid phase for 158 silica gel-sodium iodide solution slurry at a Reynolds number $=4497$. 


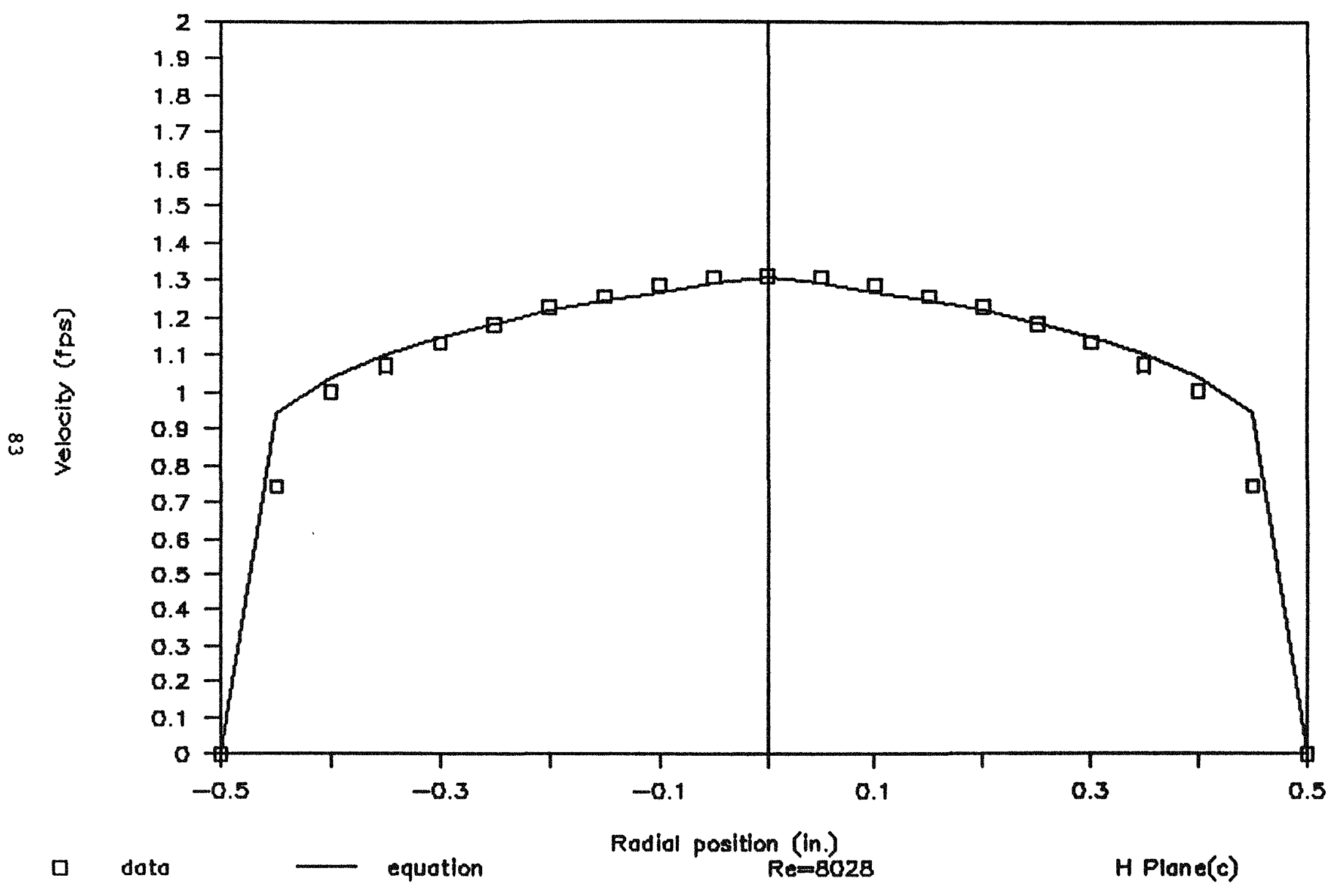

Figure 5. 27: Axial velocity profile along the horizontal diameter for 158 silica gel-sodium iodide solution slurry at a Reymolds number $=8028$. 


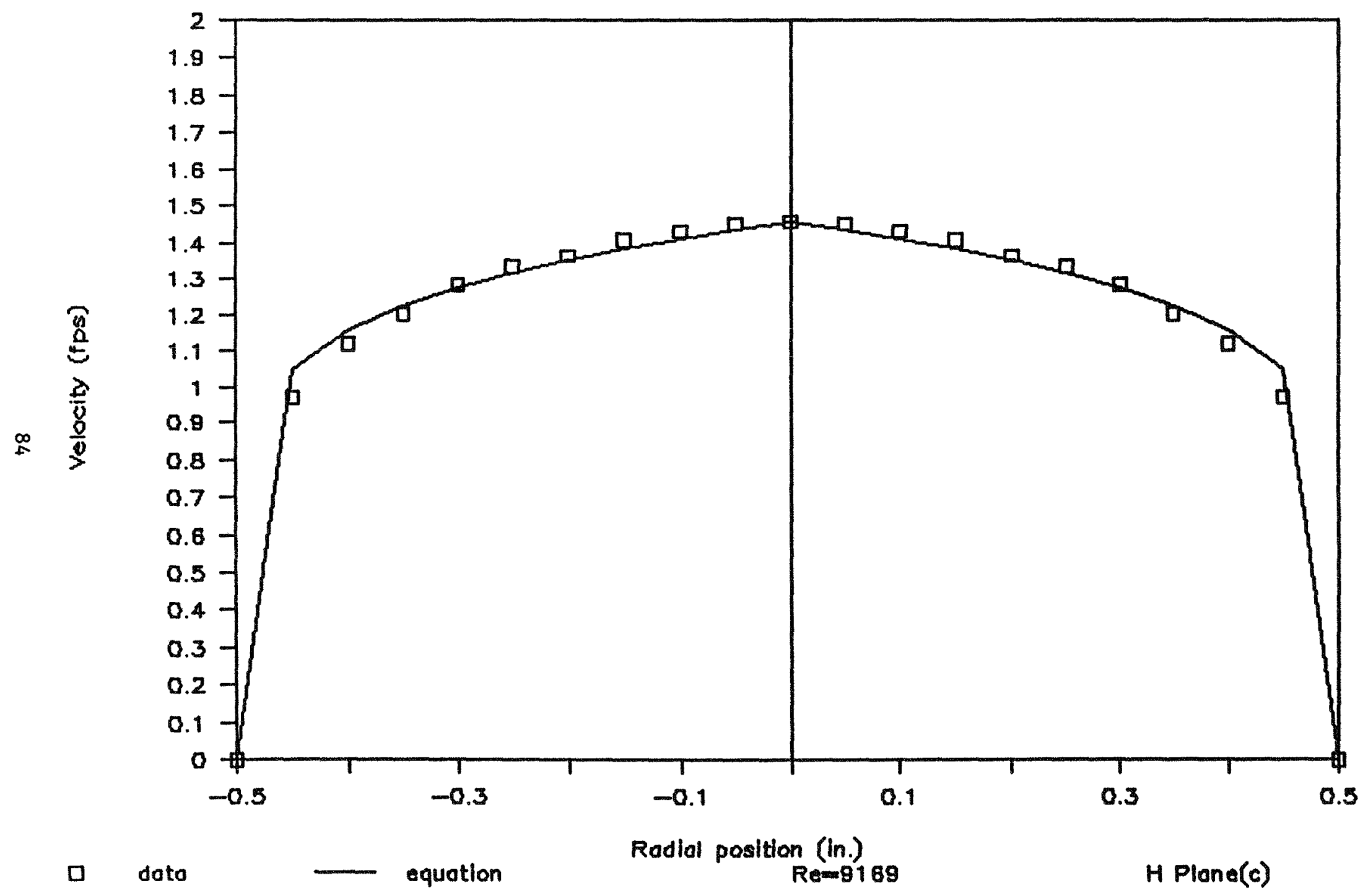

Figure 528 : Axial velocity profile along the horizontal diameter for 158 silica gel-sodium iodide solution slurry at a Reynolds number $=9169$. 
phase turbulent flow.

An interesting observation was made while conducting tests in the saltation flow regime for the $15 \%$ slurry. The axial velocity profiles along the vertical diameter at different time intervals for a Reynolds number of 2332 are shown in Figure 5.29. It normally takes about 5 minutes to obtain one set of data along the diameter. One can see that the velocity profile varied with time and it takes somewhere about 115 minutes for the initial profile to repeat itself. The variations in the velocity profile were more pronounced at a slightly higher Reynolds number of 2685.(Figure 5.30) The flow cycled between stationary bed - saltation flow - heterogeneous flow regimes. This phenomenon was observed only in this 2300-2700 Reynolds number range.

\subsubsection{Solid-Liquid Velocity Discrimination}

A signal processing technique utilizing histograms of the velocity measurements (1000 measurements at each point) was used for discriminating between the solid particle velocities and the liquid velocities. The use of the technique for the test data for $15 \%$ slurry at Reynolds number of 4499 (heterogeneous flow regime) will be discussed. The histograms showing velocity versus number of observation (i.e. number of particles) at radial locations of 0.0 (center) $, 0.05,0.10$ and 0.15 inch below the center of pipe along the vertical diameter are provided in Figures $5.31,5.32,5.33$ and 5.34 respectively. A histogram with a Gaussian distribution will indicate that the silica gel particles (40 microns average diameter) are following the fluid phase flow. Signals from the smaller particles ( $<5$ micron diameter) present in the sodium iodide solution provide the fluid velocity. However, if the solid and liquid phase velocities are different we could then see two or more Gaussian profiles in the histogram and possibly two or more peaks. Figures 5.31 is the histogram of the data taken at pipe center. The distribution has two peaks corresponding with the lower velocity of larger particle (silica gel $40 \mu \mathrm{m}$ ) and higher 


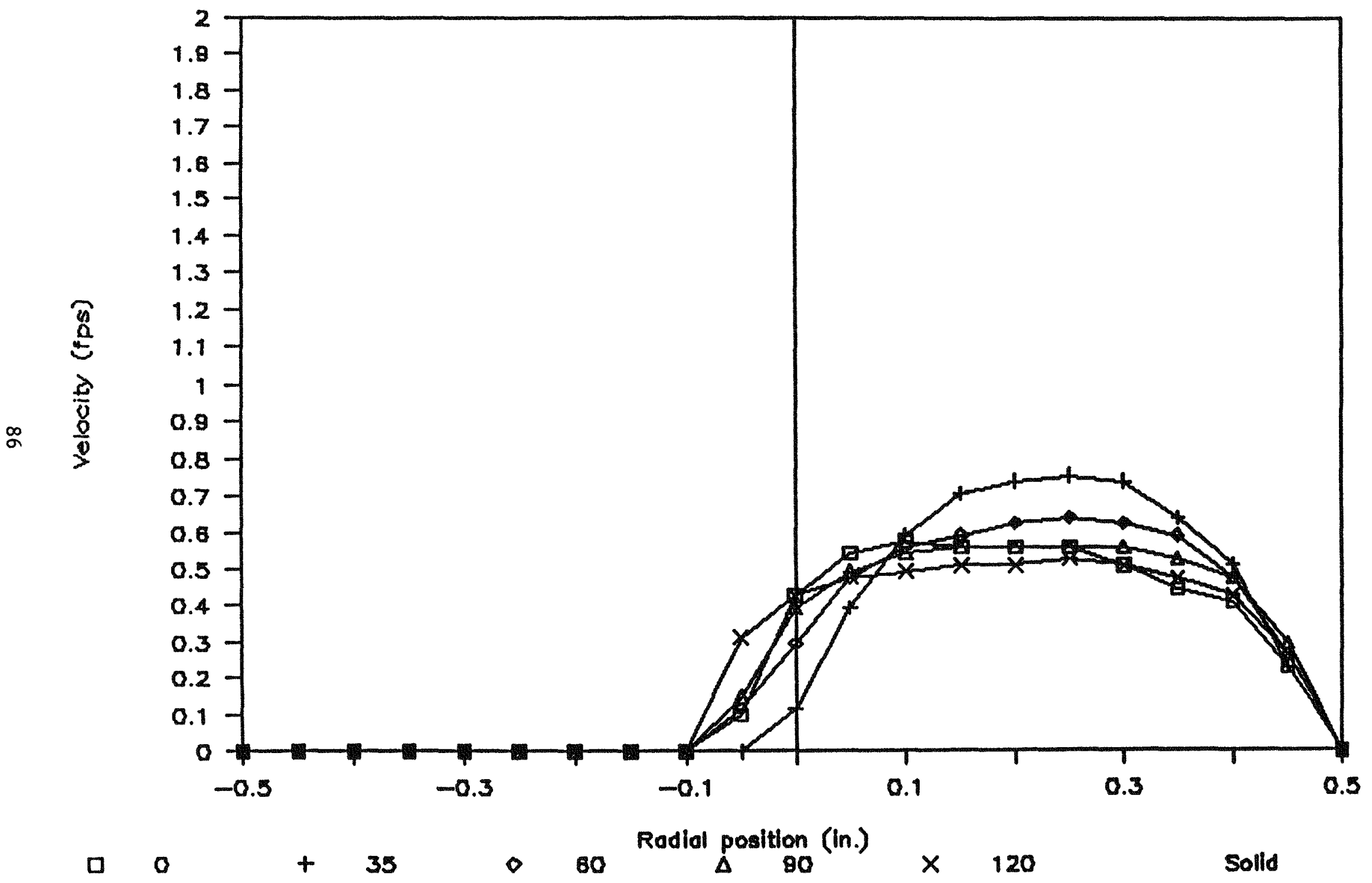

Figure 5.29: Change in axial velocity of the solid along the vertical diameter with respect to time for 158 silica gel-sodium iodide solution slurry at a Reynolds number $=2322$. 


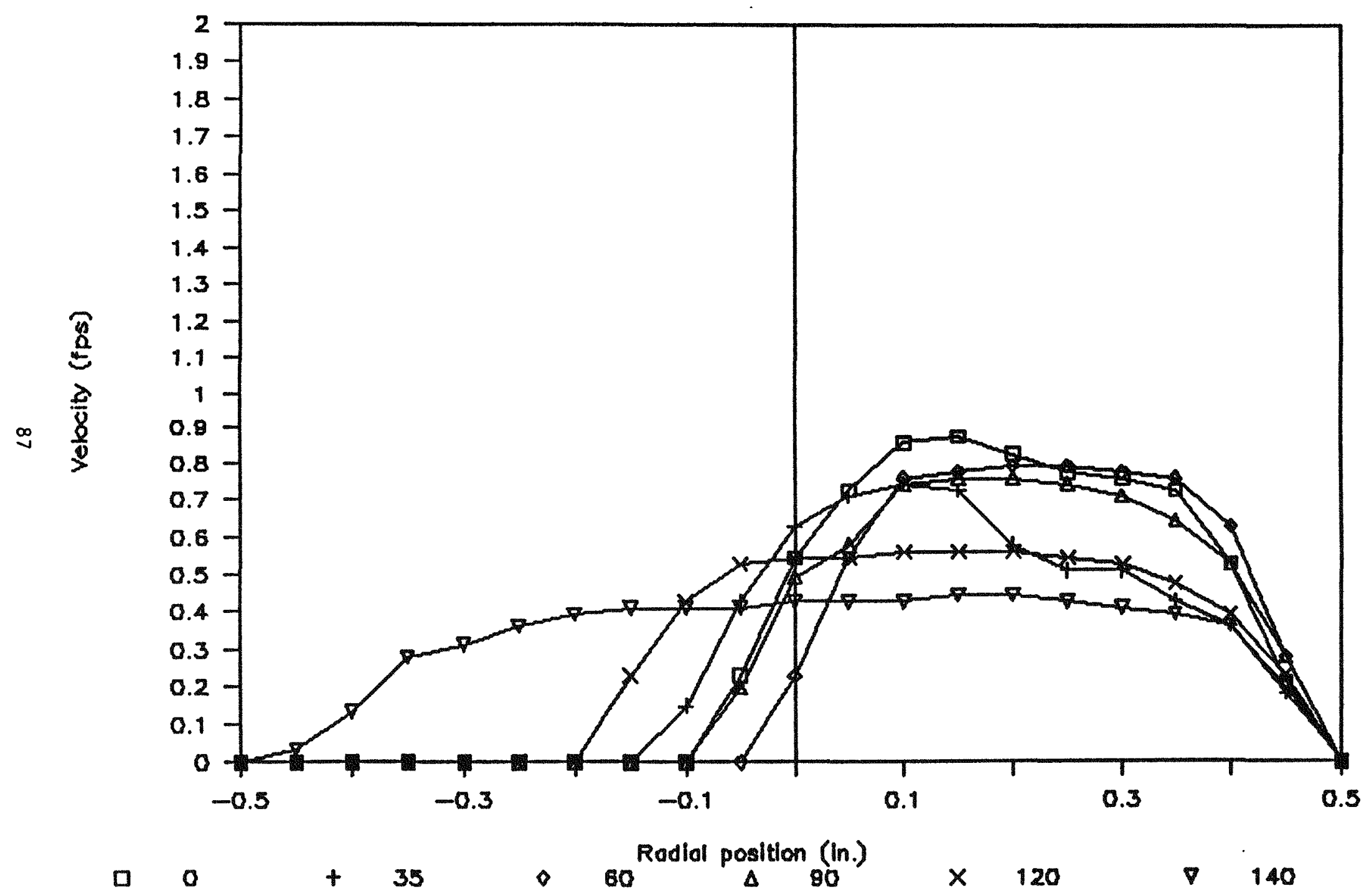

Figure 5. 30 Change in axial velocity of the solid along the vertical diameter with respect to time for 158 silica gel-sodium iodide solution slurry at a Reymolds number $=2685$. 


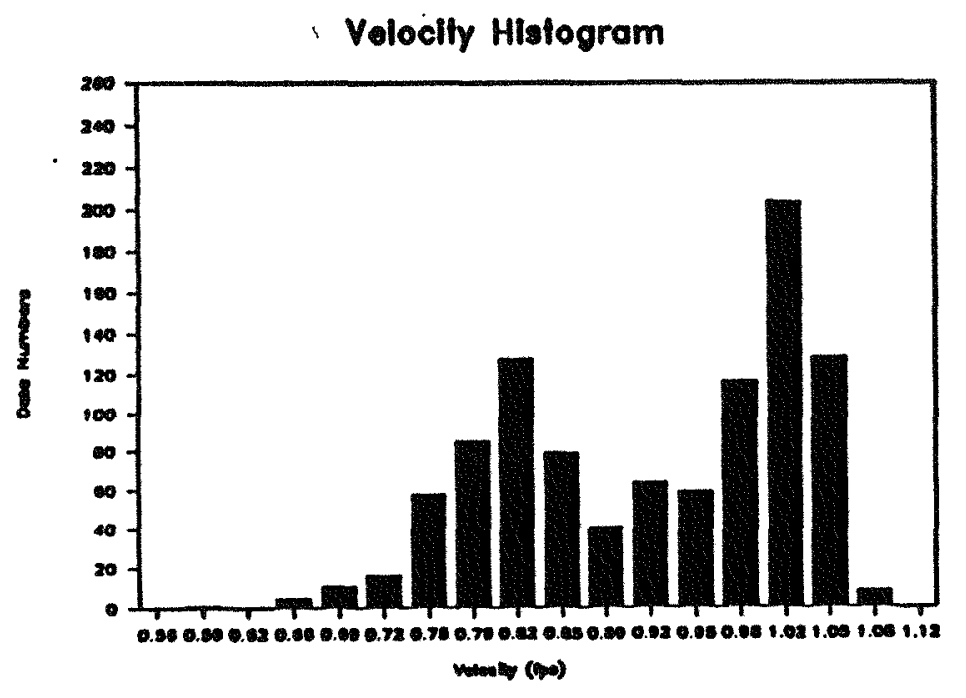

Figure 5.31: Histogram of velocity vs. number of particles for measurement location at pipe center for 158 silica gel-sodium iodide solution slurry at a Reynolds number $=4497$, the number of meas $=$ urement $=1000$.

Voloclly Hlatogram

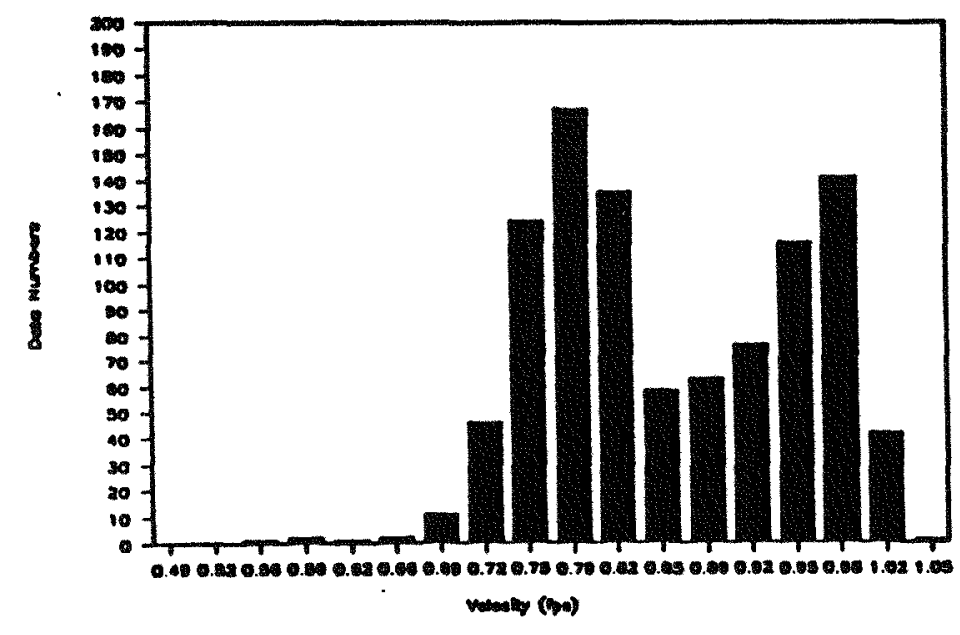

Figure 5.33. Fistogram of velocity vs. number of particles for measurement location at $0.1^{\prime \prime}$ below center for 15 percent silica gel-sodium iodide solution slurry at a Reymolds number $=4497$, the number of measurement $=1000$.

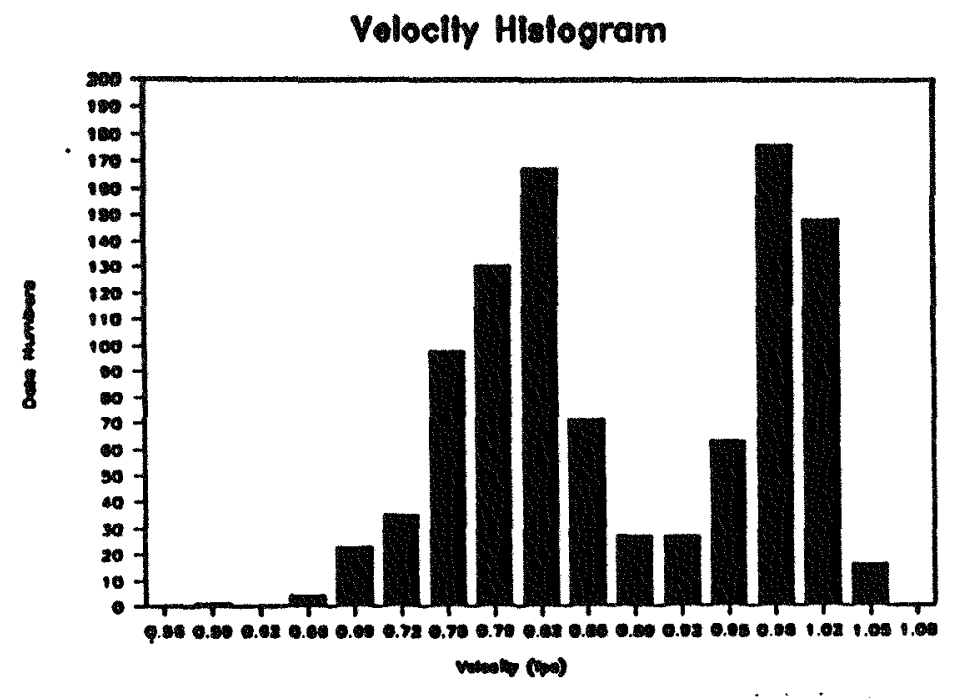

Figure 5.32: Histogram of velocity vs. number of particles for measurement location at $0.05^{\prime \prime}$ below center for $15 \%$ silica gel-sodium iodide solution slurry at a Reynolds number $=4497$, the number of measurement $=1000$.

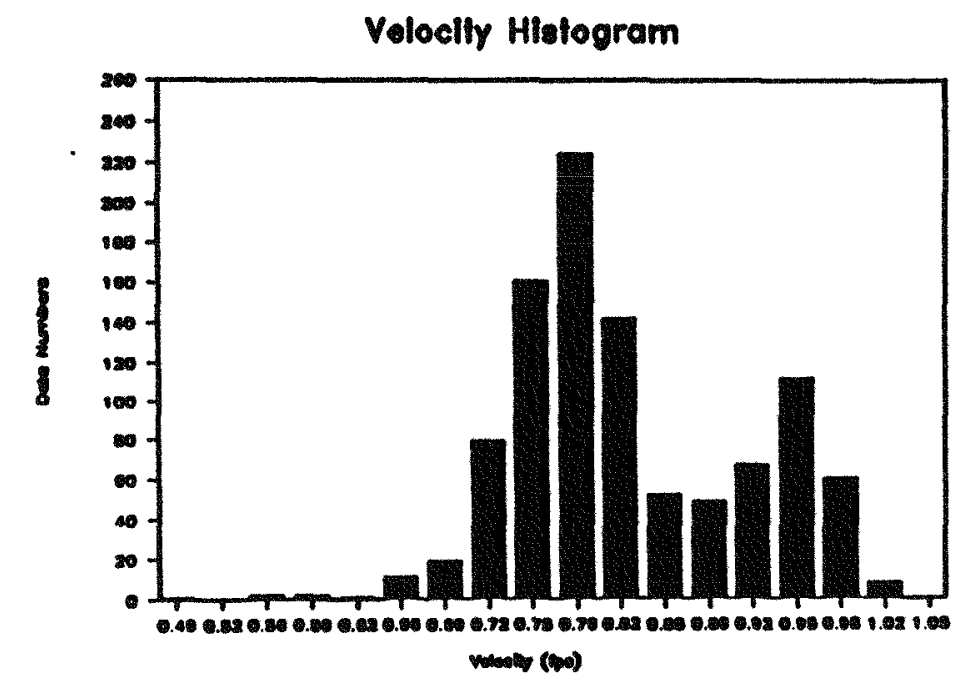

Figure 534.: Histogram of velocity vs. number of particles for measurerent location ai $0.15^{\prime \prime}$ below center for 158 silica gel. scaium iodicie solution slurry at a Reynolds number $=449 \%$, the isumber of measurement $=1000$. 
velocity of small particle $(\leq 5 \mu \mathrm{m})$ closely following the liquid phase. At this location the number of particles following the liquid dominate. As we move down below the center, the velocity histogram with two peaks which correspond with the Gaussian distributions associated with solid phase and liquid phase are still observed as shown in Figures 5.32, 5.33 and 5.34. However, the situation regarding the number of small particles dominating in the sample reverses and as we see that at $0.15^{\prime \prime}$ below the center the larger particles are in greater numbers, indicating a larger concentration of solids near the bottom of pipe which also indicates the heterogeneous flow regime.

The signal amplitude limit control switch available in TSI model \#1990 counter processor was utilized to ascertain silica gel particle velocities. By cutting off high amplitude Doppler signals by using the amplitude limit control switch resulted in attenuating substantially or eliminating completely the lower velocity peak in the velocity histograms. This confirmed the fact that the peak associated with lower velocities in the histogram resulted from the higher amplitude Doppler signals obtained from the silica gel particles (40 microns) and the peak associated with larger velocities resulted from the lower amplitude Doppler signals obtained from the smaller ( $<5$ microns) particles in the slurry. A larger number of fringe crossing (16) in the LDV measurement volume helped reduce substantially the possibility of picking up those relatively lower amplitude signals from the 40 micron silica gel particles which might be crossing a small number of fringes near the extremities of the measurement volume. Thus, combination of histogram and signal amplitude discrimination provides a technique to differentiate between the solid and liquid phase velocities. For 15 percent slurry, the difference between solid and fluid velocities was observed only in the saltation and heterogeneous flow regimes.

The velocity discrimination between the solid phase and liquid phase for $5 \%$ slurry is shown in Figures 5.35, 5.36, 5.37 and 5.38 at a Reynolds number of 3813 . The same 


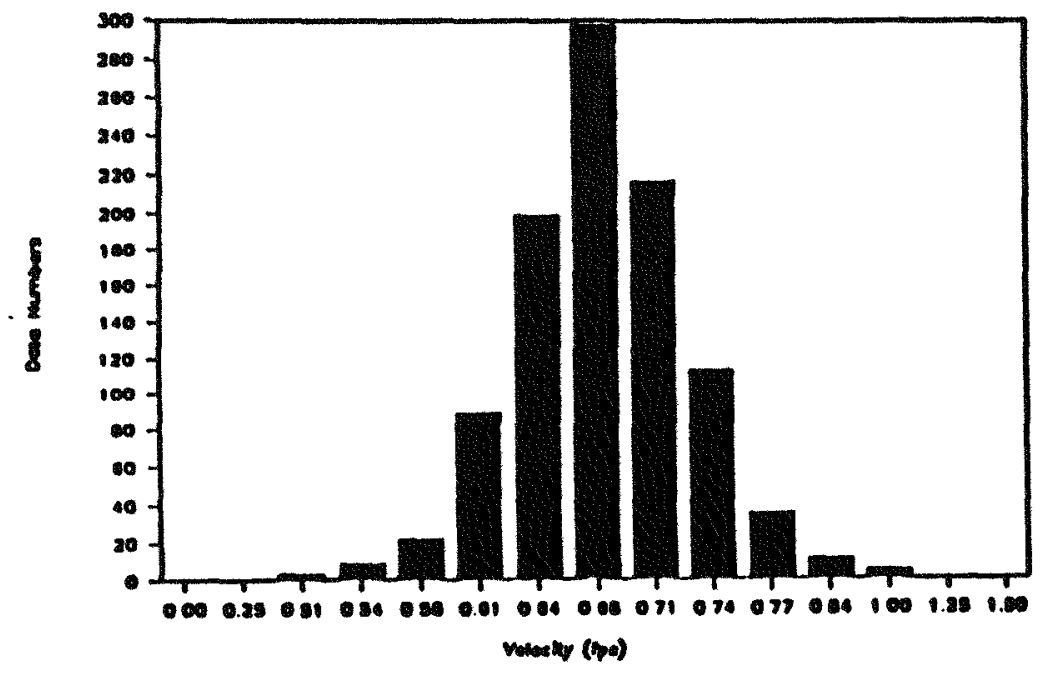

Figure 5.35: Histogram of velocity vs. number of particles for measurement location at pipe center for 58 silica gel-sodium iodide solution slurry at a Reynolds

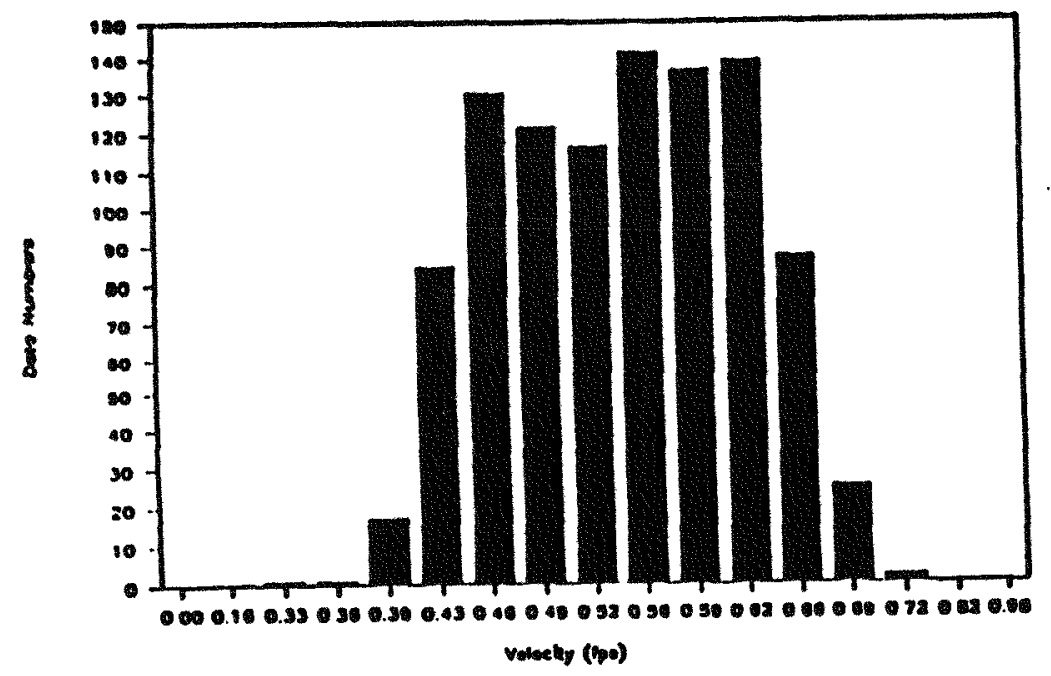

Figure 5.37 : Histogram of velocity vs. number of particles for measurement location at $0.2^{\text {" }}$ below the center for 58 silica gel-sodium iodide solution slurry at a Reynolds number $=3813$, the number of measurement $=1000$.

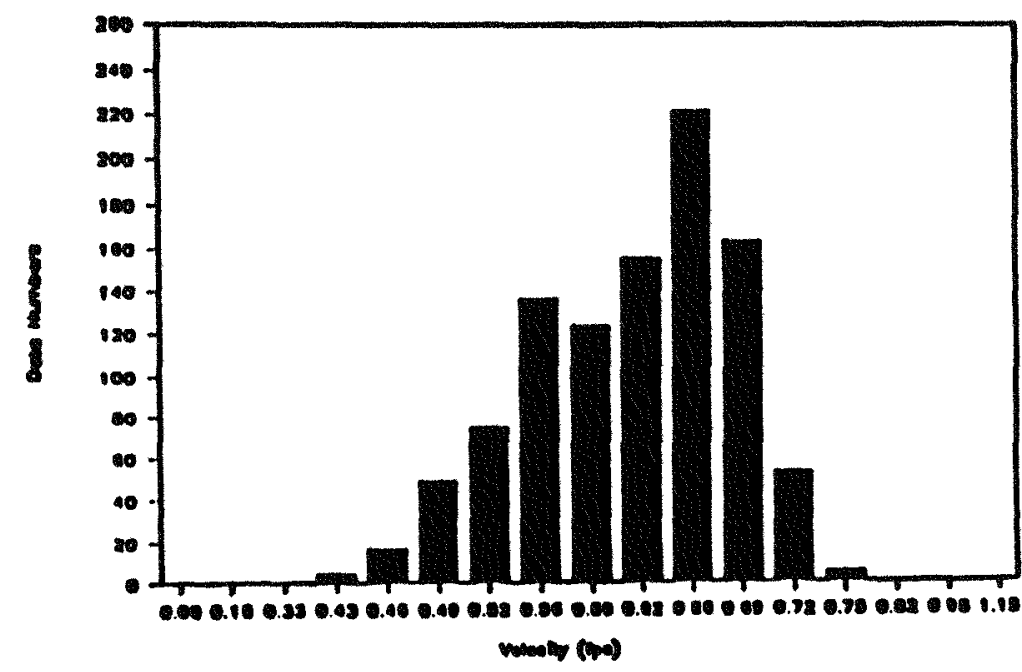

Figure 5.36: Histogram of velocity vs. number of particles for measurement location at $0.15^{\text {" below }}$ the center for 58 silica gel-sodium iodide solution slurry at a rajiclic nusicor a joij: ine numiver or

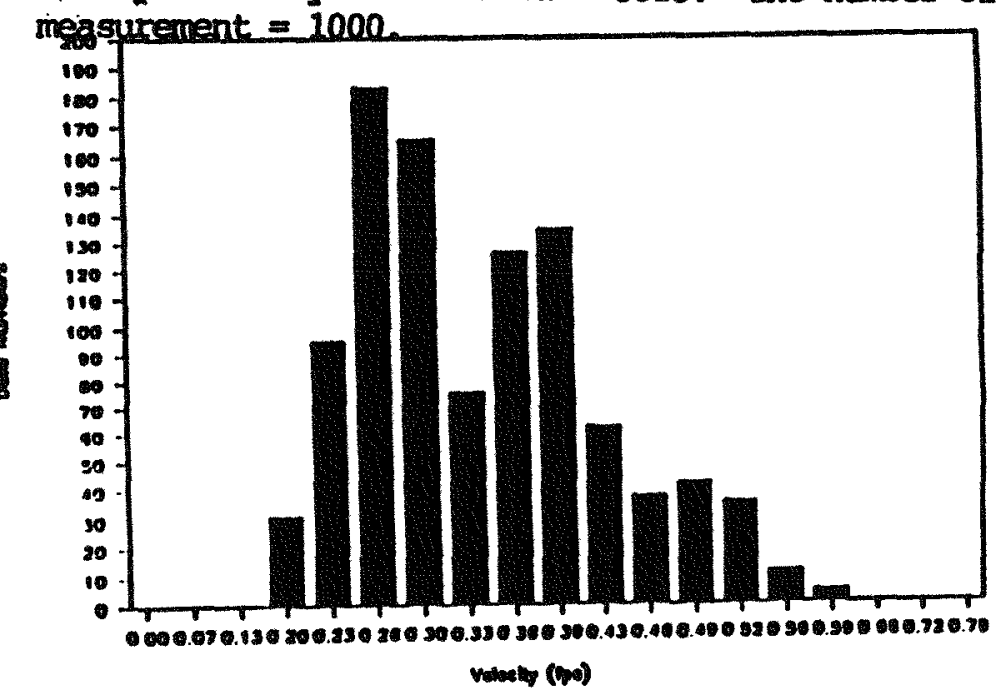

Figure 5.38. Histogram of velocity vs. number of particles for measurement location at $0.3^{\prime \prime}$ below the center for 58 silica gel-sodium iodide solution slurry at a Peynolds number. $=3813$, the number of measurement $=1000$. 
phenomena was observed. However, as explained before, for $5 \%$ slurry the difference between solid and fluid velocities could be found only in the region where there was an overlap of salutation flow and heterogeneous flow regimes.

Quantitative Flow Visualization Technique (QFV) developed at C3FM (Tjan and Dybbs, 1987) was tried for mapping the flow along the tube. Figures 5.39 and 5.40 show the axial velocity and solid concentration in the tube section for Reynolds number of 1745 and 5544 for $5 \%$ slurry. These are typical results. One can see that solid concentration at the bottom of the tube in Fig. 5.39. More work should be done for utilizing QFV to help improve our understanding of the key physics of slurry flow.

\subsection{Pressure Loss Measurements}

As stated earlier, the pressure loss was measured by using a Meriam inclined tube manometer. Initial calibration tests were conducted in water and the results were compared with Moody's chart data. The friction factor variation with the Reynolds number is provided in Figures 3.12 and 3.13 and a comparison with Moody's friction factor is also made. The water test data compares very well with Moody's chart data. Pressure drop for $5 \%$ and $15 \%$ siurry flows were obtained in the Reynolds number range of 700 to 10,000. Figure 5.41 shows the variation of the friction factor with the Reynolds number for the slurries. The difference between the friction factors for the $5 \%$ and $15 \%$ slurry is large for the lower Reynolds number range, i.e. in the stationary bed and saltation flow regimes. The reason for this can be explained from the LDV velocity profile measurements. The concentration of solids settled down in the bottom of the pipe during the stationary bed and saltation flow regime is nearly three times the initial concentration, i.e. the solid concentration for $5 \%$ and $15 \%$ slurries is nearly $15 \%$ and $45 \%$ for these flow regimes. This may lead to the big difference in the friction factors for $5 \%$ and $15 \%$ slurries and Moody's chart for flow in a smooth pipe. The differences between the friction factors for $5 \%$ and 


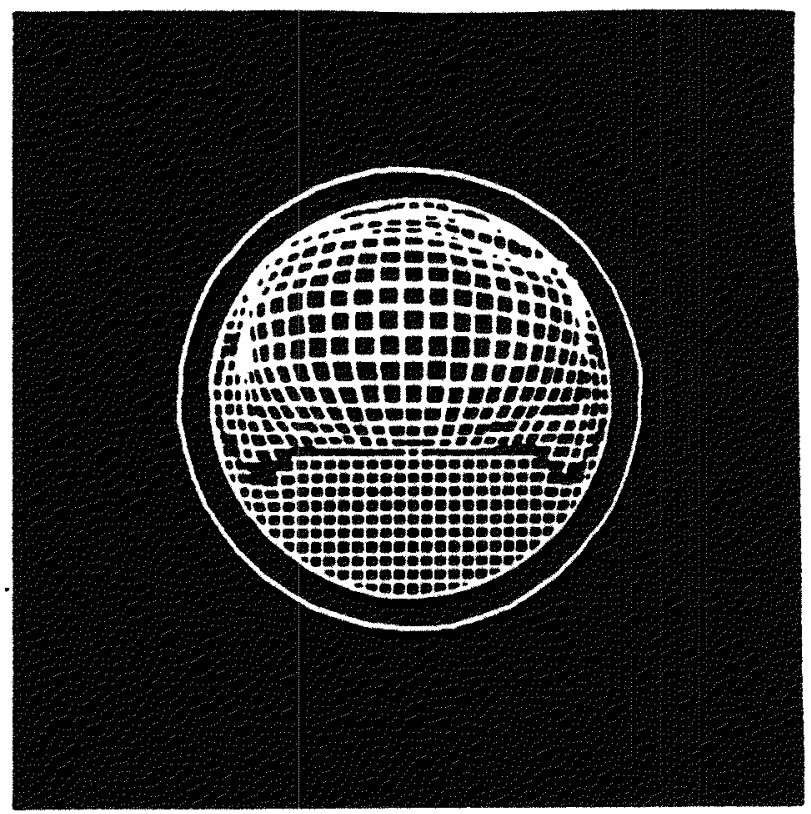

Flgure 5.39 Quancicative Flow Visualization of flow fleld along the pipe cross-section for $5 \%$ slurry at Reynolds number of 1745 (The solids are seteled down at the botrow for this Re.)

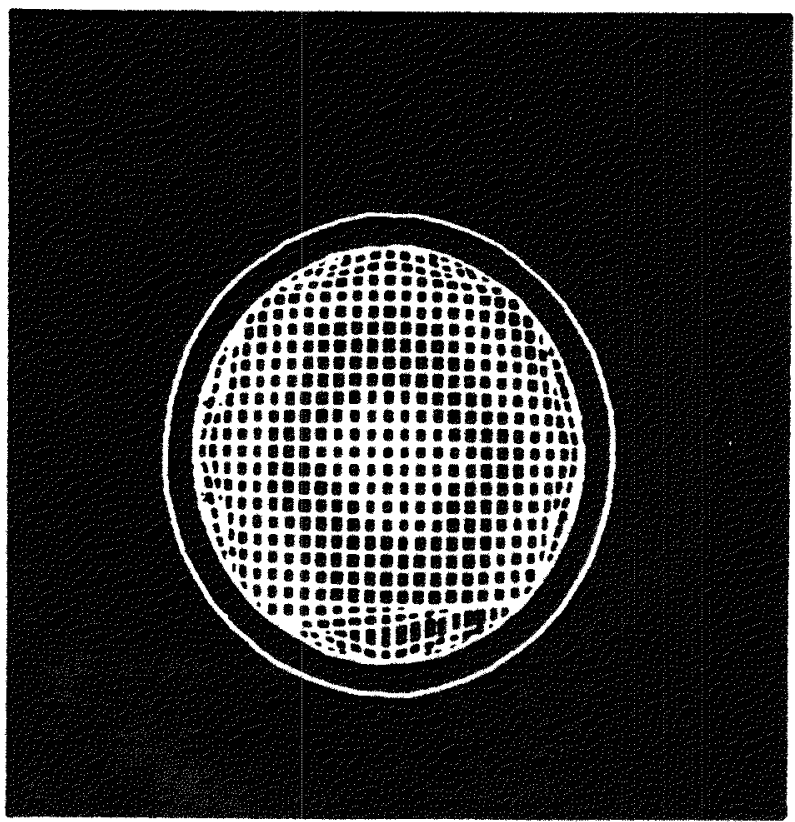

F1gure 5.40Quantitative Flow Visualization of flou fleld along the pipe cross-section for $5 \%$ slurry at Reynolds number of 5544 (Homogeneous flow regtm).

Note: Same color contours indicate same velocity. The veloctty Increases with increase in the color brightness (low for dark blue and highest for bright white). 


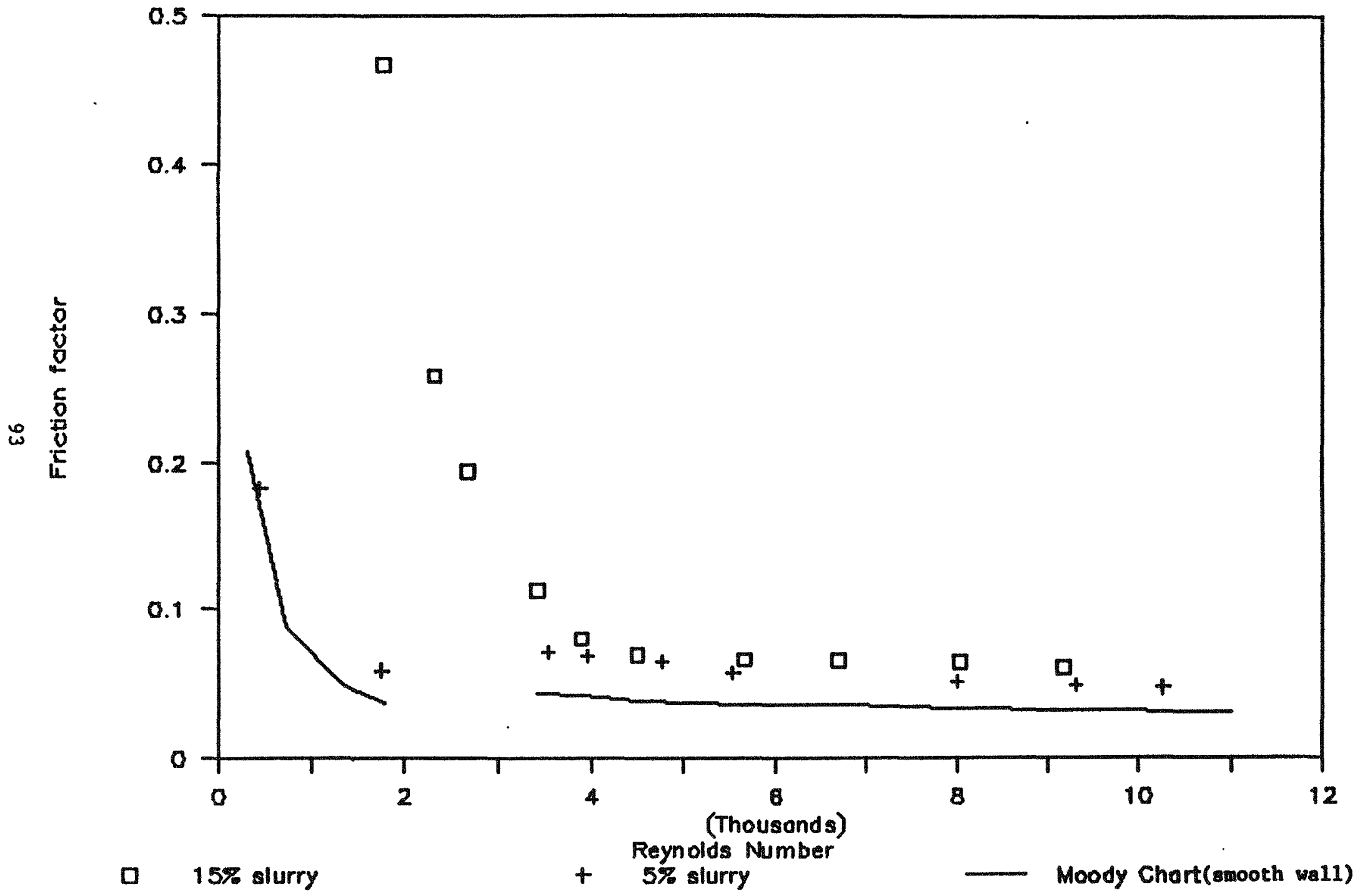

Figure 5.41 Friction factors vs. Reynolds numbers for 58 and 158 silica gel-sodium lodide solution slurry. 
$15 \%$ slurries for Reynolds numbers greater than 4000 (heterogeneous and homogeneous regimes) was relatively very small. The deviation from Moody's friction factor (for the single phase flow) in smooth pipe for the heterogeneous and homogeneous flow regimes for $5 \%$ and $15 \%$ slurries was also small as indicated in the figure. 


\section{CONCLUSIONS}

The following are the conclusions drawn from this study.

1. A refractive index matched facility to study solid-liquid flows using non-intrusive Laser Doppler Velocimetry has been designed, built and made operational. The range of test parameters are provided in Table IV. The test section configuration can be horizontal as well as inclined.

2. Initial tests conducted with water and $50 \%$ sodium iodide solution as the test fluid showed that the flow in the 1 inch diameter glass test section is fully developed for laminar and turbulent flows. The flowrate obtained from integration of the velocity profiles obtained using LDV matched within $\pm .5 \%$ with the magnetic flowmeter data.

3. Tests in the Reynolds number range of 400 to 9200 were conducted with volumetric solid concentration levels of 5 percent and 15 percent. Silica gel particles of mean diameter 40 microns were used. Measurements included mapping of solid and liquid axial velocities and obtaining pressure drop data. It appears that tests can be conducted with slurry solid concentrations as high as 50 percent by volume. The four flow regimes for the $5 \%$ an $15 \%$ slurries were identified as follows:

$\begin{array}{ll}\text { Regime } & \text { Revnolds \# range } \\ \text { stationary bed flow } & \text { up to nearly } 2000 \\ \text { saltation flow } & 2000 \text { to nearly } 4000 \\ \text { heterogeneous flow } & 4000 \text { to nearly } 5200 \\ \text { homogeneous flow } & 5200 \text { and higher }\end{array}$

4. Signal processing technique utilizing histogram and amplitude discrimination was successfully utilized to differentiate between fluid and solid particle velocities.

5. The differences in solid and liquid velocities were obtained for saltation flow and 
heterogeneous flow regimes. Solid and liquid velocities were similar in the homogeneous flow regime.

6. Friction factor of the slurry increases as the solid concentration increases. The variations of friction factor with Reynolds number $(>4000)$ were similar for solid concentrations of $5 \%$ and $15 \%$. 


\section{RECOMMENDATIONS}

The following recommendations are the result of this research.

1. Slurry flow with solid concentrations greater than $15 \%$ should be investigated.

2. Effect of particulate size should be studied. (5 micron to 150 micron)

3. Development of physical models of solid-liquid flows based on the results of the experiment is recommended.

4. Slurry flows in more complicated geometries like inclined pipes, bends, elbows and conical tubes should be studied.

5. Alternative solids and liquids for refractive index matched slurry should be investigated.

6. Methods for pressure loss measurement in denser slurry flow should b developed.

7. Local solid concentration measurement device should be developed. 
1. Fluid: Sodium Iodide Solution
a.) Viscosity: $1.47 \mathrm{cp}$
b.) Density: $1.59 \mathrm{gm} / \mathrm{cc}$
c.) Refractive Index: 1.4485

2. Solid: Silica Gel
a) Size: 10 to 100 microns (Ave. 40 microns)
b.) Density: $2.24 \mathrm{gm} / \mathrm{cc}$
c.) Bulk Density: $0.833 \mathrm{gm} / \mathrm{cc}$
d.) Porosity: 0.628
e.) Refractive Index: 1.4429
f.) Shape: Uniform to Disperse

3. Density Ratio (Hydrated Solid-Liquid): $\mathbf{1 . 1 5}$

4. Concentration of Solid: $0 \%$ to $50 \%$ by volume

5. Reynolds Number: 300 to 8000 (Based on $V_{\text {aver }} D_{\text {pipes }}$ and $\nu_{\text {pure liqure) }}$

6. Pipe Configuration:
a.) Diameter: 1"
b.) Length: $180 \mathrm{ft}$
c.) Inclined at $0^{\circ}$ to $20^{\circ}$ to the horizontal

7. State of Flow:
a.) Flow with a Stationary Bed
b.) Saltation Flow
c.) Heterogeneous Flow
d.) Homogeneous Flow

8. Pressure Drop: 


\section{REFERENCES}

Abbas, M.A., "Experimental Study of the Flow Properties in a Homogeneous Slurry", Ph.D. dissertation, Washington State Univ., Pullman (1985).

Bagnold, R.A., "Experiments in a Gravity Free Dispersion of Large Solid Spheres in a Newtonian Fluid Under Shear", Proc. Roy. Soc., A225, p.49 (1954).

Blatch, N.S., "Discussion: Water Filtration at Washington D.C.," Trans. ASCE, 57, $400-408$ (1906).

Chen, J.L.S., Ekmann, J.M., and Ekmann, A.C., "Experimental Study of Coal Slurry Flows in a Circular Duct", Proc. of the 10th international Technical Conference on Slurry Transport, Nevada (1985)

Delhaye, J.M., "Two - Phase Flow Instrumentation and Laser Beams", Proc. of the LDA - Symposium, Copenhagen (1975).

Drain, L.E., "The Laser Doppler Technique", Wiley - Interscince (1980).

Durand, R., "Basic Relationship of the Transportation of Solids in Pipes", Proc. Minnesota International Hydraulics Convention (1953).

Durst, F. and Zare, M., "Laser Doppler Measurement in Two - Phase Flows", Proc. of the LDA - Symposium, Copenhagen (1975).

Dybbs, A., Edwards, R.V., Nowshirivani, S. and Farrokhlaee, T., "Velocity Measurements in Rod Bundles", Proceedings of International Symposium on Applications of Laser Doppler Anemometry to Fluid Mechanics, eds. D.F.G. Durao (1982).

Edwards, R.V., Lading, L. and Coffield, F., "Design of a Frequency Tracker for Laser Anemometer Measurements", 5 th. Biennial Symposium on Turbulence in Liquids, Rolla, Missouri (197i).

Einav, S. and Lee, S.L., "Particles Migration in Laminar Boundary Layer Flow", International Journal of Multiphase Flow, v 1 (1973).

Ekmann, J.H., Wildman, D.J. and Chen, J.L.S., "Laminar Flow Studies of Highly Loaded Suspensions in Horizontal Pipes", International Symposium on Slurry Flows, FED-vol. 3S, ASME (1986).

Hanks, R.W., "A Generalized Criterion for Laminar-Turbulent Transition in the Flow of Fluids", Union Carbide Co. 
Howard, G.W., "Transportation of Sand and Gravel in Four Inch Pipe," Transaction of ASCE, 104 (1939).

Kadambi, J.R., Dybbs, A., Edwards, R.V. and Bhunia, S., "Laser Velocimeter Measurements of Solids in Multiphase Flow: Part 1: Design of Refractive Index Matched Multiphase Flow Test Loop", Proceedings of the Solids Transport Contractors' Review Meeting of the U.S. Department of Energy (September, 1987).

Kadambi, J.R., Bhunia, S. and Dybbs, A., "A Refractive Index Matched Test Facility for Solid-Liquid Flow Studies using Laser Velocimetry", 3rd. International Symposium on Liquid-Solid Flows, FED-vol. 75, ASME (November, 1988).

Lehamann, B., "Laser Doppler Measurements of the Probability Density Function of Local Velocities in Two Phase Droplet Flows", Proceedings of the LDA Symposium, Copenhagen (1975).

Nakajima, T., Matsumoto, R., Doi, I. and Sakuraj, S., "Velocity Measurements in Rod Bundles", Proceedings of the Osaka Symposium on Flow Measuring Techniques, Osaka, Japan (July, 1983).

Newitt, D.M., Richardson, J.F., Abbott, M. and Turtle, R.B., "Hydraulic Conveying of Solids in Horizontal Pipes", Trans. Instr. Chem. Engrs. v33 (1955).

Nouri, J.M., Whitelaw, J.H. an Yianneskis, M., "An Investigation of Refractive Index Matching of Continuous and Discontinuous Phases", 3rd. International Symposium on Application of Laser Anemometry to Fluid Mechanics, Lisbon, Portugal (1986).

Oberle, L.G. and Seasholtz, R.G., "Filter Induced Errors in Laser Anemometer Measurements using Counter Processors", NASA Technical Memorandum 87047, for International Laser Anemometry Symposium, ASME (November, 1985).

Roco, M.C. and Shook, C.A., "Modeling of Slurry Flow: The Effect of Particle Size", The Canadian Journal of Chemical Engineering, v 61 (August, 1983).

Shaw, R., "The Influence of Hole Dimensions on Static Pressure Measurements", Journal of Fluid Mechanics, v 7 (1960).

Shen, C.C., "Measurements of Particle Effects in suspensions", M.S. thesis, Course I.M.I.T. (1963).

Soo, S.L., "Fluid Dynamics of Multiphase Systems", Blaisdell (1967).

Soo, S.L., "Slurry Flow Modeling and Effects of Concentration", International Symposium on Slurry Flows, FED-vol. 38, ASME (1986).

T.S.I. Inc., "Laser Velocimetry Systems". 
Tjan, W., and Dybbs, A., "Quantitative Flow Visualization for Laser Anemometry", Third International Symposium on Applications of Laser Anemometry to Fluid Mechanics, editors, D.F.G. Durao and R.J. Adrian, Lisbon, Portugal, 1987.

Vanoni, V.A., "Transportation of Suspended Sediment by Water", Transactions of ASCE, v 111, (1946).

Wernet, M., "Application of Two Component Laser Doppler Anemometer to a Multiphase Flow Facility", Case Western Reserve University, Unpublished (1988).

Wernet, M. and Seasholtz, R.G., "Zoom Lens Compensator for a Cylindrical Windows in Laser Anemometer Uses", Applied Optics, v 26 (November, 1987).

Wilson, W., "Mechanics of Flow with Non-Colloidal Solids", Transactions of ASCE 107 (1942).

Yianneskis, M. and Whitelaw, J.H., "Velocity Characteristics of Pipe and Jet Flows with High Particle Concentration", Liquid - Solid Flows and Erosion Wear in Industrial Equipment, FED-vol. 13, ASME (1984).

Zisselmar, R. and Molerus, O., "Investigation of Solid-Liquid Pipe Flow with Regard to Turbulence Modification", The Chemical Engineering Journal, v 8, n 3 (December, 1979). 


\section{APPENDICES}

\section{A. DETERMINATION OF DENSITY OF WET SILICA GEL}

Silica gel particles are porous and are highly adsorptive. Pores are big enough (diameter $\cong 6 \mathrm{~nm}$ ) to get completely filled with the surrounding fluid. Neglecting the effect of fluid moving in and out of the pores we may assume that the wet (hydrated) silica gel particles behave as solid particles of average density.

According to manufacturer's specifications, pore volume of the silica gel used was 0.75 c.c. $/ \mathrm{gm}$. Density of solid silica gel without pores is $2.24 \mathrm{gm} / \mathrm{c} . \mathrm{c}$. Neglecting the effect of adsorption we may find the average density of the particles as follows:

$1 \mathrm{gm}$ of porous silica gel occupies $(1 / 2.24+0.75)$ c.c. $=1.20$ c.c.

Now, out of this volume if 0.75 c.c. of pores is filled with surrounding fluid of density $\rho_{\mathrm{f}} \mathrm{gm} / \mathrm{c} . c$. then the density of the wet particles is,

\begin{tabular}{|c|c|c|}
\hline & Water & $50 \% \mathrm{NaI} / \mathrm{H} 2 \mathrm{O}$ \\
\hline$\rho_{\mathrm{f}}$ & 1.00 & 1.59 \\
\hline$\rho_{\mathrm{S}}$ & 1.46 & 1.83 \\
\hline$\rho_{\mathrm{f}}$ & 1.46 & 1.15 \\
\hline
\end{tabular}




\section{B:DETERMINATION OF PARAMETERS OF SLURRY}

As shown in appendix A, $1 \mathrm{gm}$ of porous silica gel occupies 1.2 c.c. and the pore volume of the silica gel used was $0.75 \mathrm{cc} / \mathrm{gm}$ and the density of $50 \%$ sodium-iodide in water solution is $1.55 \mathrm{gm} / \mathrm{cc}$. For $\mathrm{y}$ c.c. of $50 \%$ sodium-iodide in water solution and $\mathrm{x}$ gm silica gel, we can obtain the slurry volume, slurry density and concentration as shown below.

a) The total volume of slurry

$$
V_{\text {total }}=y+1.2 x-0.75 x=y+0.45 x c c \text {. }
$$

b) The density of slurry

$$
P_{\text {slurry }}=\frac{1.55 y+x}{y+0.45 x}
$$

c) The volumetric concentration of solids in the slurry

$$
S_{\text {volume }}(\%)=\frac{1.2 x}{y+0.45 x} * 100 \%
$$




\section{C: SHIFT OF PROBE VOLUME DUE TO REFRACTION}

Fig. A-1 shows the path of a pair of laser beams of identical wave length (color) in a plane as it passes through the square test box. The beams come out of the focusing lens (focal length $=f$ ) go through air, then enter glass window, the refractive index matched fluid, the glass tube wall and finally test fluid, and cross at the measurement volume.

Applying Snell's law,

$$
\mu_{1} \sin \theta_{1}=\mu_{2} \sin \theta_{2}=\mu_{3} \operatorname{Sin} \theta_{3}
$$

from the plan view, shown in Figure $A-1$ we can derive,

$$
\begin{aligned}
& \tan \theta_{1}=\frac{h_{2}}{l_{3}}=\frac{h_{1}+h_{2}}{l_{3}+t-l_{1}}=\frac{h_{1}+h_{2}-h_{2}}{l_{3}+t-l_{1}-l_{3}}=\frac{h_{1}}{t-l_{1}} \\
& \operatorname{tn} \theta_{2}=\frac{h_{1}}{t} \\
& \tan \theta_{3}=\frac{h_{2}}{l_{2}} \\
& \ell_{3}=\mathrm{f}+\ell_{1}-\mathrm{t}-\mathrm{d} \\
& \ell_{2}=\mathrm{F} \Delta-\mathrm{d}-\mathrm{t} \\
& \theta_{1}=\frac{\phi}{2} \\
& \theta_{3}=\frac{\phi_{\mathrm{a}}}{2} \\
& \theta_{3}=\operatorname{Sin}^{-1}\left(\frac{\mu_{1}}{\mu_{3}} \operatorname{Sin} \theta_{1}\right) \\
& \Rightarrow \phi_{\mathrm{a}}=2 \operatorname{Sin}^{-1}\left(\frac{\mu_{1}}{\mu_{2}} \operatorname{Sin} \frac{\phi}{2}\right) \\
& \theta_{2}=\operatorname{Sin}^{-1}\left(\frac{\mu_{1}}{\mu_{2}} \operatorname{Sin} \frac{\phi}{2}\right) \\
& \ell_{1}=\mathrm{t}\left[1-\frac{\tan \theta_{2}}{\tan \theta_{1}}\right] \\
& F_{\mathrm{a}}=\left(\mathfrak{f}-\mathrm{t} \frac{\tan \theta_{2}}{\tan \theta_{1}}-d\right) \frac{\tan \theta_{1}}{\tan \theta_{3}}+t+d \\
& t=t_{1}+R-\sqrt{R^{2}-r_{a}^{2}} \\
& \mathrm{de}_{1}=\mathrm{F}_{\mathrm{a}}-\mathrm{f}=\left(\mathrm{f}-\mathrm{t} \frac{\tan \theta_{2}}{\tan \theta_{1}}-\mathrm{d}\right) \frac{\tan \theta_{1}}{\tan \theta_{3}}+\mathrm{t}+\mathrm{d}-\mathrm{f} \\
& \Rightarrow d e_{1}=\left(\frac{\tan \theta_{1}}{\tan \theta_{3}}-1\right) f+\left(1-\frac{\tan \theta_{2}}{\tan \theta_{3}}\right) t+\left(1-\frac{\tan \theta_{1}}{\tan \theta_{3}}\right) d
\end{aligned}
$$

From the elevation (Figure) we have:

$$
\mu_{2} \operatorname{Sin} \alpha_{\mathrm{a}}=\mu_{3} \operatorname{Sin} \alpha_{\mathrm{w}}
$$




$$
\begin{aligned}
& \alpha_{\mathrm{w}}=\operatorname{Sin}^{-1}\left(\frac{\mu_{2}}{\mu_{3}} \operatorname{Sin} \alpha_{\mathrm{a}}\right) \\
& \alpha_{\mathrm{w}}^{\prime}=\alpha_{\mathrm{w}}-\alpha_{\mathrm{a}}=\operatorname{Sin}\left(\frac{\mu_{2}}{\mu_{3}} \operatorname{Sin} \alpha_{\mathrm{a}}\right)-\alpha_{\mathrm{a}} \\
& \alpha_{\mathrm{a}}=\operatorname{Sin}^{-1} \frac{\mathrm{ra}}{\mathrm{R}} \\
& \tan \alpha_{\mathrm{w}}^{\prime}=\frac{\mathrm{de}_{2}}{\mathrm{f}+\mathrm{e}_{1}-\mathrm{t}-\mathrm{d}} \\
& \operatorname{de}_{2}=(\mathrm{f}+\mathrm{de}-\mathrm{t}-\mathrm{d}) \tan \alpha_{\mathrm{w}}^{\prime} \\
& \text { also de } 2=\ell_{2} \tan \alpha_{\mathrm{w}}^{\prime} \\
& \text { remind } \ell_{2}=\mathrm{F}_{\mathrm{a}}-\mathrm{d}-\mathrm{t}=\left(\mathrm{f}-\mathrm{t} \frac{\tan \theta_{2}}{\tan \theta_{1}}-\mathrm{d}\right) \frac{\tan \theta_{1}}{\tan \theta_{3}}+\mathrm{t}+\mathrm{d}-\mathrm{t}-\mathrm{d} \\
& \qquad \ell_{2}=\left(\mathrm{f}-\mathrm{t} \frac{\tan \theta_{2}}{\tan \theta_{1}}-\mathrm{d}\right) \frac{\tan \theta_{1}}{\tan \theta_{3}}
\end{aligned}
$$

when $d$ change from $d$ to $d-\Delta d$

$$
\begin{aligned}
& i_{2}=\left(\mathrm{f}-\mathrm{t} \frac{\tan \theta_{2}}{\tan \theta_{1}}-(\mathrm{d}-\Delta \mathrm{d})\right) \frac{\tan \theta_{1}}{\tan \theta_{3}} \\
& \text { So } \Delta \ell=\ell_{2}^{\prime}=\Delta \mathrm{d} \frac{\tan \theta_{1}}{\tan \theta_{3}} \\
& \text { that is } \quad \Delta \ell=\Delta \mathrm{d} \frac{\tan \theta_{1}}{\tan \theta_{3}} \\
& \text { and } \quad \Delta \ell=\Delta \ell \frac{\tan \theta_{3}}{\tan \theta_{1}}
\end{aligned}
$$

and if the incremental movement of lens is $\Delta d$ then $d=d t-\Delta d \cdot n$

The following parameter were used in our test

$$
\begin{aligned}
& \mu_{1}=1, \mu_{2}=\mu_{4}=\mu_{5}=1.474 . \mu_{3}=1.446 \\
& R=1^{\prime \prime}, \mathrm{t}_{1}=1.99^{\prime \prime}, \mathrm{f}=480 \mathrm{~mm}=18.848^{\prime \prime} \\
& \theta_{1}=\frac{\phi}{2} 4.912^{\circ} \Rightarrow>\tan \theta_{1}=0.0859 \Delta \\
& \theta_{2}=\operatorname{Sin}^{-}\left(\frac{\mu_{1}}{\mu_{2}} \operatorname{Sin} \theta_{1}\right)=3.330^{\circ} \Rightarrow>\tan \theta_{2}=0.05819 \\
& \theta_{3}=\operatorname{Sin}^{-}\left(\frac{\mu_{1}}{\mu_{3}} \operatorname{Sin} \theta_{1}\right)=3.3948^{\circ}=>\tan \theta_{3}=0.05932 \\
& \mathrm{di}=17.545^{\prime \prime} \\
& \Delta \ell=0.05^{\prime \prime} \Rightarrow \Delta \mathrm{d}=\Delta \ell \frac{\tan \theta_{3}}{\tan \theta_{1}}=0.0346^{\prime \prime}
\end{aligned}
$$

The following table 6 shows the important parameters and location errors of focus beam related to measuring volume location $(x, y)$. 


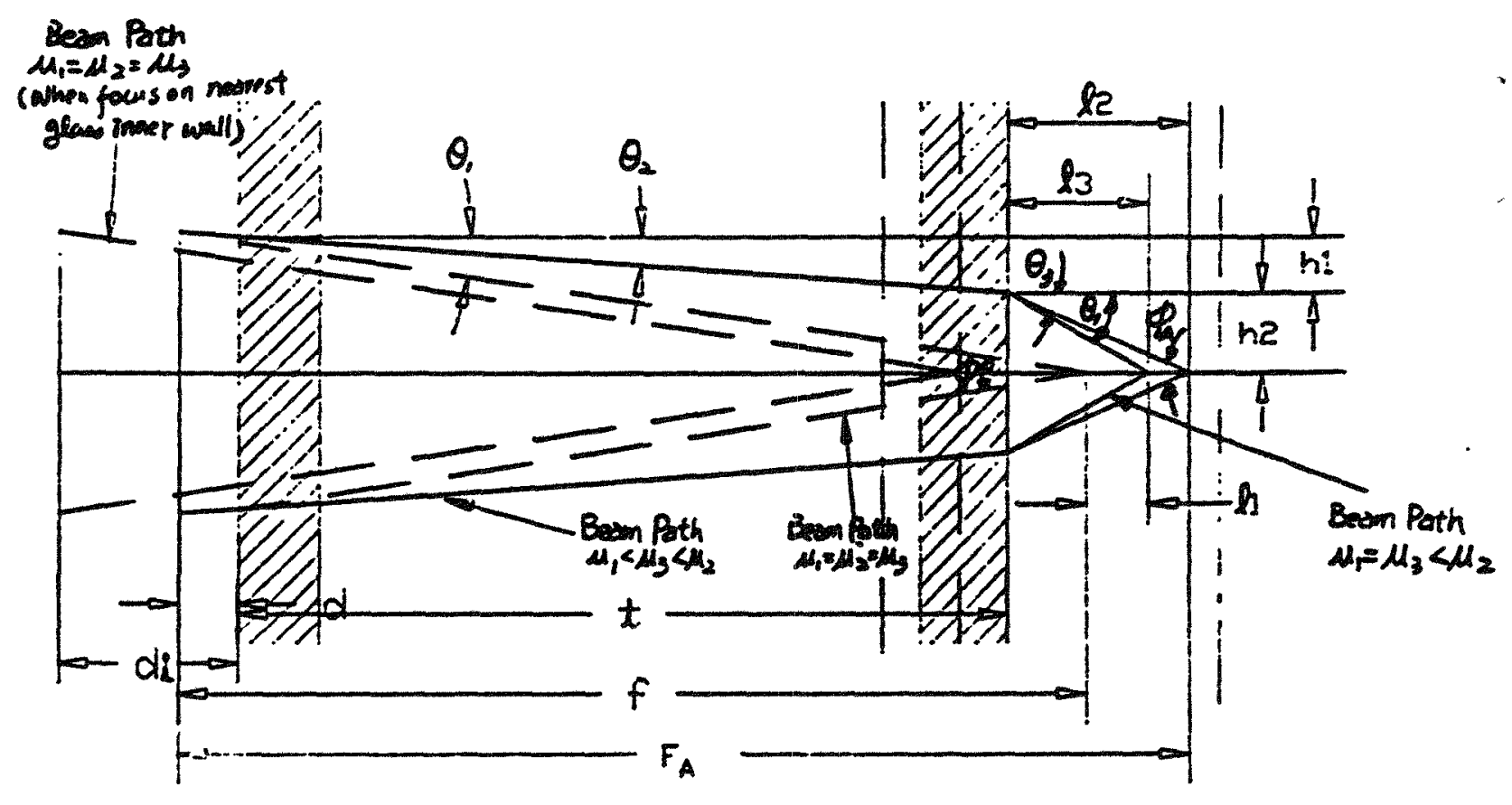

Plan View

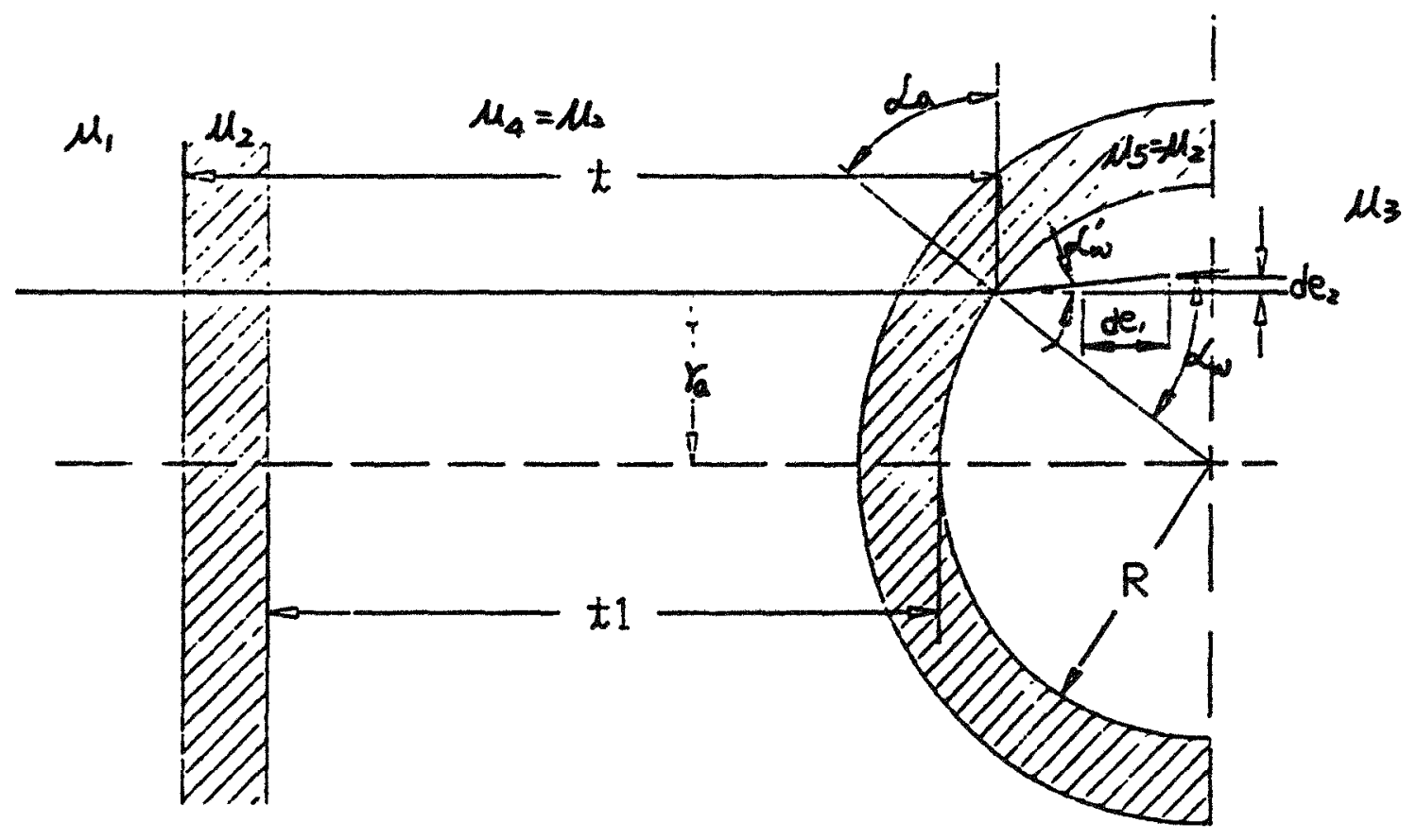

Side View

Figure A-1: Refraction of the laser beams through test section. 
TABLE A.1: The location Errors of laser beams due to refraction.

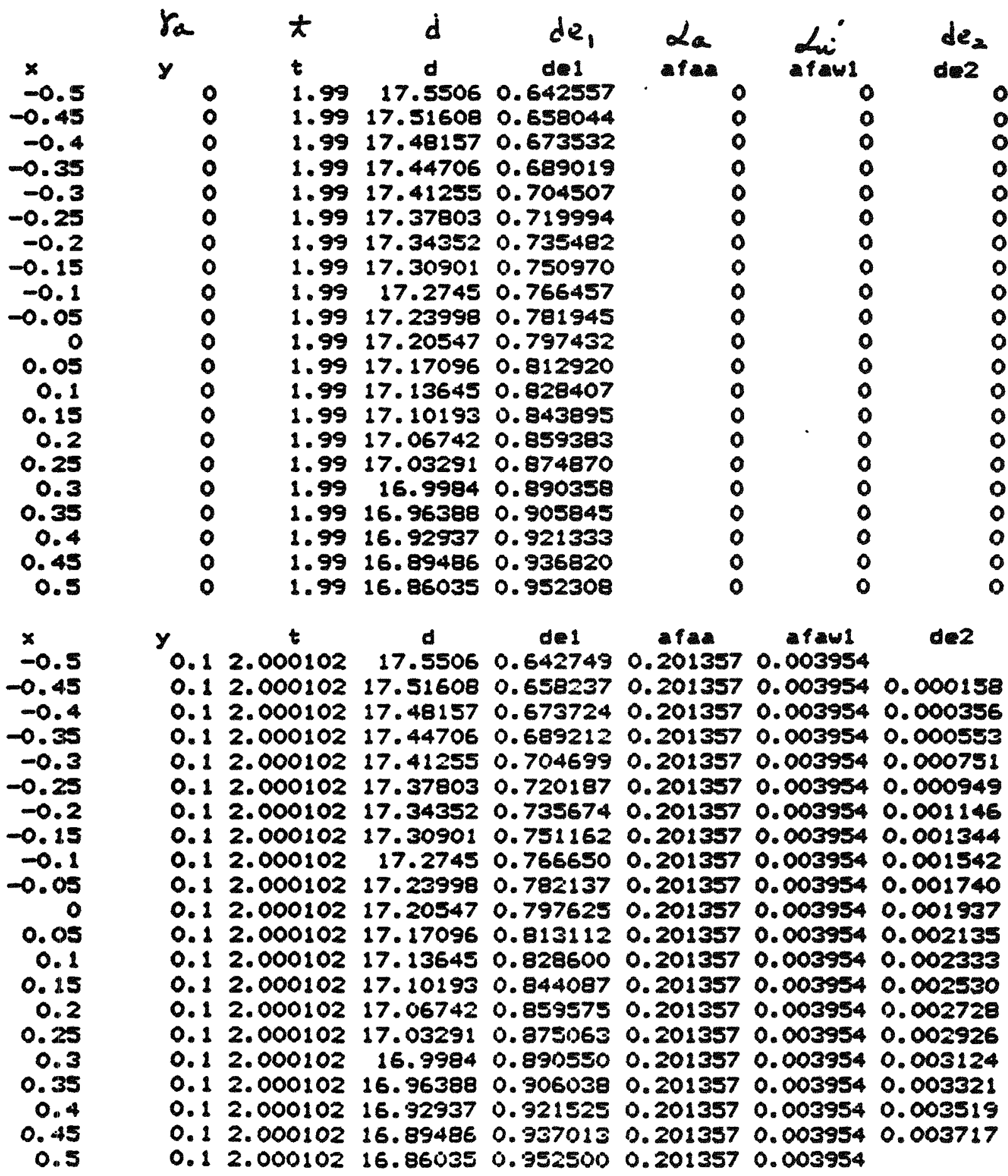


TABLE A-I (CONTINUED)

$\begin{array}{ccccccc}x & y & t & d & d e 1 & \text { afad } & \text { afaw1 } \\ -0.5 & 0.2 & 2.031742 & 17.5506 & 0.643352 & 0.411516 & 0.008466 \\ -0.45 & 0.2 & 2.031742 & 17.51608 & 0.658839 & 0.411516 & 0.008466 \\ -0.4 & 0.2 & 2.031742 & 17.48157 & 0.674327 & 0.411516 & 0.008466 \\ -0.35 & 0.2 & 2.031742 & 17.44706 & 0.689814 & 0.411516 & 0.008466 \\ -0.3 & 0.2 & 2.031742 & 17.41255 & 0.705302 & 0.411516 & 0.008466 \\ -0.25 & 0.2 & 2.031742 & 17.37803 & 0.720790 & 0.411516 & 0.008466 \\ -0.2 & 0.2 & 2.031742 & 17.34352 & 0.736277 & 0.411516 & 0.008466 \\ -0.15 & 0.2 & 2.031742 & 17.30901 & 0.751765 & 0.411516 & 0.008466 \\ -0.1 & 0.2 & 2.031742 & 17.2745 & 0.767252 & 0.411516 & 0.008466 \\ -0.05 & 0.2 & 2.031742 & 17.23998 & 0.782740 & 0.411516 & 0.008466 \\ 0 & 0.2 & 2.031742 & 17.20547 & 0.798227 & 0.411516 & 0.008466 \\ 0.05 & 0.2 & 2.031742 & 17.17096 & 0.813715 & 0.411516 & 0.008466 \\ 0.1 & 0.2 & 2.031742 & 17.13645 & 0.829203 & 0.411516 & 0.008466 \\ 0.15 & 0.2 & 2.031742 & 17.10193 & 0.844690 & 0.411516 & 0.008466 \\ 0.2 & 0.2 & 2.031742 & 17.06742 & 0.860178 & 0.411516 & 0.008466 \\ 0.25 & 0.2 & 2.031742 & 17.03291 & 0.875655 & 0.411516 & 0.008466 \\ 0.3 & 0.2 & 2.031742 & 16.9984 & 0.891153 & 0.411516 & 0.008466 \\ 0.35 & 0.2 & 2.031742 & 16.96388 & 0.906540 & 0.411516 & 0.008466 \\ 0.4 & 0.2 & 2.031742 & 16.92937 & 0.922128 & 0.411516 & 0.008466 \\ 0.45 & 0.2 & 2.031742 & 16.89486 & 0.937616 & 0.411516 & 0.008466 \\ 0.5 & 0.2 & 2.031742 & 16.86035 & 0.953103 & 0.411516 & 0.008466\end{array}$

$\begin{array}{rr}x & y \\ -0.5 & 0.3 \\ -0.45 & 0.3 \\ -0.4 & 0.3 \\ -0.35 & 0.3 \\ -0.3 & 0.3 \\ -0.25 & 0.3 \\ -0.2 & 0.3 \\ -0.15 & 0.3 \\ -0.1 & 0.3 \\ -0.05 & 0.3 \\ 0 & 0.3 \\ 0.05 & 0.3 \\ 0.1 & 0.3 \\ 0.15 & 0.3 \\ 0.2 & 0.3 \\ 0.25 & 0.3 \\ 0.3 & 0.3 \\ 0.35 & 0.3 \\ 0.4 & 0.3 \\ 0.45 & 0.3 \\ 0.5 & 0.3\end{array}$

$t$ d del afa

$\begin{array}{llllllll}2.09 & 17.5506 & 0.644462 & 0.643501 & 0.014603\end{array}$

$\begin{array}{llllll}2.09 & 17.51608 & 0.659949 & 0.643501 & 0.014603\end{array}$

$2.0917 .48157 \quad 0.675437 \quad 0.643501 \quad 0.014603$

$2.0917 .44706 \quad 0.690924 \quad 0.643501 \quad 0.014603$

$\begin{array}{lllllll}2.09 & 17.41255 & 0.706412 & 0.643501 & 0.014603\end{array}$

$\begin{array}{llllll}2.09 & 17.37803 & 0.721899 & 0.643501 & 0.014603\end{array}$

$2.0917 .34352 \quad 0.737387 \quad 0.543501 \quad 0.014603$

$\begin{array}{lllllll}2.09 & 17.30901 & 0.752875 & 0.543501 & 0.014603\end{array}$

$2.09 \quad 17.2745 \quad 0.768362 \quad 0.643501 \quad 0.014603$

$\begin{array}{llllll}2.09 & 17.23998 & 0.783850 & 0.643501 & 0.014603\end{array}$

$\begin{array}{llllllll}2.09 & 17.20547 & 0.799337 & 0.643501 & 0.014603\end{array}$

$\begin{array}{llllll}2.09 & 17.17096 & 0.814825 & 0.643501 & 0.014603\end{array}$

$2.0917 .136450 .8303120 .643501 \quad 0.014603$

$\begin{array}{llllll}2.09 & 17.10193 & 0.845800 & 0.643501 & 0.014603\end{array}$

$\begin{array}{llllll}2.09 & 17.06742 & 0.861288 & 0.643501 & 0.014603\end{array}$

$\begin{array}{lllllll}2.09 & 17.03291 & 0.876775 & 0.643501 & 0.014603\end{array}$

$\begin{array}{lllllll}2.09 & 16.9984 & 0.892263 & 0.643501 & 0.014603\end{array}$

$\begin{array}{lllllll}2.09 & 16.96388 & 0.307750 & 0.643501 & 0.014603\end{array}$

$2.0916 .92937 \quad 0.923238 \quad 0.643501 \quad 0.014603$

$2.09 \quad 16.89486 \quad 0.938725 \quad 0.643501 \quad 0.014603$

$2.09 \quad 16.86035 \quad 0.954213 \quad 0.643501 \quad 0.014603$ 
THIS PAGE INTENTIONALLY LEFT BLANK 


\section{D: UNCERTAINTY ANALYSIS}

Velocitv:

Utilizing the fringe model for Laser Doppler Velocimeter, velocity of a particle crossing the fringes is given by,

$$
\mathrm{V}=\mathrm{d} . \mathrm{f}
$$

where, $d=$ fringe spacing

$$
f=\text { frequency of the signal }
$$

So, $\frac{W_{v}}{v}=\left[\left[\frac{w_{d}}{d}\right]^{2}+\left[\frac{w_{f}}{i}\right]^{2}\right]^{1 / 2}$

$\mathrm{W}$, is the uncertainty of the variable in the subscript.

This uncertainty $W_{v}$ does not include the effect of velocity gradient across probe volume. Assuming no error is introduced by signal processors

$$
\begin{array}{ll} 
& W_{f}=0 \\
\text { So, } & W_{v} / V=W_{d} / d
\end{array}
$$

Uncertainty in fringe spacing is due to the bending of fringes within the probe volume.

Fringe spacing,

$$
\mathrm{d}=\frac{\lambda \cdot \bar{\sigma} 2}{2 \sin (\theta / 2) \sigma_{0}^{2}\left[\frac{S_{2}}{F}+\frac{S_{1}}{F}\left[1-\frac{S_{2}}{F}\right]\right]}
$$

where,

$$
\begin{gathered}
\left.\bar{\sigma}^{2}=\sigma_{0}^{2}\left[\left[\frac{\bar{\sigma}}{\sigma}\right]^{2}\left[1-\frac{S_{2}}{F}\right]^{2}+\left[\frac{S_{2}}{F}+\frac{S_{1}}{F}\right]\right]^{2}\right] \\
\sigma_{0}^{2}=\frac{F^{2}}{4 k^{2} \sigma^{2}}
\end{gathered}
$$

where, $\quad \sigma=$ standard deviation of beam intensity distribution at $s_{1}$ 
$S_{1}=$ distance behind final focusing lens where beam waist occurs

$\mathrm{S}_{2}=$ distance from front focal lens

$F=$ focal length of final focusing lens

$k=2 \pi / \lambda$

$\theta=$ angle between laser beams focused by front lens

$\sigma_{0}=$ beam standard deviation at focus point

The laser beam waist is collimated immediately after exiting the laser source. So we may assume $S_{1}=F$.

So, $\quad \bar{\sigma}^{2}=\sigma_{0}^{2}\left[\left[\frac{\bar{\sigma}}{\sigma}\right]^{2}\left[1-\frac{S_{2}}{F}\right]^{2}+1\right]$

i.e. $\quad \frac{\bar{\sigma}^{2}}{\sigma_{0}^{2}}=\left[1-\frac{\sigma_{0}^{2}}{\sigma^{2}}\left[1-\frac{S_{2}}{F}\right]^{2}\right]^{-1}$

Since, $\quad \frac{\sigma^{2}}{\sigma^{2}}\left[1-\frac{S_{2}}{F}\right]^{2}=3.3 \times 10^{-9}<<1$

fringe spacing

$$
\begin{aligned}
\mathrm{d} & \approx \frac{\lambda}{2 \sin (\theta / 2)}\left[1+\frac{\sigma_{0}^{2}}{\sigma^{2}}\left[1-\frac{S_{2}}{F}\right]^{2}\right] \\
& \approx \frac{\lambda F}{2 \mathrm{x}}\left[1+\frac{1}{4 \mathrm{k}^{2} \sigma^{4}}\left(F-S_{2}\right)^{2}\right]
\end{aligned}
$$

since the sine of a small angle is nearly equal to its tangent.

Uncertainties of various parameters:

Focal length:

$$
F=480 \mathrm{~mm}, W_{\mathrm{f}}=0.1 \mathrm{~mm}
$$

Beam $\mathrm{e}^{-2}$ diameter 
(after $3.75 \times$ expansion): $4 \sigma=1.67 \mathrm{~mm}, \mathrm{~W}_{\sigma}=0.01 \times 3.75 / 4$

$$
=0.009 \mathrm{~mm}
$$

Beam separation

(after $3.75 \mathrm{x}$ expansion): $2 \mathrm{x}=82.5 \mathrm{~mm}, \mathrm{~W}_{\mathrm{x}}=0.013 \mathrm{~mm}$

$$
\begin{aligned}
& \therefore \frac{\partial \mathrm{d}}{\partial \mathrm{F}} \delta \mathrm{F} \approx \frac{\lambda}{2 \mathrm{x}} \delta \mathrm{F}=5.9 \times 10^{-11} \\
& \frac{\partial \mathrm{d}}{\partial \mathrm{x}} \delta \mathrm{x} \approx-\frac{\lambda \mathrm{F}}{2 \mathrm{x}^{2}} \delta \mathrm{x}=-6.5 \times 10^{-9} \\
& \frac{\partial \mathrm{d}}{\partial \sigma} \delta \sigma=-\frac{\lambda \mathrm{F}}{2 \mathrm{x}} \cdot \frac{\left(\mathrm{F}-\mathrm{S}_{2}\right)}{\mathrm{k}^{2} \sigma^{5}} \delta \sigma=1.2 \times 10^{-13}
\end{aligned}
$$

The fringe spacing has got both random and bias errors. Bias error is due to the bending of the fringes. Deviation of the fringe spacing from the spacing at the center of the probe volume is given by,

$$
\frac{\lambda F}{2 \mathrm{x}} \cdot \frac{1}{4 \mathrm{k}^{2} \sigma^{2}}\left[\frac{\mathrm{F}-\mathrm{S}_{2}}{\sigma}\right]^{2}
$$

Since the intensity distribution within the probe volume is Gaussian it is appropriate to find an weighted average of this error.

$$
\begin{aligned}
& \text { Weighting Function }=\exp \left[-\left[\frac{F-S_{2}}{\sigma}\right]^{2}\right] \\
& \text { Average error occurs at } \frac{F-S_{2}}{\sigma}=1
\end{aligned}
$$

So the bias error $=8.4 \times 10^{-7} \%$ 


$$
\begin{aligned}
& \therefore \text { Total random error }=\frac{\left[\left[\frac{\partial \mathrm{d}}{\partial \mathrm{F}} \delta \mathrm{F}\right]^{2}+\left[\frac{\partial \mathrm{d}}{\partial \mathrm{x}} \delta \mathrm{x}\right]^{2}+\left[\frac{\partial \mathrm{d}}{\partial \sigma} \delta \sigma\right]^{2}\right]^{1 / 2}}{\mathrm{~d}} \\
& =0.23 \%
\end{aligned}
$$

Bias error being much smaller compared to the random error my be neglected.

So the uncertainty of velocity measurement,

$$
\frac{W_{v}}{V}=0.23 \%
$$

\section{Flowrate:}

Flowmeter was calibrated by measuring the flowrate by 'stopwatch and bucket' method. Average uncertainty in flowrate found from this,

$$
\mathrm{W}_{\mathrm{q}} / \mathrm{Q}=1.5 \%
$$

In the range $0-0.3 \mathrm{gal} / \mathrm{min}$

$$
W_{q} / Q=5 \%
$$

\section{Pressure Drop:}

Friction factor:

$$
f=\frac{\pi}{16} h \cdot \frac{D^{5}}{L} \cdot \frac{2 g}{Q^{2}}
$$

Uncertainty in friction factor is given by,

$$
\frac{W_{f}}{f}=\left[\left[\frac{W_{h}}{h}\right]^{2}+25\left[\frac{W_{d}}{D}\right]^{2}+\left[\frac{W_{L}}{L}\right]^{2}+\left[\frac{W_{g}}{Q}\right]^{2}\right]^{1 / 2}
$$

Uncertainties of various parameters:

Height difference: Average $\mathrm{h}=20 \mathrm{~mm}$,

$$
\begin{aligned}
& W_{h}=0.05 \mathrm{~mm} \\
& W_{d}=0.01^{\prime \prime}
\end{aligned}
$$$$
\text { Diameter of pipe: } D=1 " \text {, }
$$ 
Length of test section: $L=14^{\prime} 1.5^{\prime \prime}$

$$
\begin{aligned}
& W_{1}=1 / 2^{\prime \prime} \\
& W_{Q} / Q=0.015 \\
& W_{Q} / Q=0.05
\end{aligned}
$$

So the uncertainty in friction factor,

$$
W_{\mathrm{f}} / \mathrm{f}=5.8 \%
$$




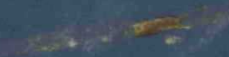

